\title{
Impact of Serving as an Extension Camping Instructor on Life Skills Development.
}

Jeffery A. Davis Jr.

Follow this and additional works at: https://researchrepository.wvu.edu/etd

\section{Recommended Citation}

Davis, Jeffery A. Jr., "Impact of Serving as an Extension Camping Instructor on Life Skills Development." (2016). Graduate Theses, Dissertations, and Problem Reports. 8173.

https://researchrepository.wvu.edu/etd/8173

This Thesis is protected by copyright and/or related rights. It has been brought to you by the The Research Repository @ WVU with permission from the rights-holder(s). You are free to use this Thesis in any way that is permitted by the copyright and related rights legislation that applies to your use. For other uses you must obtain permission from the rights-holder(s) directly, unless additional rights are indicated by a Creative Commons license in the record and/ or on the work itself. This Thesis has been accepted for inclusion in WVU Graduate Theses, Dissertations, and Problem Reports collection by an authorized administrator of The Research Repository @ WVU. For more information, please contact researchrepository@mail.wvu.edu. 
Impact of Serving as an Extension Camping Instructor on Life Skills Development

Jeffery A. Davis, Jr.

Thesis submitted to the Davis College of Agriculture, Natural Resources and Design

at West Virginia University in partial fulfillment of the requirements

for the degree of

Master of Science

in

Agricultural and Extension Education

Deborah A. Boone, Ph.D., Chair

Harry N. Boone, Jr., Ph.D.

Jean M. Woloshuk, Ed.D.

School of Design and Community Development

Morgantown, West Virginia

2016

Keywords: 4-H, Life Skills, Positive Youth Development, Volunteers, Extension Camping Instructor

Copyright 2016: Jeffery A. Davis, Jr. 


\begin{abstract}
Impact of Serving as an Extension Camping Instructor on Life Skills Development

Jeffery A. Davis, Jr.
\end{abstract}

The purpose of this study was to determine if West Virginia University Extension Camping Instructors were influencing the life skill development of 4-H youth while also developing life skills of their own. This study utilized the unique perceptions of Extension Camping Instructors who were employed from the summer of 2007 to October of 2015 by examining their current level of life skills, how they felt being employed as an Extension Camping Instructor influenced the development of each skill, and how they felt their role impacted the life skill development of 4-H youth with whom they had worked. A descriptive survey was sent to each member of the target population who were employed during the designated time. The Extension Camping Instructor experience was perceived to have the greatest influence on leadership, community service/volunteering, problem solving, and communication among the target population while the Extension Camping Instructors perceive that their role has the greatest influence on teamwork, self-esteem, and community service/volunteer life skill development among 4-H youth. Adaptability, communication, and working with others who are different were rated as the most valued life skills learned through being an Extension Camping Instructor. 


\section{ACKNOWLEDGEMENTS}

There are many people that I would like to thank for the passion to study this field and for the completion of this thesis. Thanks to:

Dr. Deborah Boone, my advisor and informant, without whom I would be lacking in the knowledge and guidance to conduct this research.

Dr. Harry Boone, an extremely knowledgeable professor and mentor who graciously assisted with the data analysis procedures.

Dr. Jean Woloshuk, whose previous work with the 4-H Youth Development Program has inspired many.

Michael Shamblin, my Extension Agent and friend, who has believed in me and has encouraged me to follow my dreams.

Ann Casto Knopp and Ian McNeil, the two Extension Camping Instructors who initially inspired me to apply for the position.

My family for loving and supporting me every step of the way.

My 4-H family for providing true friendship throughout the years, opportunities for personal growth, and instilling a passion for the 4-H program. 


\section{TABLE OF CONTENTS}

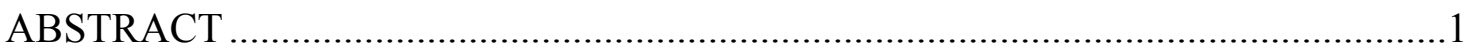

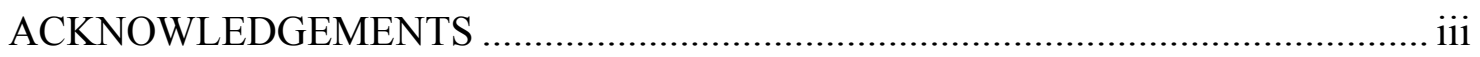

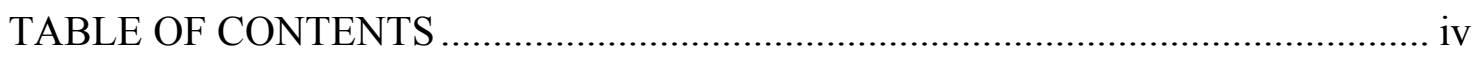

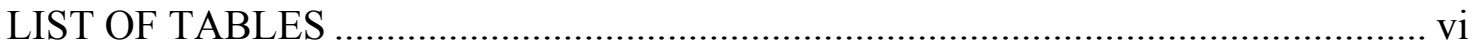

LIST OF FIGURES.................................................................................. vii

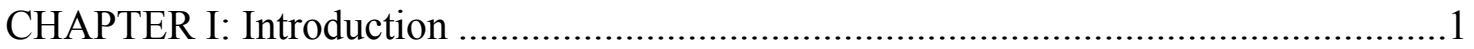

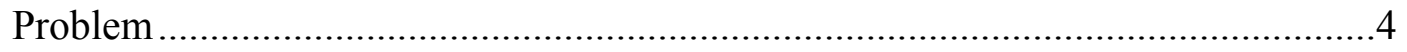

Theoretical Framework .............................................................................4

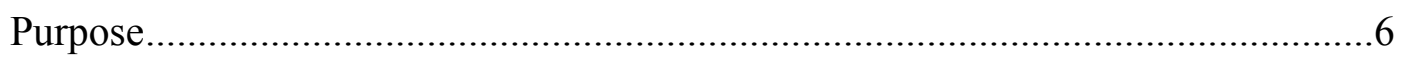

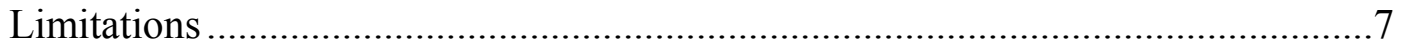

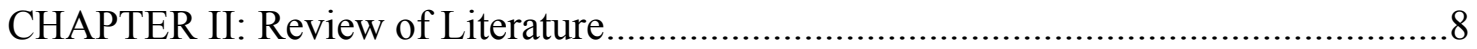

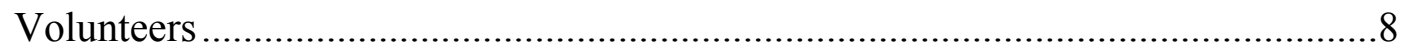

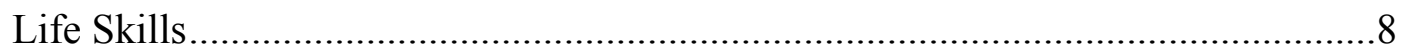

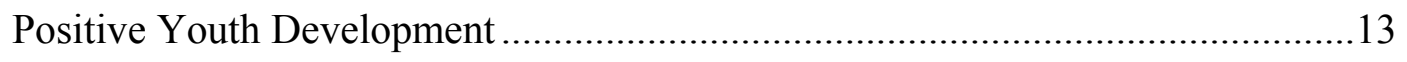

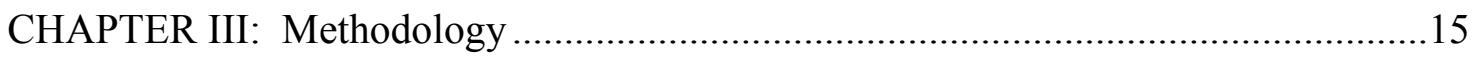

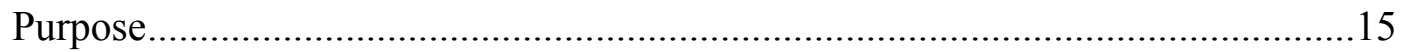

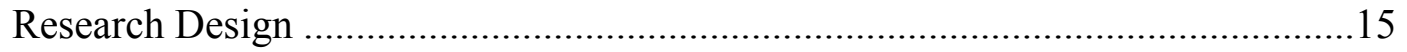

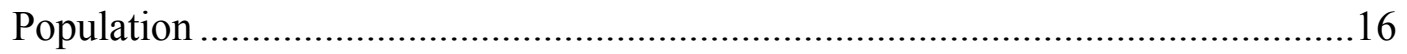

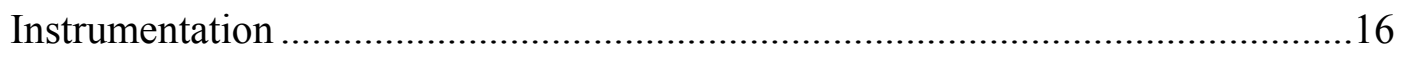

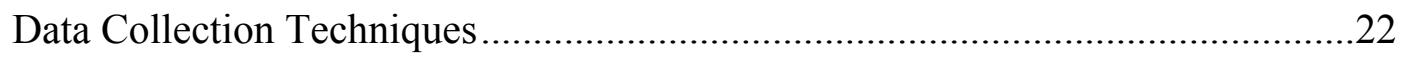

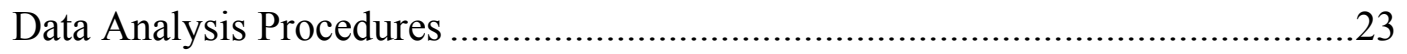

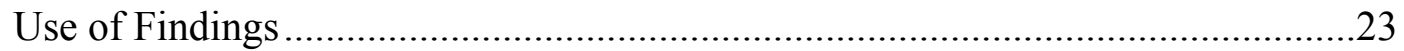

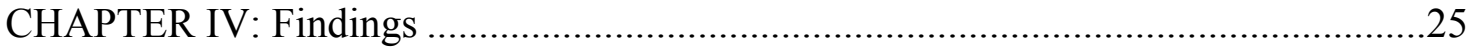

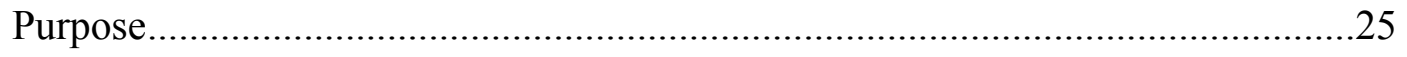

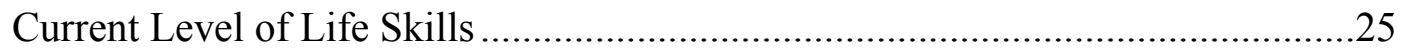

Influence of Being an Extension Camping Instructor on Development of Each

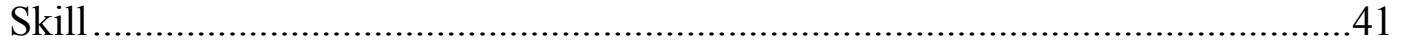

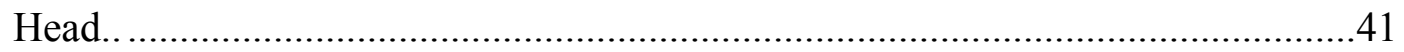

Perceived Influences on Development of Youth's Life Skills .............................55

Years Worked as Extension Camping Instructor..............................................68 
Types of Venues That The Participants Worked ................................................69

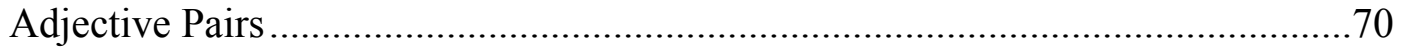

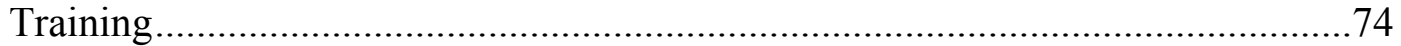

Would you recommend the Extension Camping Instructor Position to Others? ....75

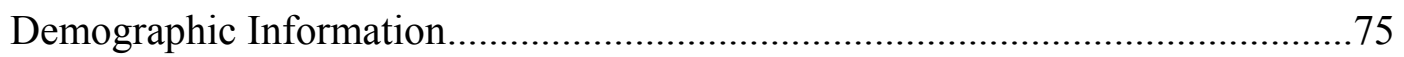

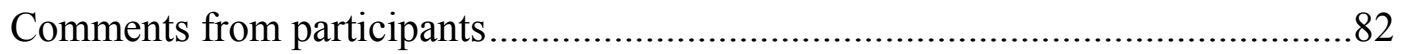

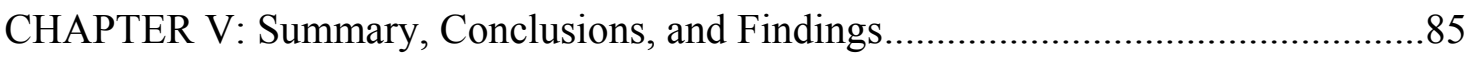

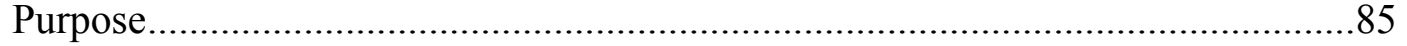

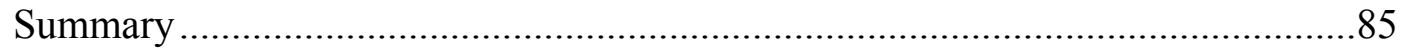

Extension Camping Instructors Current Life Skills Ability ...............................87

Influence of Being An ECI on Own Life Skill Development..............................87

Influence of Extension Camping Instructor on Youth's Development of Life

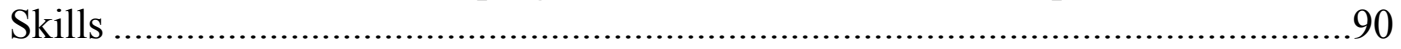

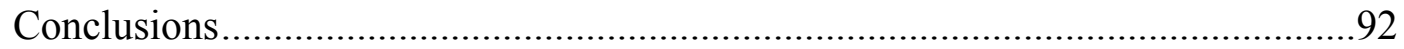

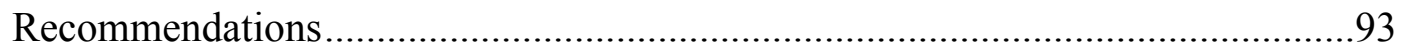

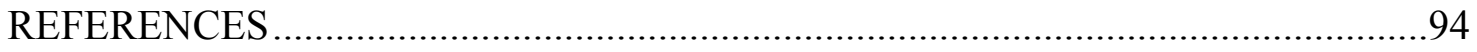

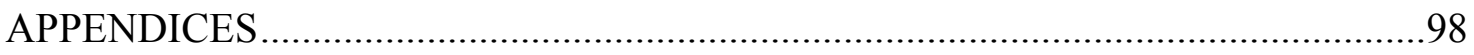

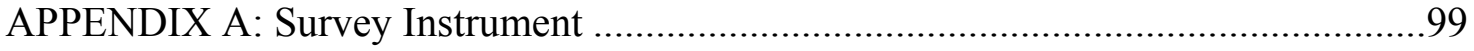

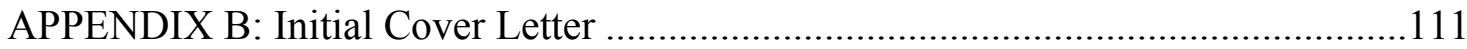

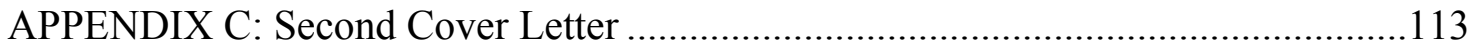

APPENDIX D: Responses to open-ended questions ...........................................115

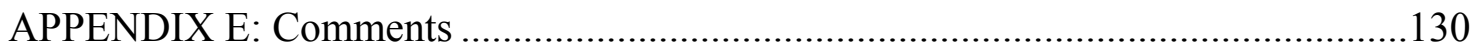

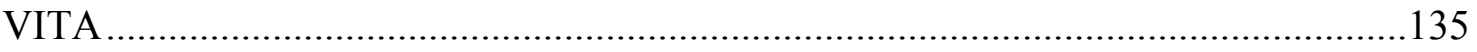




\section{LIST OF TABLES}

Table 1: Extension Camping Instructors' Perceptions of Current Life Skills Abilities

Table 2: Influence of being an Extension Camping Instructor on ECI's Life Skills Development

Table 3: Extension Camping Instructors' Perceived Influences on Youth's Development of Life Skills

Table 4: Years Worked as an Extension Camping Instructor.

Table 5: Types of Venues Worked Throughout Extension Camping Instructor Career .70

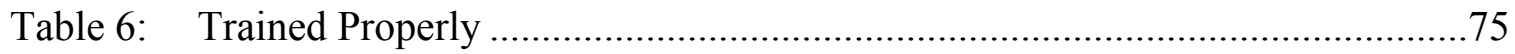

Table 7: Would you Recommend being an ECI?..................................................... 75

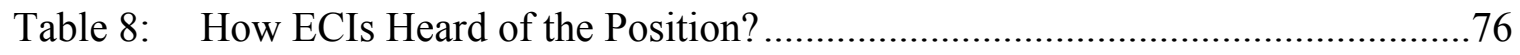

Table 9: Influence on Applying for ECI Position ................................................... 79

Table 10: Influence of Being an Extension Camping Instructor on College Major

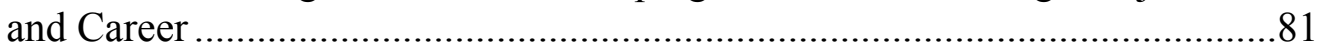

Table 11: Reasons for not Continuing Employment...................................................82 


\section{LIST OF FIGURES}

Figure 1: $\quad$ Targeting Life Skills Model.................................................................. 10

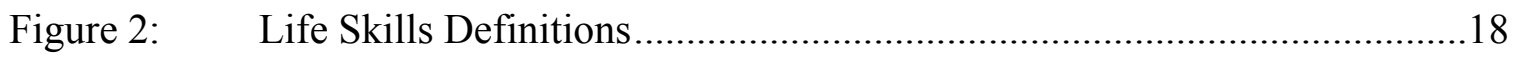

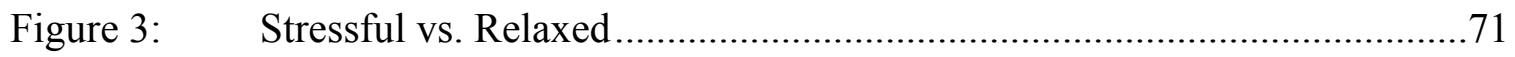

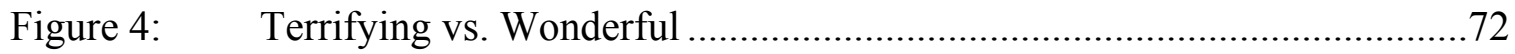

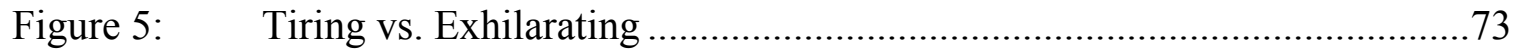

Figure 6: $\quad$ Waste of Time vs. Learning Experience ............................................ 74

Figure 7: Current Level of Life Skills Abilities ................................................8

Figure 8: $\quad$ Influence on Own Life Skills Development ........................................89

Figure 9: $\quad$ Influence on Youth's Life Skills Development .....................................91 


\section{CHAPTER I}

\section{Introduction}

In the early 1900's, agricultural clubs for young boys and girls started to appear throughout the southern United States. Educators and researchers from the United States Department of Agriculture (USDA) found that children were more open to implementing new agricultural practices than their parents (Van Horn, Flanagan, \& Thompson, 1998; Graham, 1994). Corn clubs for boys and tomato clubs for girls then became prime opportunities for young people to become involved in agriculture fields. The clubs eventually became known as 4-H Clubs.

The Cooperative Extension Service (CES) was created in 1914 as part of the Smith-Lever Act (Graham, 1994). It was designed to be an outreach of the local landgrant university and the USDA to the people of each state. Seaman Knapp also known as the "Father of Extension" is credited with creating the formation of the Extension Service through his work with the demonstration techniques (Graham, 1994). The CES operates at three levels of government with the first being that the federal government which establishes policies and practices through the USDA-NIFA. At the state level, the landgrant institutions provide staffing, and administrative oversight through funding and research. The county level are the local officials and the county agents who implement the new practices and policies in their communities. Normally, each state operates individually using a team of a specialists, district directors, county agents, and volunteers (Graham, 1994). West Virginia does not currently have any district directors.

Volunteers are an essential part of the county and state Extension Service (Boyd, 2004). Today, there are more than 611,800 volunteers involved with the $4-H$ program, 
worldwide (National 4-H Council, 2015). Connors (as cited in Boyd, 2004) states that some of the duties of a county Extension agent are to recruit, screen, educate, and recognize volunteers. Volunteers are able to serve as leaders, project leaders, record book keepers, activity planners, and recreational directors (Graham, 1994).

A study on Life Skills developed through 4-H was conducted at Tufts University in 1991. The study's purpose was to determine if there was a correlation between participation in 4-H events and a perceived level of leadership life skills. As estimated in $1991,25 \%$ percent of our nation's youth were expected to engage in high risk behavior, and the numbers were expected to increase in years following (Boyd, Herring, \& Briers, 1992). The study found that there was a significant difference between the perceptions of level of life skills attained between 4-H members and non 4-H members. The areas in which 4-H members perceived higher levels of skills included understanding self, communicating, making decisions, and leadership (Boyd et al., 1992).

In response to the study of leadership life skill development, eight essential elements of 4-H positive youth development were identified in 1999. The eight elements were created by a 4-H Impact Design Implementation Team with the collaboration of the National 4-H Council. The elements were composed of a positive relationship with a caring adult, an inclusive environment, a safe environment, opportunity to see oneself as an active participant in the future, opportunity for self-determination, engagement in learning, opportunity for mastery, and opportunity to value and practice service for others (Martz et al., 1999).

Each of the eight Essential Elements is vital to the growth and development of youth. It is the combination of the elements that creates a positive 
environment for youth development. By intentionally including these elements, youth can participate experientially in activities and events, feel nurtured in a safe environment, master new skills and abilities, and be empowered to contribute to their environment and communities in a positive way. (Martz et al., 1999, p. 2)

The West Virginia University Extension Service has taken the Essential Elements of Positive Youth Development and have implemented them throughout its 4- $\mathrm{H}$ programs. According to the West Virginia University Extension Service (2014), the 4-H program is comprised of four H's and each correspond with different aspects of the Essential Elements. "Head H- developing life skills and knowledge, Heart H- building self-esteem and supporting positive values that build character, Hands $\mathrm{H}$ - fostering active citizenship and service to others, and Health $\mathrm{H}$ - teaching healthy habits" (West Virginia University Extension Service, 2014). The 4-H program philosophy states that one of its purposes is to enhance the development of all youth (West Virginia University Extension Service, 2014).

In 2007, the West Virginia University Extension Service initiated the Extension Camping Instructors program (ECI). The purpose of the ECI was to engage the youth, act as assistants to the director of the 4-H venue (the local Extension Agent in most cases), and to create a positive atmosphere. The new group consisted of between 40 and 60 college-aged members who would be trained in the Essential Elements of Positive Youth Development and sent to different 4-H venues throughout the state. Some of those venues included 4-H camps, the State Fair, and State 4-H Days. In some cases the ECI would be sent alone, or in groups of two or more depending on the venue and the need. 


\section{Problem}

Life skills can be defined as skills needed in order to survive. Research shows that Extension programs such as 4-H can dramatically increase life skill development (Anderson, 2014; Armstrong, 2010; Arnold, Bourdeau, \& Nagele, 2005; Boyd, Herring, \& Briers, 1992; Duncan, 2000; Garst \& Johnson, 2005; Garton, Miltenberger, \& Pruett, 2007), but there is no research on whether or not Extension Camping Instructors (ECIs) are influencing life skill development. Being that ECIs are employees of the Extension Service, further research is needed to determine if they are assisting in accomplishing Extension's mission.

\section{Theoretical Framework}

Maslow's (1943) Theory of Human Motivation creates the theoretical framework for this study. According to Maslow, motivation is the result from satisfying a set of needs that for which everyone hungers. Maslow (1943) says that the needs of humans are arranged in a hierarchy based on pre-potency meaning that once each level is satisfied, the next level of needs emerges.

The hierarchy that Maslow created is comprised of five levels of basic needs. The first level that must be satisfied in order to move on are the physiological needs. This level of needs includes needs that are basic in order for a human to survive such as hunger, thirst, and sexual desires. If these needs are not satisfied, they have been shown to completely control the way someone thinks and rule all other needs obsolete. This is why the physiological needs are the basic needs (Maslow, 1943).

Once the physiological needs have been met, the level of safety needs emerges. Having both a physically and mentally safe environment are essential to the positive 
growth of a child. The lack therein can create a skewed vision as the child grows into adulthood. As a parent or guardian, it is part of the duty to create that safe environment so that a child will feel protected (Maslow, 1943). If fear is constant in a child's environment, it can create an emotional distance from others in which the child secludes themselves. Maslow states that children seem to thrive in an environment that has a structured framework because it creates a feeling of being safe.

Once safety needs are satisfied, the love needs are next on the hierarchy. In this stage, children focus on affection and having a sense of belonging. While not all children show that they want to belong, it is proven that all humans crave an affectionate relationship. "In our society the thwarting of these needs is the most commonly found core in cases of maladjustment and more severe psychopathology" (Maslow, 1943, p. $381)$.

The next level of needs that will emerge are the esteem needs. A person seems to thrive in the world when they are feeling that they matter. A person needs to have a high opinion of themselves so that they can continue growing. Without the satisfaction of the esteem needs, humans can feel that they are worthless, weak, or simply do not matter at all.

The highest level of Maslow's (1943) hierarchy of needs is the need for selfactualization. This term can be defined as someone's purpose. The idea of fulfilling one's purpose can be correlated to one's happiness. When self-actualization is satisfied, we can only expect the best from that person. "We shall call people who are satisfied in these needs, basically satisfied people, and it is from these that we may expect the fullest (and healthiest) creativeness" (Maslow, 1943, p. 383). 
To determine if positive youth development was being promoted by Extension Camping Instructors, this study was designed to determine if Extension Camping Instructors are developing their own life skills and if they perceive they are influencing life skill development of the 4-H youth with whom they had worked. This study sought to determine the extent of the Extension Camping Instructors' influence.

\section{Purpose}

The purpose of this study was to determine if West Virginia University Extension Camping Instructors (ECIs) were influencing the life skills development of 4-H youth while also developing life skills of their own. This study utilized the unique perceptions of ECIs who were employed from the summer of 2007 to October of 2015 by examining their current level of life skills, how they felt being employed as an ECI influenced the development of each skill, and how they felt their role impacted the life skill development of 4-H youth with whom they had worked.

The following research questions were used to guide this study of the impact of an Extension Camping Instructor (ECI) on life skill development.

1. How will the ECIs perceive their current level of life skill development defined by the Targeting Life Skills Model (Hendricks, 1996)?

2. How do ECIs perceive the impact of their employment on their current level of life skills?

3. How do ECIs perceive their role impacted the life skill development of the 4-H youth with whom they had worked? 


\section{Limitations}

The participants in this study were limited to the Extension Camping Instructors who were employed by the West Virginia University Extension Service from the summer of 2007 to October of 2015. Any similar employee that worked before the summer of 2007 held a different title and position and were not included in this study. 


\section{CHAPTER II}

\section{Review of Literature}

\section{Volunteers}

Volunteers are an essential part of the Cooperative Extension Service because they are local people with an interest in helping other local people. The National 4-H Website (2015) states that there are more than 611,800 volunteers working with the 4-H program, worldwide. Graham (1994) defined major roles as 4-H volunteers which include leaders, project leaders, record book keepers, and activity directors.

Extension agents need to learn how to manage these volunteers. Boyd (2004) describes extension agents as "administrators of volunteers" and studied ways of thinking that will make their job easier. This study found that in order to properly manage volunteers, future extension agents should work on organizational leadership, systems leadership, organizational culture, personal skills, and management skills (Boyd, 2004).

In a 4-H camp setting, volunteers act as camp counselors, class leaders, songs/games leaders, and teachers. In a study of camp volunteers (Garth \& Johnston, 2005) sought to determine how volunteers perceived that they helped out at camp. The responses differed in many ways but included topics such as talking, listening, sharing, empathizing, and teaching new skills.

\section{Life Skills}

Hamburg (1989) found that "successful" youth programs could teach many skills to their participants. Some of those skills included decision making, communications, interpersonal strategies, and self-regulations. With 4-H being a youth program, a number of studies have been conducted, focusing on life skill development through 4-H activities 
(Anderson, 2014; Armstrong, 2010; Arnold, Bourdeau, \& Nagele, 2005; Boyd, Herring, \& Briers, 1992; Duncan, 2000; Garst \& Johnson, 2005; Garton, Miltenberger, \& Pruett, 2007).

Boyd, Herring, \& Briers (1992) sought to determine if participation in 4-H was positively correlated to perceived leadership life skills. They wanted to know if the perceived level of skills would increase as the amount of participation in 4-H programs increased. It was discovered that 4-H members had statistically higher perceptions of life skills than the non 4-H members. 4-H members ranked highest in working with groups and understanding self (Boyd, Herring, \& Briers, 1992).

Hendricks (1996) developed the "Targeting Life Skills Model.” The model is divided up into the four H's (Head, Heart, Health, and Hands), and was designed so that 4-H leaders could create their educational content around any particular skill listed. The list is comprised of life skills which should be the result from participating in any 4-H program.

Each of the four H's are made up of two categories of life skills. The "Head H" consists of managing and thinking. The "Heart $\mathrm{H}$ " consists of relating and resolution. The "Hands H" consists of giving and working. The "Health H" consists of being and living (see Figure 1). The national department of 4-H Youth Development adopted the "Targeting Life Skills Model” in 2003 as a protocol for all 4-H programs. 


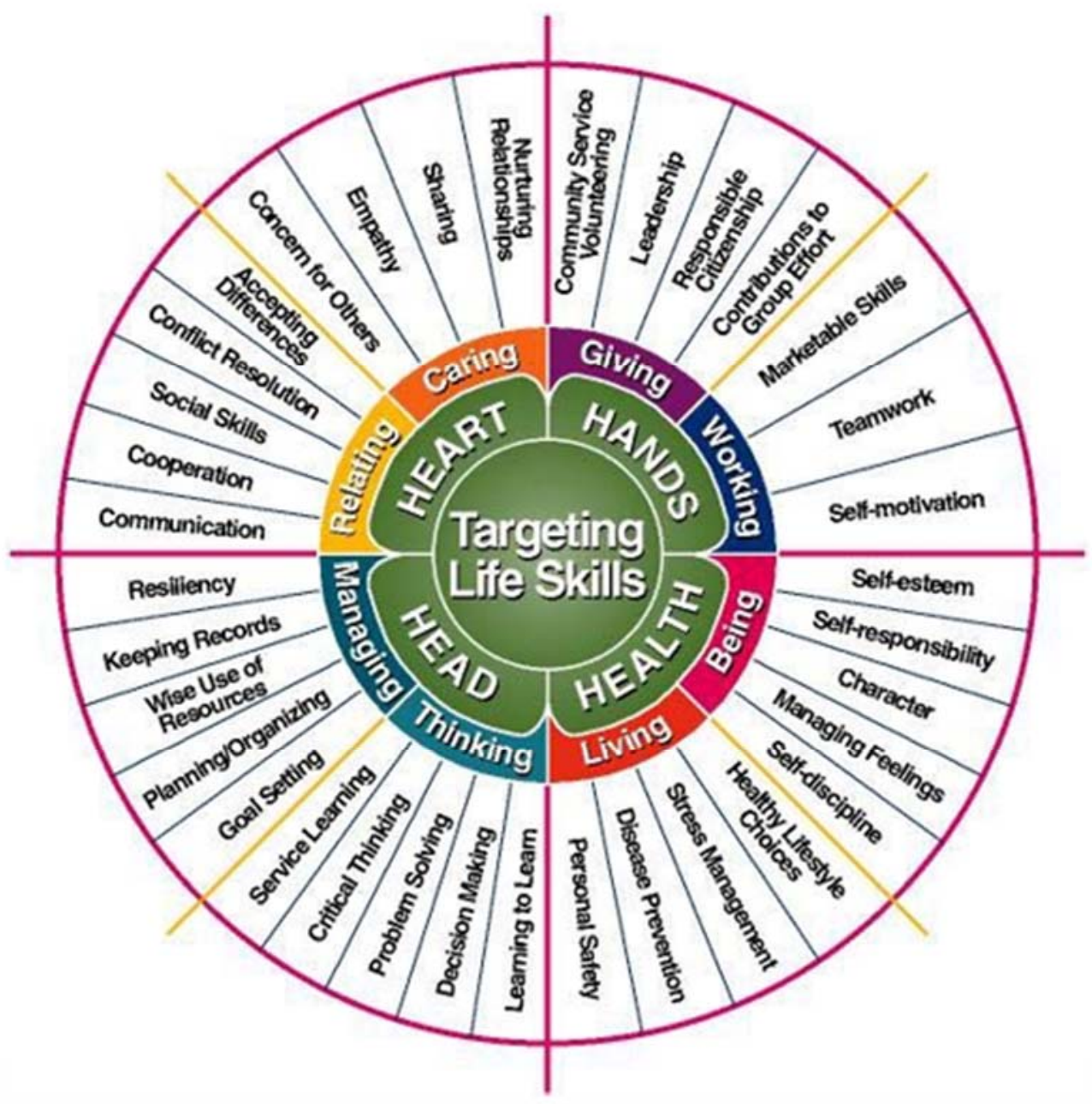

Figure 1: Targeting Life Skills Model, (C) Iowa State University Extension, Hendricks, P.

\section{A. 1998}

Anderson (2014) studied the influence of 4-H judging teams on career life skill development. Focusing on members of 4-H agriculture judging teams who won state championships, the study found that participation positively influenced their education and career choices. A few of the life skills gained from such activities included learning to learn, teamwork, and decision making. 
Life skills developed through a 4-H camp setting has been the focus of a number of studies including Arnold, et al., 2005; Duncan, 2000; Garst \& Bruce, 2003; Garton, et al., 2007. According to Garst \& Bruce (2003), the purpose of camp is to learn new skills through hands on programming. Garst \& Bruce (2003) created a standardized procedure of evaluation to determine how 4-H camp benefits youth. Both camp participants and their parents/guardians were surveyed to find the perceived benefits. Taking care of his/her belongings, sharing work responsibilities, and taking initiative as a self-starter all received the highest ratings among both the youth and the parents/guardians.

A study conducted in Oregon determined how 4-H camp impacted the youth (Arnold, et al., 2005). The study assessed three areas which included personal growth, life skill development, and camper satisfaction. In the category of personal growth, no skills were found significantly changed after camp. Some of the items included in this category were being away from home, knowledge about nature, and managing free time. In the Life Skill category, skills were taken from the "Targeting Life Skills Model" (Hendricks, 1996), and all skills averaged "above average" on how camp impacted them. Of the campers, $91 \%$ said that camp had made them find new interests. Eighty-nine percent said that camp wanted to make them try new things, while, $87 \%$ said that camp made them feel good about themselves.

In the camper satisfaction category, campers indicated how much they enjoyed the various aspects of camp. The highest mean scores were reported for "liked camp counselors," "made new friends," and "going to share about camp with friends" (Arnold et al., 2005). 
Duncan (2000) studied the relationship between youth leadership life skill development and participation in the West Virginia 4-H Camping Program. The participants in the study were $4-\mathrm{H}$ members; 13 to 15 years old. The results indicated that if a member was given a leadership role in a camp setting, they perceived that their level of leadership life skills was higher than those who hadn't. The skills which received the highest ratings after camp were getting along with others, respecting others, being more open minded, and considering the needs of others (Duncan, 2000).

Garton et al (2007) studied 4-H members, across 15 different counties, who attended 4-H camp in West Virginia during the 2003 camping season. Both older and younger members who attended camp showed that their greatest gains in skills were those of getting along with others, responsible citizenship, and accepting differences of others (Garton et al., 2007).

Life skills development is one aspect of adolescent development, otherwise known as the developmental stages from approximately 10 to 20 years old. Granville Stanley Hall was the first researcher to study the development of adolescents and much of his work inspired the research of the study for the first half of the $20^{\text {th }}$ century (Lerner, 2005). While many people viewed the time of adolescence as a time of stress, disaster, and risky behaviors (including Hall), research proved in the latter half of the $20^{\text {th }}$ century that this was not true. During the 1960s, researchers began to focus on individual adolescent development rather than theories about development (Lerner, 2005). During that time period, aspects of adolescent development were broken down into simple behaviors, thoughts, and social interactions. 


\section{Positive Youth Development}

The Essential Elements of 4-H Youth Development Programs were designed by a team of researchers from the National 4-H Council in 1999. The eight elements are necessary in order to optimize the development of 4-H participants. These eight elements are critical in achieving a positive experience (Martz et al., 1999). The eight elements can be separated into four categories of: Belonging, Mastery, Independence, and Generosity. All Extension employees, including volunteers, are required to be trained in the elements so that they know what is expected of them. In 2009, the National 4-H Council copyrighted a curriculum full of training exercises and notes so that Extension employees across the United States will be able to utilize the information more easily.

The Tufts University study of 4-H Positive Youth Development was a longitudinal study that began in 2002 and surveyed more than 7,000 adolescents throughout the next eight years. "The study was conducted to test the idea that when the strengths of youth are aligned with family, school, and community resources across adolescence, positive youth development will occur” (Lerner \& Lerner, 2013, p. 3).

The researchers discovered that positive youth development can be defined by the five C's which are competence, confidence, character, connection, and caring (Lerner \& Lerner, 2013; Zarrett \& Lerner, 2008). When the five C's are combined, a sixth C (contribution) emerges. Surveying adolescents over the course of eight years allowed the researchers to test how participating in 4-H relates to positive youth development.

Three factors were identified as helping to predict positive youth development; assets that family possessed such as eating dinner together, the adult-child relationship, and the role of out of school activities. The study also found that keeping a positive 
attitude, feeling welcome in your environment, and the relationship with the people around you all can lead to positive youth development (Lerner \& Lerner, 2013). The researchers concluded that 4-H participants are more likely to make contribution to their communities and be civically active than non 4-H participants (Lerner \& Lerner, 2013). 


\section{CHAPTER III}

\section{Methodology}

\section{Purpose}

The purpose of this study was to determine if West Virginia University Extension Camping Instructors (ECIs) were influencing the life skill development of 4-H youth while also developing life skills of their own. This study utilized the perceptions of ECIs who were employed from the summer of 2007 to October of 2015 by examining their current level of life skills, how they felt being employed as an ECI influenced the development of each skill, and how they felt their role impacted the life skill development of 4-H youth with whom they had worked.

The following research questions were used to guide this study of the impact of an Extension Camping Instructor (ECI) on life skill development.

1. How will the ECIs perceive their current level of life skill development as defined by the Targeting Life Skills model by Hendricks (1996)?

2. How do ECIs perceive the impact of their employment on their current level of life skills?

3. How do ECIs perceive their role impacted the life skill development of the 4-H youth with whom they had worked?

\section{Research Design}

For this study, the researchers used a descriptive research design (Ary, Jacobs, Sorenson, \& Walker, 2014). By using a descriptive design, the researchers were able to collect both quantitative and qualitative data in a broader field. A descriptive design

allowed the researchers to develop a survey instrument using Qualtrics Survey Software 
and aggregate the responses to test the hypotheses. A descriptive survey instrument, as well as some open ended questions, was able to satisfy both the purpose and objectives of this study.

\section{Population}

The target population for the study were all Extension Camping Instructors that were employed from the summer of 2007 to October of 2015. The accessible population were the 192 current and former ECIs provided in a list from the West Virginia University Extension Service 4-H Youth Development office. A census of the accessible population was used. While similar organizations have existed, the group was referred to under a different name prior to 2007.

\section{Instrumentation}

Based on the review of literature, including the Targeting Life Skills Model (Hendricks, 1996) and a similar study conducted by Anderson (2014), the researchers were able to develop an online questionnaire using Qualtrics Survey Software. Sampling and selection errors were controlled by utilizing the entire population of the target audience.

Both content and face validity were established by a panel of experts, consisting of West Virginia University faculty from the Agricultural and Extension Education department and an Extension Specialist. The Institutional Review Board requirements for West Virginia University were met.

Reliability for the survey instrument was determined using a Split-half method and the Spearman-Brown Coefficient. Based on the data, a rating of exemplary was 
found with a Spearman-Brown Coefficient of .919 (Robinson, Shaver, \& Wrightsman, 1991).

The survey instrument was developed to utilize the unique perspectives of the Extension Camping Instructors to determine whether or not they felt that they influenced the life skill development of 4-H youth while developing life skills of their own. The survey instrument was divided into three main sections; life skills, demographic information, and opinions of the target population.

A list of 35 life skills were taken from the Targeting Life Skills Model (Hendricks, 1996) and were broken down into the four aspects of four-fold development; Head, Heart, Hands and Health. From there, the life skills were broken down into subcategories; Thinking, Managing, Caring, Relating, Giving, Working, Being and Living (Hendricks, 1996). Each group of life skills are defined in Figure 2. For each group of life skills, three questions were asked. The first question asked for the Extension Camping Instructors to rate their current level of ability for each skill listed on a scale of 1 - Very Poor, 2 - Poor, 3 - Average, 4 - Good, and 5 - Excellent.

The second question sought to determine how influential working as an Extension Camping Instructor was on the development of each skill by asking the participants to rate the influence on a five point scale. The rating scale included: 1 - Not At All Influential, 2 - Mildly Influential, 3 - Moderately Influential, 4 - Highly Influential, and 5 - Almost Essential. Utilizing the same scale, the third question examined how the Extension Camping Instructor's perceived their role as an ECI influenced a youth's development of each life skill. 


\begin{tabular}{|c|c|c|}
\hline \multirow{10}{*}{$\begin{array}{l}0 \\
10 \\
11 \\
1\end{array}$} & \multirow{5}{*}{ 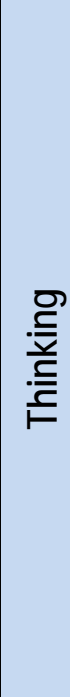 } & $\begin{array}{l}\text { Service Learning - gaining skill and experience through active participation } \\
\text { in organized service experiences, that meet actual community needs and that } \\
\text { are coordinated with the school and community; learning linked with real life. }\end{array}$ \\
\hline & & $\begin{array}{l}\text { Critical Thinking - strategies for analyzing, comparing, reasoning, and } \\
\text { reflecting focused on deciding what to believe or do; discovering meaning; } \\
\text { building connections with past learning. }\end{array}$ \\
\hline & & $\begin{array}{l}\text { Problem Solving - clearly identifying a problem and a plan of action for } \\
\text { resolution of the problem. }\end{array}$ \\
\hline & & Decision Making — choosing among several alternatives. \\
\hline & & $\begin{array}{l}\text { Learning to Learn - acquiring, evaluating and using information; } \\
\text { understanding the methods and skills for learning. }\end{array}$ \\
\hline & \multirow{5}{*}{8} & $\begin{array}{l}\text { Resiliency - adaptability; the ability to recover after experiencing misfortune } \\
\text { or disease; coping with change; overcoming problems and difficulties. }\end{array}$ \\
\hline & & $\begin{array}{l}\text { Keeping Records - recording selected useful information, usually focused } \\
\text { for a specific purpose. }\end{array}$ \\
\hline & & $\begin{array}{l}\text { Wise Use of Resources - using sound judgment; not wasteful; being } \\
\text { responsible; setting priorities. }\end{array}$ \\
\hline & & $\begin{array}{l}\text { Planning/Organizing - a method for doing something that has been thought } \\
\text { out ahead of time; how the parts can be put together. }\end{array}$ \\
\hline & & $\begin{array}{l}\text { Goal Setting - deciding on the purpose or desired result; something to work } \\
\text { toward. }\end{array}$ \\
\hline
\end{tabular}

Figure 2: Life Skills Definitions 


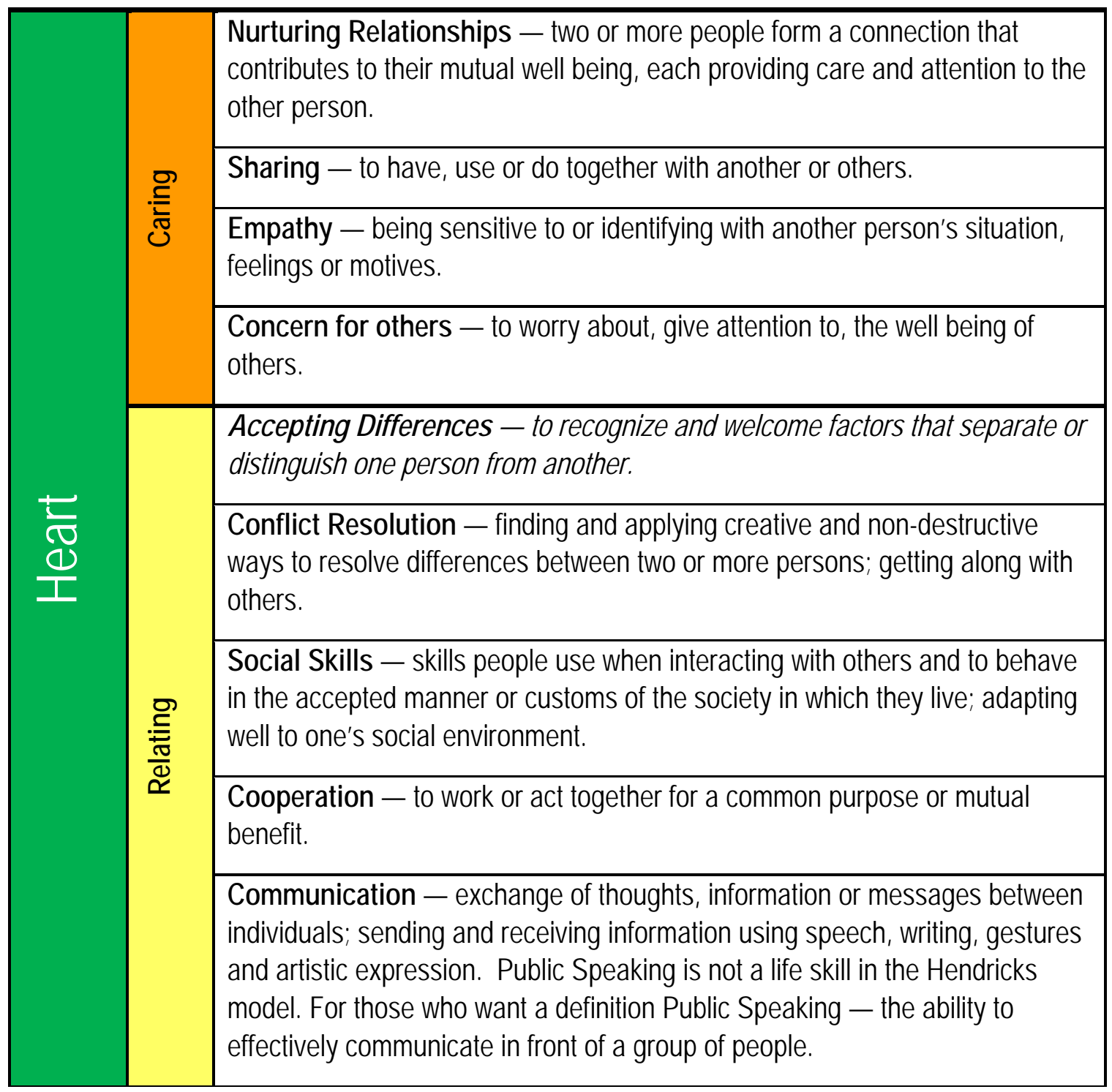

Figure 2 (continued): Life Skill Definitions 


\begin{tabular}{|c|c|c|}
\hline \multirow{7}{*}{$\frac{0}{\frac{0}{6}}$} & \multirow{4}{*}{ : } & $\begin{array}{l}\text { Community Service/Volunteering - to donate one's time and/or effort of } \\
\text { one's own free will for the benefit of the group without guarantee. }\end{array}$ \\
\hline & & $\begin{array}{l}\text { Leadership - to assist the group in meeting its goals by showing or directing } \\
\text { along the way; using personal influence to guide the group in reaching its } \\
\text { goals. }\end{array}$ \\
\hline & & $\begin{array}{l}\text { Responsible Citizenship - an individual demonstrating love and devotion in } \\
\text { response to duties, rights, and privileges as a member of a community or } \\
\text { country. }\end{array}$ \\
\hline & & $\begin{array}{l}\text { Contributions to group efforts - to give or supply along with others for a } \\
\text { common purpose. }\end{array}$ \\
\hline & \multirow{3}{*}{$\frac{8}{\frac{8}{0}}$} & $\begin{array}{l}\text { Marketable Skills - to have the abilities wanted by employers and needed } \\
\text { to hold a job. }\end{array}$ \\
\hline & & $\begin{array}{l}\text { Teamwork - work done by two or more people, each doing parts of the } \\
\text { whole task. }\end{array}$ \\
\hline & & $\begin{array}{l}\text { Self-motivation - able to make the needed effort to carry out a task or a } \\
\text { plan; personal will to take action. }\end{array}$ \\
\hline
\end{tabular}

Figure 2 (continued): Life Skill Definitions 


\begin{tabular}{|c|c|c|}
\hline \multirow{9}{*}{$\frac{c}{c}$} & \multirow{5}{*}{$\frac{8}{8}$} & $\begin{array}{l}\text { Self-esteem - pride in oneself; proper regard for oneself as a human being; } \\
\text { valuing oneself; a feeling of ability to cope; learning to accept and like oneself. }\end{array}$ \\
\hline & & $\begin{array}{l}\text { Self-responsibility - taking care of oneself; being accountable for one's } \\
\text { behavior and obligations; choosing for oneself between right and wrong. }\end{array}$ \\
\hline & & $\begin{array}{l}\text { Character - a person's moral strength; integrity, fortitude, reputation; a } \\
\text { person's usual qualities or traits; adherence to a code of values or ethical } \\
\text { principles. }\end{array}$ \\
\hline & & $\begin{array}{l}\text { Managing Feelings - expressing one's feelings appropriately and in } \\
\text { proportion to circumstance. }\end{array}$ \\
\hline & & $\begin{array}{l}\text { Self-discipline - control of self and one's conduct in line with moral } \\
\text { character (what is right and wrong), personal values (what one considers } \\
\text { important), and societal expectations; control before acting in a hurtful or } \\
\text { harmful way. }\end{array}$ \\
\hline & \multirow{4}{*}{ ב } & $\begin{array}{l}\text { Healthy Lifestyle Choices - increased knowledge, attitudes and behaviors } \\
\text { that insure current good health, as well as those that assure future well-being } \\
\text { such as: exercise, nutrition, disease prevention, personal safety and stress } \\
\text { management. }\end{array}$ \\
\hline & & $\begin{array}{l}\text { Stress Management - to direct or have control over physical or mental } \\
\text { strain and pressure, or one's reaction to it; coping with change. }\end{array}$ \\
\hline & & $\begin{array}{l}\text { Disease Prevention - to anticipate and ward off conditions that keep the } \\
\text { body from functioning normally, such as infection or stress that impairs normal } \\
\text { physiological functioning. }\end{array}$ \\
\hline & & $\begin{array}{l}\text { Personal Safety - taking care to avoid danger, risk, or harm; self-protection; } \\
\text { being cautious, careful; physically and emotionally safe. }\end{array}$ \\
\hline
\end{tabular}

Figure 2 (continued): Life Skill Definitions 
The second section of the survey instrument allowed the target population to express their opinions about the Extension Camping Instructor experience. In this section, an open-ended question was provided and asked the target population to list what they felt was the most useful life skill that they had gained from working as an Extension Camping Instructor and to explain their reasoning behind it. The other opportunity to express their opinions about their experience came in the form of four sliding scales with opposite adjective pairs on each. With each sliding scale, the participant was asked to rank on a five point scale their opinion of their experience, with one meaning the more negative adjective, and five meaning the positive adjective. The adjective pairs consisted of "Stressful" and "Relaxed." "Terrifying" and "Wonderful," "Tiring" and "Exhilarating," "Waste of Time” and "Learning Experience."

The third section of the survey instrument consisted of demographic information. This section of the survey instrument sought to find out how the target population initially heard of the Extension Camping Instructor position, who influenced their decision to apply for the position, how many years they worked as an Extension Camping Instructor, what type of venues they worked at and how many, if their role as an Extension Camping Instructor influenced their college major or career choice, why they did not continue with their employment, and whether or not they would encourage others to apply for the position.

\section{Data Collection Techniques}

Data collection procedures were based on Dillman, Smyth, \& Christian (2009). A list of 192 email addresses of the target population was constructed. An individually addressed email was sent to each address on November 9, 2015 containing a link to the 
survey instrument using the Qualtrics Survey Software, a brief message detailing the study, and a deadline to have the survey completed by of November 20, 2015. A second email containing a link to the survey instrument on the Qualtrics website, a brief message detailing the study, and a second deadline was sent to each of the initial non-responders on December 1, 2015. Out of the initial 192 target population, 155 responses were recorded giving a total response rate of 80.73 percent.

\section{Data Analysis Procedures}

Data collected from the survey results was analyzed and entered into Excel spreadsheets and then imported into SPSS. The alpha level of significance was set $a$ priori at $\alpha \leq .05$ for all statistical tests. Respective scales of measurement including those of both central tendency and variability were performed on the data with the results being reported in frequencies and percentages.

A comparison of early respondents to late respondents were made to address the non-response error (Miller \& Smith, 1983). Three variables were used in this comparison: Years that the Extension Camping Instructor had worked, the amount of county camps that the Extension Camping Instructor had worked, and the amount of state camps that the Extension Camping Instructor had worked. A Chi-Square statistic was performed on all three variables and no significant difference was found, therefore findings can be generalized to the entire target population.

\section{Use of Findings}

The conclusions and findings of this study will provide the West Virginia 4-H Youth Development Program with a future promotional tool for hiring Extension Camping Instructors. It will provide information of the life skills developed while being 
employed as an Extension Camping Instructor as well as their perceptions of how they are influencing the life skill development of 4-H youth throughout the state. The researchers hope that this study may also be used by other state $4-\mathrm{H}$ programs to create similar Extension Camping Instructor programs. 


\section{CHAPTER IV}

\section{Findings}

\section{Purpose}

The purpose of this study was to determine if West Virginia University Extension Camping Instructors (ECIs) were influencing the life skills development of 4-H youth while also developing life skills of their own. This study utilized the unique perceptions of ECIs who were employed from the summer of 2007 to October of 2015 by examining their current level of life skills, how they felt being employed as an ECI influenced the development of each skill, and how they felt their role impacted the life skill development of 4-H youth with whom they had worked.

The following research questions were used to guide this study of the impact of an Extension Camping Instructor on life skill development.

1. How will the ECIs perceive their current level of life skill development as defined by the Targeting Life Skills model by Hendricks (1996)?

2. How do ECIs perceive the impact of their employment on their current level of life skills?

3. How do ECIs perceive their role impacted the life skill development of the 4-H youth with whom they had worked?

\section{Current Level of Life Skills}

Respondents were given a list of 35 life skills, along with definitions of each, taken from the Targeting Life Skills Model (Hendricks, 1996). The list of life skills were separated into four categories of "Head", "Heart", "Hands", and "Health." For each life skill, the participants were asked to rate their current level of ability. 
Head. The life skills listed under the "Head" category were divided into the two sub-categories of Thinking and Managing. Thinking is composed of Service Learning, Critical Thinking, Problem Solving, Decision Making, and Learning to Learn. Managing is composed of Resiliency, Keeping Records, Wise Use of Resources, Planning/Organizing, and Goal Setting.

Thinking Skills. Service Learning was defined - gaining skill and experience through active participation in organized service experiences, that meet actual community needs and that are coordinated with the school and community; learning linked with real life (Hendricks, 1996). When asked to rate their current level of ability in "Service Learning," 45 participants (32.14\%) reported their current level of ability as excellent, 70 $(50.00 \%)$ reported their current level of ability as good, $22(15.71 \%)$ reported their current level of ability as average, and three participants (2.14\%) reported their current level of ability as poor (see Table 1). 
Table 1

Extension Camping Instructors' Perceptions of Current Life Skills Abilities

\begin{tabular}{|c|c|c|c|c|c|c|c|c|c|c|}
\hline & \multicolumn{2}{|c|}{ Very Poor } & \multicolumn{2}{|c|}{ Poor } & \multicolumn{2}{|c|}{ Average } & \multicolumn{2}{|c|}{ Good } & \multicolumn{2}{|c|}{ Excellent } \\
\hline & $\mathrm{f}$ & $\%$ & $\mathrm{f}$ & $\%$ & $\mathrm{f}$ & $\%$ & $\mathrm{f}$ & $\%$ & $\mathrm{f}$ & $\%$ \\
\hline \multicolumn{11}{|l|}{ Giving } \\
\hline \multicolumn{11}{|l|}{ Community } \\
\hline Service/Volunteering & 0 & 0.00 & 0 & 0.00 & 15 & 10.27 & 64 & 43.84 & 67 & 45.89 \\
\hline Leadership & 0 & 0.00 & 0 & 0.00 & 7 & 4.79 & 58 & 39.73 & 81 & 55.48 \\
\hline Responsible Citizenship & 0 & 0.00 & 0 & 0.00 & 9 & 6.16 & 76 & 52.05 & 61 & 41.78 \\
\hline Contributions to Group Effort & 0 & 0.00 & 0 & 0.00 & 5 & 3.42 & 55 & 37.67 & 86 & 58.90 \\
\hline \multicolumn{11}{|l|}{ Working } \\
\hline Marketable Skills & 0 & 0.00 & 0 & 0.00 & 14 & 9.59 & 62 & 42.47 & 70 & 47.95 \\
\hline Teamwork & 0 & 0.00 & 0 & 0.00 & 3 & 2.08 & 47 & 32.64 & 94 & 65.28 \\
\hline Self Motivation & 0 & 0.00 & 0 & 0.00 & 26 & 18.06 & 70 & 48.61 & 48 & 33.33 \\
\hline
\end{tabular}


Table 1 (continued)

Extension Camping Instructors’ Perceptions of Current Life Skills Abilities

\begin{tabular}{|c|c|c|c|c|c|c|c|c|c|c|}
\hline & \multicolumn{2}{|c|}{ Very Poor } & \multicolumn{2}{|c|}{ Poor } & \multicolumn{2}{|c|}{ Average } & \multicolumn{2}{|c|}{ Good } & \multicolumn{2}{|c|}{ Excellent } \\
\hline & $\mathrm{f}$ & $\%$ & $\mathrm{f}$ & $\%$ & $\mathrm{f}$ & $\%$ & $f$ & $\%$ & $\mathrm{f}$ & $\%$ \\
\hline \multicolumn{11}{|l|}{ Being } \\
\hline Self Esteem & 0 & 0.00 & 2 & 1.40 & 29 & 20.28 & 70 & 48.95 & 42 & 29.37 \\
\hline Self Responsibility & 0 & 0.00 & 0 & 0.00 & 8 & 5.56 & 65 & 45.14 & 71 & 49.31 \\
\hline Character & 0 & 0.00 & 0 & 0.00 & 4 & 2.78 & 60 & 41.67 & 80 & 55.56 \\
\hline Managing Feelings & 0 & 0.00 & 2 & 1.41 & 23 & 16.20 & 88 & 61.97 & 29 & 20.42 \\
\hline Self Discipline & 0 & 0.00 & 3 & 2.11 & 29 & 20.42 & 73 & 51.41 & 37 & 26.06 \\
\hline \multicolumn{11}{|l|}{ Living } \\
\hline Healthy Lifestyle Choices & 0 & 0.00 & 4 & 2.82 & 46 & 32.39 & 74 & 52.11 & 18 & 12.68 \\
\hline Stress Management & 1 & 0.70 & 6 & 4.23 & 53 & 37.32 & 60 & 42.25 & 22 & 15.49 \\
\hline Disease Prevention & 0 & 0.00 & 2 & 1.41 & 32 & 22.54 & 57 & 40.14 & 51 & 35.92 \\
\hline Personal Safety & 0 & 0.00 & 0 & 0.00 & 8 & 5.67 & 67 & 47.52 & 66 & 46.81 \\
\hline
\end{tabular}


Table 1 (continued)

Extension Camping Instructors’ Perceptions of Current Life Skills Abilities

\begin{tabular}{|c|c|c|c|c|c|c|c|c|c|c|}
\hline & \multicolumn{2}{|c|}{ Very Poor } & \multicolumn{2}{|c|}{ Poor } & \multicolumn{2}{|c|}{ Average } & \multicolumn{2}{|c|}{ Good } & \multicolumn{2}{|c|}{ Excellent } \\
\hline & $\mathrm{f}$ & $\%$ & $\mathrm{f}$ & $\%$ & $\mathrm{f}$ & $\%$ & $\mathrm{f}$ & $\%$ & $\mathrm{f}$ & $\%$ \\
\hline \multicolumn{11}{|l|}{ Thinking } \\
\hline Learning to Learn & 0 & 0.00 & 0 & 0.00 & 6 & 4.29 & 62 & 44.29 & 72 & 51.43 \\
\hline Decision Making & 0 & 0.00 & 0 & 0.00 & 10 & 7.09 & 80 & 56.74 & 51 & 36.17 \\
\hline Problem Solving & 0 & 0.00 & 0 & 0.00 & 7 & 4.96 & 58 & 41.13 & 76 & 53.90 \\
\hline Critical Thinking & 0 & 0.00 & 1 & 0.71 & 7 & 4.96 & 54 & 38.30 & 79 & 56.03 \\
\hline Service Learning & 0 & 0.00 & 3 & 2.14 & 22 & 15.71 & 70 & 50.00 & 45 & 32.14 \\
\hline \multicolumn{11}{|l|}{ Managing } \\
\hline Goal Setting & 0 & 0.00 & 2 & 1.43 & 18 & 12.86 & 72 & 51.43 & 48 & 34.29 \\
\hline Planning/Organizing & 0 & 0.00 & 3 & 2.14 & 21 & 15.00 & 54 & 38.57 & 62 & 44.29 \\
\hline Wise use of Resources & 0 & 0.00 & 2 & 1.43 & 12 & 8.57 & 82 & 58.57 & 44 & 31.43 \\
\hline Keeping Records & 1 & 0.72 & 11 & 7.91 & 34 & 24.46 & 52 & 37.41 & 41 & 29.50 \\
\hline Resiliency & 0 & 0.00 & 0 & 0.00 & 17 & 12.41 & 69 & 50.36 & 51 & 37.23 \\
\hline
\end{tabular}


Table 1 (continued)

Extension Camping Instructors' Perceptions of Current Life Skills Abilities

\begin{tabular}{|c|c|c|c|c|c|c|c|c|c|c|}
\hline & \multicolumn{2}{|c|}{ Very Poor } & \multicolumn{2}{|c|}{ Poor } & \multicolumn{2}{|c|}{ Average } & \multicolumn{2}{|c|}{ Good } & \multicolumn{2}{|c|}{ Excellent } \\
\hline & $\mathrm{f}$ & $\%$ & $\mathrm{f}$ & $\%$ & $\mathrm{f}$ & $\%$ & $\mathrm{f}$ & $\%$ & $\mathrm{f}$ & $\%$ \\
\hline \multicolumn{11}{|l|}{ Relating } \\
\hline Communication & 0 & 0.00 & 1 & 0.74 & 9 & 6.62 & 67 & 49.26 & 59 & 43.38 \\
\hline Cooperation & 0 & 0.00 & 0 & 0.00 & 6 & 4.38 & 57 & 41.61 & 74 & 54.01 \\
\hline Social Skills & 0 & 0.00 & 1 & 0.73 & 14 & 10.22 & 49 & 35.77 & 73 & 53.28 \\
\hline Conflict Resolution & 0 & 0.00 & 0 & 0.00 & 13 & 9.49 & 65 & 47.45 & 59 & 43.07 \\
\hline Accepting Differences & 0 & 0.00 & 0 & 0.00 & 0 & 0.00 & 45 & 32.85 & 92 & 67.15 \\
\hline \multicolumn{11}{|l|}{ Caring } \\
\hline Concern for Others & 0 & 0.00 & 0 & 0.00 & 2 & 1.46 & 42 & 30.66 & 93 & 67.88 \\
\hline Empathy & 0 & 0.00 & 2 & 1.46 & 11 & 8.03 & 36 & 26.28 & 88 & 64.23 \\
\hline Sharing & 0 & 0.00 & 0 & 0.00 & 9 & 6.57 & 61 & 44.53 & 67 & 48.91 \\
\hline Nurturing Relationships & 0 & 0.00 & 0 & 0.00 & 15 & 10.95 & 52 & 37.96 & 70 & 51.09 \\
\hline
\end{tabular}


The Critical Thinking life skill was defined - strategies for analyzing, comparing, reasoning, and reflecting focused on deciding what to believe or do; discovering meaning; building connections with past learning (Hendricks, 1996). When asked to rate their current level of ability in "Critical Thinking," 79 participants (56.03\%) indicated that their current level of ability was excellent, $54(38.30 \%)$ rated their current level of ability as good, seven participants (4.96\%) reported their current level of ability as average, and one $(0.71 \%)$ reported their current level of ability as poor (see Table 1$)$.

The Problem Solving life skill was defined - clearly identifying a problem and a plan of action for resolution of the problem (Hendricks, 1996). When asked to indicate their current level of ability in "Problem Solving," 76 (53.90\%) participants rated their current level of ability as excellent, $58(41.13 \%)$ reported their current level of ability as good, and seven (4.96\%) selected average as their current level of ability (see Table 1).

The Decision Making life skill was defined - choosing among several alternatives (Hendricks, 1996). The current level of abilities in "Decision Making" went as follows: 51 participants (36.17\%) rated their current level of ability as excellent, $80(56.74 \%)$ stated that their current level of ability was good, and 10 (7.09\%) perceived their current level of ability as average (see Table 1).

The Learning to Learn life skill was defined - acquiring, evaluating and using information; understanding the methods and skills for learning (Hendricks, 1996). When asked about their current level of ability in "Learning to Learn," 72 of the participants (51.43\%) reported their current level of ability as excellent, 62 (44.29\%) reported their 
current level of ability as good, and six (4.29\%) reported their current level of ability as average (see Table 1).

Managing Skills. The life skill of Resiliency was defined - adaptability; the ability to recover after experiencing misfortune or disease; coping with change; overcoming problems and difficulties (Hendricks, 1996). In response to their current level of ability in "Resiliency," 51 participants (37.23\%) replied that their current level of ability was excellent, $69(50.36 \%)$ reported their current level of ability as good, and 17 $(12.41 \%)$ rated their current level of ability as average.

The Keeping Records life skill was defined as - recording selected useful information, usually focused for a specific purpose (Hendricks, 1996). In regards to their current level of ability for "Keeping Records," 41 participants $(29.50 \%)$ selected that their current level of ability was excellent, 52 (37.41\%) reported their current level of ability as good, $34(24.46 \%)$ reported their current level of ability as average, $11(7.91 \%)$ rated their current level of ability as poor, and one $(0.72 \%)$ reported their current level of ability as very poor (see Table 1).

Wise Use of Resources was defined - using sound judgment; not wasteful; being responsible; setting priorities (Hendricks, 1996). In regards to the current level of ability for "Wise Use of Resources," 44 participants (31.43\%) reported that their current level of ability was excellent, $82(58.57 \%)$ reported their current level of ability as good, 12 $(8.57 \%)$ reported their current level of ability as average, and two $(1.43 \%)$ reported their current level of ability as poor (see Table 1). 
The Planning/Organizing life skill was defined - a method for doing something that has been thought out ahead of time; how the parts can be put together (Hendricks, 1996). While rating their current level of ability for "Planning/Organizing," 62 participants (44.29\%) reported that their current level of ability was excellent, 54 (38.57\%) indicated that their current level of ability was good, $21(15.00 \%)$ reported their current level of ability as average, and three (2.14\%) stated that their current level of ability was poor (see Table 1).

The Goal Setting life skill was defined - deciding on the purpose or desired result; something to work toward (Hendricks, 1996). In regards to their current level of ability for "Goal Setting," 48 participants (34.29\%) reported their current level of ability as excellent, $72(51.43 \%)$ indicated that their current level of ability was good, 18 $(12.86 \%)$ perceived that their current level of ability was average, and two $(1.43 \%)$ reported their current level of ability as poor (see Table 1).

Heart. The life skills listed under the "Heart" category were separated into two sub-categories of Caring and Relating. Caring consisted of Nurturing Relationships, Sharing, Empathy, and Concern for Others. The Relating section included Accepting Differences, Conflict Resolution, Social Skills, Cooperation, and Communication.

Caring Skills. The life skill of Nurturing Relationships was defined - two or more people form a connection that contributes to their mutual wellbeing, each providing care and attention to the other person (Hendricks, 1996). When asked to rate their current level of ability for "Nurturing Relationships," 70 of the participants (51.09\%) selected that their current level of ability was excellent, $52(37.96 \%)$ reported their current level of 
ability as good, and $15(10.95 \%)$ rated their current level of ability as average (see Table $1)$.

The life skill of Sharing was defined - to have, use or do together with another or others (Hendricks, 1996). In regards to the current level of ability of "Sharing," 67 participants (48.91\%) rated their current level of ability as excellent, 61 (44.53\%) reported their current level of ability as good, and nine $(6.57 \%)$ reported their current level of ability as average (see Table 1).

The life skill of Empathy was defined - being sensitive to or identifying with another person's situation, feelings or motives (Hendricks, 1996). When asked about their current level of ability for "Empathy," 88 participants (64.23\%) reported their current level of ability as excellent, $36(26.28 \%)$ rated their current level of ability as good, 11 $(8.03 \%)$ reported their current level of ability as average, and two $(1.46 \%)$ selected that their current level of ability was poor (see Table 1).

Concern for Others was defined - finding and applying creative and nondestructive ways to resolve differences between two or more persons; getting along with others (Hendricks, 1996). In response to rating their current level of ability for "Concern for Others," 93 participants $(67.88 \%)$ perceived their current level of ability as excellent, $42(30.66 \%)$ reported their current level of ability as good, and two $(1.46 \%)$ rated their current level of ability as average (see Table 1).

Relating Skills. Accepting Differences was defined - to recognize and welcome factors that separate or distinguish one person from another (Hendricks, 1996). Under the life skill of "Accepting Differences," 92 participants (67.15\%) reported that their current 
level of ability was excellent, and $45(32.85 \%)$ stated that their current level of ability was good (see Table 1).

The life skill of Conflict Resolution was defined - finding and applying creative and non-destructive ways to resolve differences between two or more persons; getting along with others (Hendricks, 1996). Current levels of ability in "Conflict Resolution" were as follows: 59 participants (43.07\%) reported their current level of ability as excellent, $65(45.75 \%)$ stated that their current level of ability was good, and $13(9.49 \%)$ reported their current level of ability as average (see Table 1).

Social Skills was defined - skills people use when interacting with others and to behave in the accepted manner or customs of the society in which they live; adapting well to one's social environment (Hendricks, 1996). When asked to rate their current level of ability in "Social Skills," 73 participants (53.28\%) stated that their current level of ability was excellent, $49(35.77 \%)$ reported their current level of ability as good, $14(10.22 \%)$ perceived their current level of ability as average, and one $(0.73 \%)$ reported their current level of ability as poor (see Table 1).

The Cooperation life skill was defined - to work or act together for a common purpose or mutual benefit (Hendricks, 1996). When asked to rate their current level of ability in "Cooperation," 74 participants (54.01\%) reported their current level of ability as excellent, 57 (41.61\%) reported their current level of ability as good, and six (4.38\%) reported their current level of ability as average (see Table 1).

Communication was defined - exchange of thoughts, information or messages between individuals; sending and receiving information using speech, writing, gestures 
and artistic expression. Public Speaking is not a life skill in the Hendricks model. For those who want a definition Public Speaking — the ability to effectively communicate in front of a group of people (Hendricks, 1996). When rating their current level of ability for "Communication," 59 participants $(43.38 \%)$ perceived their current level of ability as excellent, 67 (49.26\%) reported their current level of ability as good, nine (6.62\%) indicated that their current level of ability was average, and one $(0.74 \%)$ reported their current level of ability as poor.

Hands. Life skills listed under "Hands" were divided into the two sub-categories of Giving and Working. Giving consisted of Community Service/Volunteering, Leadership, Responsible Citizenship, and Contributions to group efforts. The Working sub-category included Marketable Skills, Teamwork, and Self-motivation.

Giving Skills. Community Service/Volunteering was defined - to donate one's time and/or effort of one's own free will for the benefit of the group without guarantee (Hendricks, 1996). While 67 of the participants (45.89\%) reported their current level of ability in "Community Service/Volunteering" was excellent, 64 (43.84\%) reported their current level of ability as good, and $15(10.27 \%)$ stated that their current level of ability was average (see Table 1).

The life skill of Leadership was defined - to assist the group in meeting its goals by showing or directing along the way; using personal influence to guide the group in reaching its goals (Hendricks, 1996). When asked about their current level of ability in “Leadership," 81 participants (55.48\%) reported their current level of ability as excellent, 
58 participants (39.74\%) reported their current level of ability as good, and seven participants (4.79\%) reported their current level of ability as average (see Table 1 ).

Responsible Citizenship was defined - an individual demonstrating love and devotion in response to duties, rights, and privileges as a member of a community or country (Hendricks, 1996). When asked to rate their current level of ability for "Responsible Citizenship," 61 participants (41.78\%) reported their current level of ability as excellent, 76 participants (52.05\%) reported their current level of ability as good, and nine participants (6.16\%) reported their current level of ability as average (see Table 1).

The life skill of Contributions to group effort was defined - to give or supply along with others for a common purpose (Hendricks, 1996). Under "Contributions to group effort," 86 participants (58.90\%) stated that their current level of ability was excellent, 55 participants (37.67\%) reported their current level of ability as good, and five $(3.42 \%)$ indicated that their current level of ability was average (see Table 1).

Working Skills. Marketable Skills was defined - to have the abilities wanted by employers and needed to hold a job (Hendricks, 1996). In response to current levels of ability in "Marketable Skills," 70 participants (47.95\%) replied that their current level of ability was excellent, $62(42.47 \%)$ reported their current level of ability as good, and 14 (9.59\%) indicated their current level of ability was average (see Table 1).

Teamwork was defined - work done by two or more people, each doing parts of the whole task (Hendricks, 1996). In regards to their current level of ability in “Teamwork," 94 (65.28\%) reported their current level of ability as excellent, 47 (32.64\%) 
reported their current level of ability as good, and three (2.08\%) perceived their current level of ability as average (see Table 1).

The life skill of Self-motivation was defined - able to make the needed effort to carry out a task or a plan; personal will to take action (Hendricks, 1996). For "Selfmotivation," 48 of the participants (33.33\%) reported their current level of ability as excellent, 70 (48.61) reported their current level of ability as good, and 26 (18.06) reported their current level of ability as average (see Table 1).

Health. The life skills listed under "Health" were separated into two sections of Being and Living. Being consisted of Self-esteem, Self-responsibility, Character, Managing Feelings, and Self-discipline. The sub-category of Living included Healthy Lifestyle Choices, Stress Management, Disease Prevention, and Personal Safety.

Being Skills. The life skill of Self-esteem was defined - pride in oneself; proper regard for oneself as a human being; valuing oneself; a feeling of ability to cope; learning to accept and like oneself (Hendricks, 1996). In regards to their current level of ability in "Self-esteem," 42 participants (29.37\%) stated that their current level of ability was excellent, $70(48.95 \%)$ reported their current level of ability as good, $29(20.28 \%)$ perceived their current level of ability as average, and two $(1.40 \%)$ reported their current level of ability as poor (see Table 1).

Self-responsibility was defined - taking care of oneself; being accountable for one's behavior and obligations; choosing for oneself between right and wrong (Hendricks, 1996).When asked about their current level of ability in "Self-responsibility," 71 participants (49.31\%) reported their current level of ability as excellent, $65(45.14 \%)$ 
reported their current level of ability as good, and eight (5.56\%) reported their current level of ability as average.

The life skill Character was defined - a person's moral strength; integrity, fortitude, reputation; a person's usual qualities or traits; adherence to a code of values or ethical principles (Hendricks, 1996). When asked about their current level of ability in "Character," 80 participants (55.56\%) reported their current level of ability as excellent, $60(41.67 \%)$ selected that their current level of ability was good, and four $(2.78 \%)$ reported their current level of ability as average (see Table 1).

Managing Feelings was defined - expressing one's feelings appropriately and in proportion to circumstance (Hendricks, 1996). When rating their current level in "Managing Feelings," 29 participants (20.42\%) reported their current level of ability as excellent, $88(61.97 \%)$ reported their current level of ability as good, $23(16.20 \%)$ reported their current level of ability as average, and two (1.41\%) reported their current level of ability as poor (see Table 1).

Self-discipline was defined - control of self and one's conduct in line with moral character (what is right and wrong), personal values (what one considers important), and societal expectations; control before acting in a hurtful or harmful way (Hendricks, 1996). When asked about their current level of ability in "Self-discipline," 37 participants (26.06\%) reported their current level of ability as excellent, $73(51.41 \%)$ stated that their current level of ability was good, $29(20.42 \%)$ reported their current level of ability as average, and three (2.11\%) selected that their current level of ability was poor (see Table $1)$. 
Living Skills. The life skill of Healthy Lifestyle Choices was defined - increased knowledge, attitudes and behaviors that insure current good health, as well as those that assure future well-being such as: exercise, nutrition, disease prevention, personal safety and stress management (Hendricks, 1996). In regards to the current level of ability for "Healthy Lifestyle Choices," 18 (12.68\%) reported their current level of ability as excellent, 74 (52.11) reported their current level of ability as good, 46 (32.39\%) reported their current level of ability as average, and four $(2.82 \%)$ reported their current level of ability as poor (see Table 1).

Stress Management was defined - to direct or have control over physical or mental strain and pressure, or one's reaction to it; coping with change (Hendricks, 1996). When questioned about their current level of ability for "Stress Management," 22 participants $(15.49 \%)$ reported their current level of ability as excellent, $60(42.25 \%)$ rated their current level of ability as good, 53 (37.32\%) reported their current level of ability as average, six (4.23\%) perceived their current level of ability as poor, and one $(0.70 \%)$ reported their current level of ability as very poor (see Table 1$)$.

The life skill of Disease Prevention was defined - to anticipate and ward off conditions that keep the body from functioning normally, such as infection or stress that impairs normal physiological functioning (Hendricks, 1996). Under "Disease Prevention," 51 (35.92\%) of the participants reported their current level as excellent, 57 (40.14\%) rated their current level of ability as good, 32 (22.54\%) reported their current level of ability as average, and two (1.41\%) stated that their current level of ability was poor (see Table 1). 
Personal Safety was defined - taking care to avoid danger, risk, or harm; selfprotection; being cautious, careful; physically and emotionally safe (Hendricks, 1996). In regards to the current ability level in "Personal Safety," 66 (46.81\%) selected that their current level of ability was excellent, 67 (47.52\%) reported their current level of ability as good, and eight (5.67\%) rated their current level of ability as average (see Table 1).

\section{Influence of Being an Extension Camping Instructor on Development of Each Skill}

Head. The objective sought to determine how influential working as an Extension Camping Instructor was on the development of each life skill. Participants were asked to rate the influence of being an ECI had on skill development using a five-point scale. The rating scale was: 1 - Not At All Influential, 2 - Mildly Influential, 3 - Moderately Influential, 4 - Highly Influential, and 5 - Almost Essential.

Thinking Skills. In response to rating the impact of being an ECI on their life skill development in "Service Learning," 46 participants (32.86\%) stated that their role as an ECI was almost essential to their life skill development, 62 (44.29\%) reported that their role was highly influential to their life skill development, 29 (20.71\%) indicated that their role was moderately influential to their life skill development, and three (2.14) reported that their role was mildly influential to their life skill development of this skill (see Table 2). When asked to rate the influence of being an ECI on their life skill development in "Critical thinking," 34 participants (24.11\%) rated that their role was almost essential to their life skill development, $64(45.39 \%)$ reported that their role was highly influential to their life skill development, $30(21.28 \%)$ perceived that their role was moderately influential to their life skill development, 12 (8.51\%) reported that their 
role was mildly influential to their life skill development, and one $(0.71 \%)$ rated that their role was not at all influential on their life skill development of this skill (see Table 2).

When asked to rate the influence of their role as an ECI on their life skill development in "Problem Solving," 39 participants $(27.66 \%)$ replied that their role was almost essential to their life skill development, 74 (52.48\%) reported that their role was highly influential to their life skill development, $19(13.48 \%)$ indicated that their role was moderately influential to their life skill development, eight (5.67\%) reported that their role was mildly influential to their life skill development, and one $(0.71 \%)$ reported that their role was not at all influential to their life skill development of this skill (see Table 2). In response to rating the influence of their role as an ECI on their life skill development in "Decision Making," 38 participants (26.95\%) reported that their role was almost essential to their life skill development, 68 (48.23\%) stated that their role was highly influential to their life skill development, 27 (19.15\%) perceived that their role was moderately influential to their life skill development, six (4.26\%) reported that their role was mildly influential to their life skill development, and two (1.42\%) replied that their role was not at all influential to their life skill development of this skill (see Table 2). When questioned about the influence of their role as an ECI on their life skill development of "Learning to Learn", 24 participants (17.14\%) replied that their role was almost essential to their life skill development, 69 (49.29\%) reported that their role was highly influential to their life skill development, 34 (24.29\%) selected that their role was moderately influential to their life skill development, $11(7.86 \%)$ reported that their role was mildly influential to their life skill development, and two $(1.43 \%)$ stated that their role was not at all influential to their life skill development of this skill (see Table 2). 
Table 2

Influence of being an Extension Camping Instructor on ECI's Life Skills Development

\begin{tabular}{|c|c|c|c|c|c|c|c|c|c|c|}
\hline & \multicolumn{2}{|c|}{$\begin{array}{l}\text { Not at all } \\
\text { Influential }\end{array}$} & \multicolumn{2}{|c|}{ Mildly Influential } & \multicolumn{2}{|c|}{$\begin{array}{l}\text { Moderately } \\
\text { Influential }\end{array}$} & \multicolumn{2}{|c|}{ Highly Influential } & \multicolumn{2}{|c|}{ Almost Essential } \\
\hline & $\mathrm{f}$ & $\%$ & $\mathrm{f}$ & $\%$ & $\mathrm{f}$ & $\%$ & $\mathrm{f}$ & $\%$ & $\mathrm{f}$ & $\%$ \\
\hline \multicolumn{11}{|l|}{ Giving } \\
\hline Community Service/Volunteering & 0 & 0.00 & 11 & 7.59 & 25 & 17.24 & 82 & 56.55 & 27 & 18.62 \\
\hline Leadership & 0 & 0.00 & 0 & 0.00 & 8 & 5.52 & 65 & 44.83 & 72 & 49.66 \\
\hline Responsible Citizenship & 0 & 0.00 & 5 & 3.45 & 44 & 30.34 & 71 & 48.97 & 25 & 17.24 \\
\hline Contributions to Group Effort & 0 & 0.00 & 3 & 2.07 & 20 & 13.79 & 71 & 48.97 & 51 & 35.17 \\
\hline \multicolumn{11}{|l|}{ Working } \\
\hline Marketable Skills & 0 & 0.00 & 7 & 4.83 & 29 & 20.00 & 65 & 44.83 & 44 & 30.34 \\
\hline Teamwork & 0 & 0.00 & 2 & 1.39 & 13 & 9.03 & 77 & 53.47 & 52 & 36.11 \\
\hline Self-Motivation & 1 & 0.69 & 11 & 7.64 & 31 & 21.53 & 70 & 48.61 & 31 & 21.53 \\
\hline
\end{tabular}


Table 2 (continued)

Influence of being an Extension Camping Instructor on ECI's Life Skills Development

\begin{tabular}{|c|c|c|c|c|c|c|c|c|c|c|}
\hline & \multicolumn{2}{|c|}{$\begin{array}{l}\text { Not at all } \\
\text { Influential }\end{array}$} & \multicolumn{2}{|c|}{ Mildly Influential } & \multicolumn{2}{|c|}{$\begin{array}{c}\text { Moderately } \\
\text { Influential }\end{array}$} & \multicolumn{2}{|c|}{ Highly Influential } & \multicolumn{2}{|c|}{ Almost Essential } \\
\hline & $\mathrm{f}$ & $\%$ & $\mathrm{f}$ & $\%$ & $\mathrm{f}$ & $\%$ & $\mathrm{f}$ & $\%$ & $\mathrm{f}$ & $\%$ \\
\hline \multicolumn{11}{|l|}{ Being } \\
\hline Self Esteem & 2 & 1.40 & 5 & 3.50 & 25 & 17.48 & 64 & 44.76 & 47 & 32.87 \\
\hline Self Responsibility & 0 & 0.00 & 6 & 4.17 & 19 & 13.19 & 75 & 52.08 & 44 & 30.56 \\
\hline Character & 0 & 0.00 & 5 & 3.47 & 16 & 11.11 & 67 & 46.53 & 56 & 38.89 \\
\hline Managing Feelings & 2 & 1.41 & 21 & 14.79 & 39 & 27.46 & 54 & 38.03 & 26 & 18.31 \\
\hline Self Discipline & 2 & 1.42 & 11 & 7.80 & 35 & 24.82 & 62 & 43.97 & 31 & 21.99 \\
\hline \multicolumn{11}{|l|}{ Living } \\
\hline Healthy Lifestyle Choices & 5 & 3.52 & 22 & 15.49 & 49 & 34.51 & 47 & 33.10 & 19 & 13.38 \\
\hline Stress Management & 5 & 3.55 & 21 & 14.89 & 43 & 30.50 & 51 & 36.17 & 21 & 14.89 \\
\hline Disease Prevention & 22 & 15.60 & 28 & 19.86 & 40 & 28.37 & 34 & 24.11 & 17 & 12.06 \\
\hline Personal Safety & 3 & 2.13 & 12 & 8.51 & 47 & 33.33 & 56 & 39.72 & 23 & 16.31 \\
\hline
\end{tabular}


Table 2 (continued)

Influence of being an Extension Camping Instructor on ECI's Life Skills Development

\begin{tabular}{|c|c|c|c|c|c|c|c|c|c|c|}
\hline & \multicolumn{2}{|c|}{$\begin{array}{l}\text { Not at all } \\
\text { Influential }\end{array}$} & \multicolumn{2}{|c|}{ Mildly Influential } & \multicolumn{2}{|c|}{$\begin{array}{c}\text { Moderately } \\
\text { Influential }\end{array}$} & \multicolumn{2}{|c|}{ Highly Influential } & \multicolumn{2}{|c|}{ Almost Essential } \\
\hline & $\mathrm{f}$ & $\%$ & $\mathrm{f}$ & $\%$ & $\mathrm{f}$ & $\%$ & $\mathrm{f}$ & $\%$ & $f$ & $\%$ \\
\hline \multicolumn{11}{|l|}{ Thinking } \\
\hline Learning to Learn & 2 & 1.43 & 11 & 7.86 & 34 & 24.29 & 69 & 49.29 & 24 & 17.14 \\
\hline Decision Making & 2 & 1.42 & 6 & 4.26 & 27 & 19.15 & 68 & 48.23 & 38 & 26.95 \\
\hline Problem Solving & 1 & 0.71 & 8 & 5.67 & 19 & 13.48 & 74 & 52.48 & 39 & 27.66 \\
\hline Critical Thinking & 1 & 0.71 & 12 & 8.51 & 30 & 21.28 & 64 & 45.39 & 34 & 24.11 \\
\hline Service Learning & 0 & 0.00 & 3 & 2.14 & 29 & 20.71 & 62 & 44.29 & 46 & 32.86 \\
\hline \multicolumn{11}{|l|}{ Managing } \\
\hline Goal Setting & 2 & 1.44 & 8 & 5.76 & 43 & 30.94 & 56 & 40.29 & 30 & 21.58 \\
\hline Planning/Organizing & 0 & 0.00 & 4 & 2.90 & 30 & 21.74 & 55 & 39.86 & 49 & 35.51 \\
\hline Wise use of Resources & 3 & 2.14 & 8 & 5.71 & 36 & 25.71 & 49 & 35.00 & 44 & 31.43 \\
\hline Keeping Records & 9 & 6.47 & 21 & 15.11 & 45 & 32.37 & 37 & 26.62 & 27 & 19.42 \\
\hline Resiliency & 2 & 1.47 & 3 & 2.21 & 28 & 20.59 & 63 & 46.32 & 40 & 29.41 \\
\hline
\end{tabular}


Table 2 (continued)

Influence of being an Extension Camping Instructor on ECI's Life Skills Development

\begin{tabular}{|c|c|c|c|c|c|c|c|c|c|c|}
\hline & \multicolumn{2}{|c|}{$\begin{array}{l}\text { Not at all } \\
\text { Influential }\end{array}$} & \multicolumn{2}{|c|}{ Mildly Influential } & \multicolumn{2}{|c|}{$\begin{array}{l}\text { Moderately } \\
\text { Influential }\end{array}$} & \multicolumn{2}{|c|}{ Highly Influential } & \multicolumn{2}{|c|}{ Almost Essential } \\
\hline & $\mathrm{f}$ & $\%$ & $\mathrm{f}$ & $\%$ & $\mathrm{f}$ & $\%$ & $\mathrm{f}$ & $\%$ & $\mathrm{f}$ & $\%$ \\
\hline \multicolumn{11}{|l|}{ Relating } \\
\hline Communication & 0 & 0.00 & 3 & 2.19 & 6 & 4.38 & 72 & 52.55 & 56 & 40.88 \\
\hline Cooperation & 1 & 0.73 & 2 & 1.46 & 14 & 10.22 & 69 & 50.36 & 51 & 37.23 \\
\hline Social Skills & 0 & 0.00 & 6 & 4.38 & 16 & 11.68 & 60 & 43.80 & 55 & 40.15 \\
\hline Conflict Resolution & 0 & 0.00 & 6 & 4.38 & 15 & 10.95 & 57 & 41.61 & 59 & 43.07 \\
\hline Accepting Differences & 2 & 1.47 & 6 & 4.41 & 14 & 10.29 & 58 & 42.65 & 56 & 41.18 \\
\hline \multicolumn{11}{|l|}{ Caring } \\
\hline Concern for Others & 1 & 0.74 & 7 & 5.15 & 25 & 18.38 & 53 & 38.97 & 50 & 36.76 \\
\hline Empathy & 0 & 0.00 & 10 & 7.30 & 28 & 20.44 & 62 & 45.26 & 37 & 27.01 \\
\hline Sharing & 3 & 2.22 & 12 & 8.89 & 31 & 22.96 & 54 & 40.00 & 35 & 25.93 \\
\hline Nurturing Relationships & 2 & 1.46 & 12 & 8.76 & 25 & 18.25 & 55 & 40.15 & 43 & 31.39 \\
\hline
\end{tabular}


Managing Skills. In regards to the influence of their role as an ECI on their life skill development in "Resiliency," 40 participants $(29.41 \%)$ rated that their role was almost essential to their life skill development, $63(46.32 \%)$ stated that their role was highly influential to their life skill development, $28(20.59 \%)$ reported that their role was moderately influential to their life skill development, three (2.21\%) selected that their role was mildly influential to their life skill development, and two $(1.47 \%)$ reported that their role was not at all influential to their life skill development of this skill (see Table 2). When asked to rate the influence of their role as an ECI on their life skill development of "Keeping Records," 27 participants (19.42\%) perceived that their role was almost essential to their life skill development, $37(26.62 \%)$ rated that their role was highly influential to their life skill development, $45(32.37 \%)$ reported that their role was moderately influential to their life skill development, $21(15.11 \%)$ stated that their role was mildly influential to their life skill development, and nine $(6.47 \%)$ indicated that their role as not at all influential to their life skill development of this skill (see Table 2).

When questioned about the influence of their role of being an ECI on the life skill development of "Wise Use of Resources," 44 participants (31.43) replied that their role was almost essential to their life skill development, 49 (35.00\%) reported that their role was highly influential to their life skill development, $36(25.71 \%)$ stated that their role was moderately influential to their life skill development, eight $(5.71 \%)$ reported that their role was mildly influential to their life skill development, and three $(2.14 \%)$ perceived that their role was not at all influential to their life skill development of this skill (see Table 2). In regards to rating the influence of being an ECI on their life skill development in "Planning/Organizing," 49 participants $(35.51 \%)$ stated that their role 
was almost essential to their life skill development, 55 (39.86\%) reported that their role was highly influential to their life skill development, $30(21.74 \%)$ selected that their role was moderately influential to their life skill development, and four $(2.90 \%)$ reported that their role was mildly influential to their life skill development (see Table 2). When rating the influence of being an ECI on their life skill development in "Goal Setting", 30 participants $(21.58 \%)$ perceived that their role was almost essential to their life skill development, $56(40.29 \%)$ reported that their role was highly influential to their life skill development, 43 (30.94) indicated that their role was moderately influential to their life skill development, eight (5.76\%) reported that their role was mildly influential to their life skill development, and two (1.44\%) selected that their role was not at all influential to the life skill development of this skill (see Table 2).

\section{Heart.}

Caring Skills. In response to rating the influence of being an ECI on their life skill development in "Nurturing Relationships," 43 of the participants (31.39\%) replied that their role was almost essential to their life skill development, 55 (40.15\%) reported that their role was highly influential to their life skill development, 25 (18.25\%) stated that their role was moderately influential to their life skill development, $12(8.76 \%)$ perceived that their role was mildly influential to their life skill development, and two $(1.46 \%)$ reported that their role was not at all influential to their life skill development of this skill (see Table 2). When questioned about the influence of being an ECI on their life skill development of "Sharing," 35 of the participants (25.93\%) reported that their role was almost essential to their life skill development, 54 (40.00\%) stated that their role was highly influential to their life skill development, $31(22.96 \%)$ reported that their role 
was moderately influential to their life skill development, $12(8.89 \%)$ selected that their role was mildly influential to their life skill development, and three $(2.22 \%)$ replied that their role was not at all influential to the life skill development of this skill (see Table 2).

When asked to rate the influence of being an ECI on their life skill development of "Empathy," 37 of the participants (27.01\%) perceived that their role was almost essential to their life skill development, two (45.26\%) reported that their role was highly influential to their life skill development, 28 (20.44\%) stated that their role was moderately influential to their life skill development, and $10(7.30 \%)$ reported that their role was mildly influential to the life skill development of this skill (see Table 2). When regard to the influence of being an ECI on their life skill development in "Concern for Others," 50 of the participants $(36.76 \%)$ replied that their role was almost essential to their life skill development, 53 (38.97\%) indicated that their role was highly influential to their life skill development, 25 (18.38\%) reported that their role was moderately influential to their life skill development, seven (5.15\%) selected that their role was mildly influential to their life skill development, and one (.074\%) reported that their role was not at all influential to their life skill development of this skill (see Table 2).

Relating Skills. When questioned about the influence of being an ECI on their life skill development in "Accepting Differences," 56 of the participants (41.18\%) stated that their role was almost essential to their life skill development, 58 (42.65\%) reported that their role was highly influential to their life skill development, 14 (10.29\%) perceived that their role was moderately influential to their life skill development, six $(4.41 \%)$ rated that their role was mildly influential to their life skill development, and two $(1.47 \%)$ reported that their role was not at all influential to their life skill development of 
this skill (see Table 2). Fifty-nine of the participants (43.07\%) reported that their role was almost essential to their life skill development in "Conflict Resolution." while 57 $(41.61 \%)$ reported that their role was highly influential to their life skill development, 15 $(10.95 \%)$ rated that their role was moderately influential to their life skill development, and six (4.38\%) selected that their role was mildly influential to their life skill development of this skill (see Table 2).

When asked to rate the influence of their role of being an ECI on their life skill development in "Social Skills," 55 of the participants $(40.15 \%)$ indicated that their role was almost essential to their life skill development, $60(43.80 \%)$ perceived that their role was highly influential to their life skill development, $16(11.68 \%)$ reported that their role was moderately influential to their life skill development, and six $(4.38 \%)$ replied that their role was mildly influential to their life skill development of this skill (see Table 2). When considering the influence of being an ECI on their life skill development in "Cooperation," 51 of the participants (37.23\%) stated that their role was almost essential to their life skill development, $69(50.36 \%)$ reported that their role was highly influential to their life skill development, $14(10.22 \%)$ rated that their role was moderately influential to their life skill development, two (1.46\%) selected that their role was mildly influential to their life skill development, and one $(0.73 \%)$ reported that their role was not at all influential to their life skill development of this skill (see Table 2). In regards to rating the influence of being an ECI on their life skill development in "Communication," 56 of the participants $(40.88 \%)$ perceived that their role was almost essential to their life skill development, $72(52.55 \%)$ reported that their role was highly influential to their life skill development, six (4.38\%) rated that their role was moderately influential to their life 
skill development, and three (2.19\%) indicated that their role was mildly influential to their life skill development of this skill (see Table 2).

\section{Hands.}

Giving Skills. When questioned about the influence of being an ECI on their life skill development in “Community Service/Volunteering," 27 participants (18.62\%) replied that their role was almost essential to their life skill development, 82 (56.55\%) stated that their role was highly influential on their life skill development, 25 (17.24\%) selected that their role was moderately influential on their life skill development, and 11 (7.59\%) reported that their role was mildly influential on their life skill development of this skill (see Table 2). When asked to rate the influence of being an ECI on their life skill development of "Leadership," 72 participants (49.66\%) stated that their role was almost essential to their life skill development, $65(44.83 \%)$ rated their role as highly influential to their life skill development, and eight (5.52\%) reported that their role was moderately influential to their life skill development of this skill (see Table 2).

In regards to the influence of being an ECI on their life skill development in "Responsible Citizenship," 25 participants (17.24\%) rated their role as almost essential to their life skill development, $71(48.97 \%)$ perceived that their role was highly influential to their life skill development, 44 (30.34\%) reported that their role was moderately influential to their life skill development, and five (3.45\%) selected that their role was mildly influential to their life skill development of this skill (see Table 2). When questioned about the influence of being an ECI on their life skill development in "Contributions to group effort," 51 participants (35.17\%) responded that their role was almost essential to their life skill development, $71(48.97 \%)$ reported that their role was 
highly influential to their life skill development, $20(13.79 \%)$ replied that their role was moderately influential to their life skill development, and three (2.07\%) stated that their role was mildly influential to their life skill development of this skill (see Table 2).

Working Skills. When asked to rate the influence of being an ECI on their life skill development of "Marketable Skills," 44 participants (30.34\%) reported that their role was almost essential to their life skill development, 65 (44.83\%) rated that their role was highly influential to their life skill development, 29 (20.00) reported that their role was moderately influential to their life skill development, and seven $(4.83 \%)$ selected that their role was mildly influential to their life skill development of this skill (see Table 2). In regards to rating the influence of being an ECI on their life skill development of "Teamwork," 52 participants $(36.11 \%)$ replied that their role was almost essential to their life skill development, 77 (53.47\%) reported that their role was highly influential to their life skill development, $13(9.03 \%)$ rated that their role was moderately influential to their life skill development, and two (1.39\%) selected that their role was mildly influential to their life skill development of this skill (see Table 2). When indicating the influence of being an ECI on their life skill development in "Self-motivation," 31 participants $(21.53 \%)$ responded that their role was almost essential to their life skill development, 70 (48.61\%) reported that their role was highly influential to their life skill development, 31 (21.53\%) perceived that their role was moderately influential to their life skill development, $11(7.64 \%)$ rated that their role was mildly influential to their life skill development, and one $(0.69 \%)$ reported that their role was not at all influential to their life skill development of this skill (see Table 2). 


\section{Health}

Being Skills. When asked to rate the influence of being an ECI on their life skill development in "Self-esteem," 47 (32.87\%) reported that their role was almost essential to their life skill development, $64(44.76 \%)$ stated that their role was highly influential to their life skill development, 25 (17.48\%) reported that their role was moderately influential to their life skill development, five $(3.50 \%)$ indicated that their role was mildly influential to their life skill development, and two (1.40\%) reported that their role was not at all influential to their life skill development of this skill (see Table 2). In regards to rating the influence of being an ECI on their life skill development of "Selfresponsibility," 44 participants $(30.56 \%)$ replied that their role was almost essential to their life skill development, 75 (52.08\%) reported that their role was highly influential to their life skill development, 19 (13.19\%) responded that their role was moderately influential to their life skill development, and six (4.17\%) stated that their role was mildly influential to their life skill development of this skill (see Table 2).

When questioned about the influence of being an ECI on their life skill development in "Character," 56 participants (38.89\%) perceived that their role was almost essential to their life skill development, 67 (46.53\%) reported that their role was highly influential to their life skill development, $16(11.11 \%)$ stated that their role was moderately influential to their life skill development, and five (3.47\%) reported that their role was mildly influential to their life skill development of this skill (see Table 2). When rating the influence of being an ECI on their life skill development of "Managing Feelings," 26 participants (18.31\%) selected that their role was almost essential to their life skill development, $54(38.03 \%)$ reported that their role was highly influential to their 
life skill development, $39(27.46 \%)$ stated that their role was moderately influential to their life skill development, $21(14.79 \%)$ perceived that their role was mildly influential to their life skill development, and two (1.41\%) reported that their role was not at all influential to their life skill development of this skill (see Table 2). When asked to rate the influence of being an ECI on their life skill development of "Self-discipline," 31 participants (21.99\%) replied that their role was almost essential to their life skill development, 62 (43.97\%) indicated that their role was highly influential to their life skill development, 35 (24.82\%) reported that their role was moderately influential to their life skill development, $11(7.80 \%)$ stated that their role was mildly influential to their life skill development, and two (1.42\%) selected that their role was not at all influential to their life skill development of this skill (see Table 2).

Living Skills. In response to being questioned about the influence of being an ECI on their life skill development of "Healthy Lifestyle Choices," 19 participants (13.38\%) stated that their role was almost essential to their life skill development, 47 (33.10\%) reported that their role was highly influential to their life skill development, 49 (34.51\%) replied that their role was moderately influential to their life skill development, $22(15.49 \%)$ selected that their role was mildly influential to their life skill development, and five $(3.52 \%)$ rated that their role was not at all influential to their life skill development of this skill (see Table 2). In regards to the influence of being an ECI on their life skill development in "Stress Management," 21 participants (14.89\%) stated that their role was almost essential to their life skill development, $51(36.17 \%)$ reported that their role was highly influential to their life skill development, 43 (30.50\%) reported that their role was moderately influential to their life skill development, $21(14.89 \%)$ selected 
that their role was mildly influential to their life skill development, and five (3.55\%) perceived that their role was not at all influential to their life skill development of this skill (see Table 2).

Rating the influence of being an ECI on their life skill development of "Disease Prevention" had the following responses: While 17 participants (12.06\%) stated that their role was almost essential to their life skill development, 34 (24.11\%) reported that their role was highly influential to their life skill development, 40 (28.37\%) selected that their role was moderately influential to their life skill development, 28 (19.86\%) reported that their role was mildly influential to their life skill development, and $22(15.60 \%)$ indicated that their role was not at all influential to their life skill development of this skill (see Table 2). When questioned about the influence of being an ECI on their life skill development of "Personal Safety," 23 participants (16.31\%) rated that their role was almost essential to their life skill development, $56(39.72 \%)$ reported that their role was highly influential to their life skill development, $47(33.33 \%)$ replied that their role was moderately influential to their life skill development, $12(8.51 \%)$ reported that their role was mildly influential to their life skill development, and three (2.13\%) perceived that their role was not at all influential to their life skill development of this skill (see Table 2).

\section{Perceived Influences on Development of Youth's Life Skills}

Objective three sought to examine how the Extension Camping Instructors perceived that their role as an ECI had influenced 4-H campers' life skill development in each area. The participants were asked to rate what they perceived to be their level of influence on a youth's development of each skill on a five point scale. The rating scale 
was: 1 - Not At All Influential, 2 - Mildly Influential, 3 - Moderately Influential, 4 Highly Influential, and 5 - Almost Essential.

\section{Head.}

Thinking Skills. Participants were asked to rate their perceived level of influence on a youth's life skill development in "Service Learning." While 35 of the participants $(25.00 \%)$ reported their influence as almost essential, $63(45.00 \%)$ stated that their influence was highly influential, 33 (23.57\%) selected that their influence was moderately influential, and $9(6.43 \%)$ reported their influence as mildly influential (see Table 3). When asking the participants to rate their perceived level of influence on a youth's life skill development in "Critical Thinking," 30 of the participants $(21.43 \%)$ rated their influence as almost essential, 63 (45.00\%) reported their influence as highly influential, $35(25.00 \%)$ perceived their influence was moderately influential, 10 (7.14\%) reported their influence as mildly influential, and two (1.43\%) indicated that their influence was not at all influential (see Table 3).

When questioned about their perceived level of influence on a youth's life skill development of "Problem Solving," 33 of the participants $(23.40 \%)$ replied that their influence was almost essential, 66 (46.81\%) stated that their influence was highly influential, 32 (22.70) reported their influence as moderately influential, nine $(6.38 \%)$ selected that their influence was mildly influential, and $1(0.71 \%)$ reported their influence as not at all influential (see Table 3). Asking the participants to rate their perceived level of influence on a youth's life skill development in "Decision Making" resulted in the following: 25 of the participants (17.73\%) reported their influence as almost essential, $72(51.06 \%)$ stated that their influence was highly influential, $35(24.82 \%)$ perceived that 
their influence was moderately influential, eight (5.67\%) reported their influence as mildly influential, and one $(0.71 \%)$ rated their influence as not at all influential (see Table 3). In response to rating their perceived level of influence on a youth's life skill development in "Learning to Learn," 26 of the participants (18.57\%) rated their influence as almost essential, 69 (49.29\%) reported their influence as highly influential, 33 $(23.57 \%)$ stated that their influence was moderately influential, and $12(8.57 \%)$ indicated that their influence was mildly influential (see Table 3).

Managing Skills. When asked to rate their perceived level of influence on a youth's life skill development in "Resiliency," 27 of the participants (19.71\%) rated their influence as almost essential, 64 (46.72\%) reported their influence as highly influential, 38 (27.74\%) perceived that their influence was moderately influential, and eight (5.84\%) reported their influence as mildly influential (see Table 3). In regards to rating their perceived level of influence on a youth's life skill development in "Keeping Records," 14 of the participants (10.00\%) rated their influence as almost essential, $42(30.00 \%)$ perceived that their influence was highly influential, 41 (29.29\%) selected that their influence was moderately influential, 29 (20.71\%) reported their influence as mildly influential, and $14(10.00 \%)$ stated that their influence was not at all influential (see Table $3)$. 
Table 3

Extension Camping Instructors’ Perceived Influences on Youth's Development of Life Skills

\begin{tabular}{|c|c|c|c|c|c|c|c|c|c|c|}
\hline & \multicolumn{2}{|c|}{$\begin{array}{l}\text { Not at all } \\
\text { Influential }\end{array}$} & \multicolumn{2}{|c|}{ Mildly Influential } & \multicolumn{2}{|c|}{$\begin{array}{l}\text { Moderately } \\
\text { Influential }\end{array}$} & \multicolumn{2}{|c|}{ Highly Influential } & \multicolumn{2}{|c|}{ Almost Essential } \\
\hline & $\mathrm{f}$ & $\%$ & $\mathrm{f}$ & $\%$ & $\mathrm{f}$ & $\%$ & $\mathrm{f}$ & $\%$ & $f$ & $\%$ \\
\hline \multicolumn{11}{|l|}{ Giving } \\
\hline \multicolumn{11}{|l|}{ Community } \\
\hline Service/Volunteering & 0 & 0.00 & 9 & 6.21 & 29 & 20.00 & 77 & 53.10 & 30 & 20.69 \\
\hline Leadership & 0 & 0.00 & 0 & 0.00 & 9 & 6.16 & 92 & 63.01 & 45 & 30.82 \\
\hline Responsible Citizenship & 0 & 0.00 & 8 & 5.48 & 34 & 23.29 & 73 & 50.00 & 31 & 21.23 \\
\hline Contributions to Group Effort & 0 & 0.00 & 1 & 0.68 & 22 & 15.07 & 71 & 48.63 & 52 & 35.62 \\
\hline \multicolumn{11}{|l|}{ Working } \\
\hline Marketable Skills & 2 & 1.37 & 12 & 8.22 & 48 & 32.88 & 62 & 42.47 & 22 & 15.07 \\
\hline Teamwork & 0 & 0.00 & 1 & 0.69 & 18 & 12.50 & 84 & 58.33 & 41 & 28.47 \\
\hline Self-Motivation & 1 & 0.69 & 8 & 5.56 & 33 & 22.92 & 72 & 50.00 & 30 & 20.83 \\
\hline
\end{tabular}


Table 3 (continued)

Extension Camping Instructors’ Perceived Influences on Youth's Development of Life Skills

\begin{tabular}{|c|c|c|c|c|c|c|c|c|c|c|}
\hline & \multicolumn{2}{|c|}{$\begin{array}{l}\text { Not at all } \\
\text { Influential }\end{array}$} & \multicolumn{2}{|c|}{ Mildly Influential } & \multicolumn{2}{|c|}{$\begin{array}{c}\text { Moderately } \\
\text { Influential }\end{array}$} & \multicolumn{2}{|c|}{ Highly Influential } & \multicolumn{2}{|c|}{ Almost Essential } \\
\hline & $\mathrm{f}$ & $\%$ & $\mathrm{f}$ & $\%$ & $\mathrm{f}$ & $\%$ & $\mathrm{f}$ & $\%$ & $\mathrm{f}$ & $\%$ \\
\hline \multicolumn{11}{|l|}{ Being } \\
\hline Self Esteem & 0 & 0.00 & 3 & 2.08 & 16 & 11.11 & 82 & 56.94 & 43 & 29.86 \\
\hline Self Responsibility & 0 & 0.00 & 2 & 1.39 & 28 & 19.44 & 71 & 49.31 & 43 & 29.86 \\
\hline Character & 0 & 0.00 & 3 & 2.10 & 22 & 15.38 & 70 & 48.95 & 48 & 33.57 \\
\hline Managing Feelings & 0 & 0.00 & 8 & 5.63 & 45 & 31.69 & 63 & 44.37 & 26 & 18.31 \\
\hline Self Discipline & 2 & 1.41 & 14 & 9.86 & 43 & 30.28 & 53 & 37.32 & 30 & 21.13 \\
\hline \multicolumn{11}{|l|}{ Living } \\
\hline Healthy Lifestyle Choices & 1 & 0.70 & 16 & 11.27 & 37 & 26.06 & 65 & 45.77 & 23 & 16.20 \\
\hline Stress Management & 4 & 2.82 & 22 & 15.49 & 39 & 27.46 & 53 & 37.32 & 24 & 16.90 \\
\hline Disease Prevention & 12 & 8.45 & 26 & 18.31 & 44 & 30.99 & 40 & 28.17 & 20 & 14.08 \\
\hline Personal Safety & 3 & 2.13 & 17 & 12.06 & 38 & 26.95 & 60 & 42.55 & 23 & 16.31 \\
\hline
\end{tabular}


Table 3 (continued)

Extension Camping Instructors’ Perceived Influences on Youth's Development of Life Skills

\begin{tabular}{|c|c|c|c|c|c|c|c|c|c|c|}
\hline & \multicolumn{2}{|c|}{$\begin{array}{l}\text { Not at all } \\
\text { Influential }\end{array}$} & \multicolumn{2}{|c|}{ Mildly Influential } & \multicolumn{2}{|c|}{$\begin{array}{l}\text { Moderately } \\
\text { Influential }\end{array}$} & \multicolumn{2}{|c|}{ Highly Influential } & \multicolumn{2}{|c|}{ Almost Essential } \\
\hline & $\mathrm{f}$ & $\%$ & $\mathrm{f}$ & $\%$ & $\mathrm{f}$ & $\%$ & $\mathrm{f}$ & $\%$ & $\mathrm{f}$ & $\%$ \\
\hline \multicolumn{11}{|l|}{ Thinking } \\
\hline Learning to Learn & 0 & 0.00 & 12 & 8.57 & 33 & 23.57 & 69 & 49.29 & 26 & 18.57 \\
\hline Decision Making & 1 & 0.71 & 8 & 5.67 & 35 & 24.82 & 72 & 51.06 & 25 & 17.73 \\
\hline Problem Solving & 1 & 0.71 & 9 & 6.38 & 32 & 22.70 & 66 & 46.81 & 33 & 23.40 \\
\hline Critical Thinking & 2 & 1.43 & 10 & 7.14 & 35 & 25.00 & 63 & 45.00 & 30 & 21.43 \\
\hline Service Learning & 0 & 0.00 & 9 & 6.43 & 33 & 23.57 & 63 & 45.00 & 35 & 25.00 \\
\hline \multicolumn{11}{|l|}{ Managing } \\
\hline Goal Setting & 2 & 1.43 & 9 & 6.43 & 42 & 30.00 & 65 & 46.43 & 22 & 15.71 \\
\hline Planning/Organizing & 4 & 2.86 & 15 & 10.71 & 36 & 25.71 & 64 & 45.71 & 21 & 15.00 \\
\hline Wise use of Resources & 6 & 4.29 & 14 & 10.00 & 43 & 30.71 & 53 & 37.86 & 24 & 17.14 \\
\hline Keeping Records & 14 & 10.00 & 29 & 20.71 & 41 & 29.29 & 42 & 30.00 & 14 & 10.00 \\
\hline Resiliency & 0 & 0.00 & 8 & 5.84 & 38 & 27.74 & 64 & 46.72 & 27 & 19.71 \\
\hline
\end{tabular}


Table 3 (continued)

Extension Camping Instructors’ Perceived Influences on Youth's Development of Life Skills

\begin{tabular}{|c|c|c|c|c|c|c|c|c|c|c|}
\hline & \multicolumn{2}{|c|}{$\begin{array}{l}\text { Not at all } \\
\text { Influential }\end{array}$} & \multicolumn{2}{|c|}{ Mildly Influential } & \multicolumn{2}{|c|}{$\begin{array}{l}\text { Moderately } \\
\text { Influential }\end{array}$} & \multicolumn{2}{|c|}{ Highly Influential } & \multicolumn{2}{|c|}{ Almost Essential } \\
\hline & $\mathrm{f}$ & $\%$ & $\mathrm{f}$ & $\%$ & $\mathrm{f}$ & $\%$ & $\mathrm{f}$ & $\%$ & $\mathrm{f}$ & $\%$ \\
\hline \multicolumn{11}{|l|}{ Relating } \\
\hline Communication & 0 & 0.00 & 4 & 2.92 & 19 & 13.87 & 69 & 50.36 & 45 & 32.85 \\
\hline Cooperation & 0 & 0.00 & 6 & 4.38 & 12 & 8.76 & 71 & 51.82 & 48 & 35.04 \\
\hline Social Skills & 0 & 0.00 & 4 & 2.92 & 14 & 10.22 & 71 & 51.82 & 48 & 35.04 \\
\hline Conflict Resolution & 0 & 0.00 & 5 & 3.68 & 23 & 16.91 & 67 & 49.26 & 41 & 30.15 \\
\hline \multicolumn{11}{|l|}{ Caring } \\
\hline Accepting Differences & 0 & 0.00 & 0 & .00 & 18 & 13.14 & 68 & 49.64 & 51 & 37.23 \\
\hline Concern for Others & 0 & 0.00 & 3 & 2.19 & 25 & 18.25 & 68 & 49.64 & 41 & 29.93 \\
\hline Empathy & 0 & 0.00 & 6 & 4.38 & 31 & 22.63 & 62 & 45.26 & 38 & 27.74 \\
\hline Sharing & 1 & 0.73 & 7 & 5.11 & 21 & 15.33 & 64 & 46.72 & 44 & 32.12 \\
\hline Nurturing Relationships & 1 & 0.73 & 5 & 3.65 & 28 & 20.44 & 56 & 40.88 & 47 & 34.31 \\
\hline
\end{tabular}


When responding to their perceived level of influence on a youth's life skill development in "Wise Use of Resources," 24 of the participants (17.14\%) stated that their influence was almost essential, 53 (37.86\%) reported their influence as highly influential, 43 (30.71\%) rated their influence as moderately influential, $14(10.00 \%)$ perceived that their influence was mildly influential, and six (4.29\%) reported their influence as not at all influential (see Table 3). When asked to rate their perceived level of influence on a youth's life skill development in "Planning/Organizing," 21 of the participants (15.00\%) indicated that their influence was almost essential, 64 (45.71\%) reported their influence as highly influential, 36 (25.71\%) reported their influence as moderately influential, 15 (10171\%) rated their influence as mildly influential, and four (2.86\%) selected that their influence was not at all influential (see Table 3). When asked to rate their perceived level of influence on a youth's life skill development in "Goal Setting," 22 of the participants (15.71\%) stated that their influence was almost essential, $65(46.43 \%)$ reported their influence as highly influential, $42(30.0 \%)$ selected that their influence was moderately influential, nine (6.43\%) reported their influence as mildly influential, and two (1.43\%) perceived that their influence was not at all influential (see Table 3).

\section{Heart.}

Caring Skills. When questioned about their perceived level of influence on a youth's life skill development in "Nurturing Relationships," 47 of the participants (34.31\%) responded that their influence was almost essential, $56(40.88 \%)$ reported their influence as highly influential, 28 (20.44\%) reported their influence as moderately influential, five (3.65\%) replied that their influence was mildly influential, and one 
$(0.73 \%)$ perceived their influence as not at all influential (see Table 3 ). In regards to rating their perceived level of influence on a youth's life skill development in "Sharing," 44 of the participants (32.12\%) selected that their influence was almost essential, 64 $(46.72 \%)$ rated their influence as highly influential, $21(15.33 \%)$ reported their influence as moderately influential, seven (5.11\%) indicated that their influence was mildly influential, and one $(0.73 \%)$ selected that their influence was not at all influential (see Table 3).

Rating their perceived level of influence on a youth's life skill development in "Empathy" had the following responses: While 38 of the participants (27.74\%) stated that their influence was almost essential, $62(45.26 \%)$ replied that their influence was highly influential, 31 (22.63\%) indicated that their influence was moderately influential, and six (4.38\%) selected that their influence was mildly influential (see Table 3). When asked to rate their perceived level of influence on a youth's life skill development in "Concern for Others," 41 of the participants (29.93\%) rated their influence as almost essential, 68 (49.64\%) reported their influence as highly influential, 25 (18.25\%) perceived that their influence was moderately influential, and three (2.19\%) stated that their influence was mildly influential (see Table 3).

Relating Skills. When asked to rate their perceived level of influence on a youth's life skill development of "Accepting Differences", 51 of the participants (37.23\%) reported their influence as almost essential, 68 (49.64\%) responded that their influence was highly influential, and 18 (13.14\%) indicated that their influence was moderately influential (see Table 3). When questioned about their perceived level of influence on a youth's life skill development in "Conflict Resolution," 41 of the 
participants (30.15) responded that their influence was almost essential, 67 (49.26\%) reported their influence as highly influential, 23 (16.91\%) stated that their influence was moderately influential, and five (3.68\%) perceived that their influence was mildly influential (see Table 3).

In regards to their perceived level of influence on a youth's life skill development in "Social Skills," 48 of the participants (35.04\%) stated that their influence was almost essential, 71 (51.82\%) reported their influence as highly influential, 14 (10.22\%) replied that their influence was moderately influential, and four $(2.92 \%)$ selected that their influence was mildly influential (see Table 3). When asked to rate their perceived level of influence on a youth's life skill development in "Cooperation," 48 of the participants (35.04\%) rated their influence as almost essential, 71 (51.82\%) reported their influence as highly influential, 12 (8.76\%) perceived that their influence was moderately influential, and $6(4.38 \%)$ selected that their influence was mildly influential (see Table 3$)$. When questioned about their perceived level of influence on a youth's life skill development in "Communication," 45 of the participants (32.85\%) selected that their influence was almost essential, $69(50.36 \%)$ reported their influence as highly influential, 19 (13.87\%) indicated that their influence was moderately influential, and four $(2.92 \%)$ stated that their influence was mildly influential (see Table 3).

\section{Hands.}

Giving Skills. When asked to rate their perceived level of influence on a youth's life skill development in "Community Service/Volunteering," 30 participants (20.69\%) reported their influence as almost essential, 77 (53.10\%) rated their influence as highly influential, 29 (20.00\%) reported their influence as moderately influential, and nine 
(6.21\%) perceived that their influence was not at all influential (see Table 3). Asking to rate their perceived level of influence on a youth's life skill development in "Leadership" resulted in the following: 45 of the participants (30.82\%) stated that their influence was almost essential, 92 (63.01\%) perceived that their influence was highly influential, and nine $(6.16 \%)$ reported their influence as moderately influential (see Table 3).

When rating their perceived level of influence on a youth's life skill development of "Responsible Citizenship", 31 of the participants (21.23\%) rated their influence as almost essential, 73 (50.00\%) reported their influence as highly influential, 34 (23.39\%) replied that their influence was moderately influential, and eight (5.48\%) selected that their influence was mildly influential (see Table 3). In regards to their perceived level of influence on a youth's life skill development in "Contributions to group effort," 52 of the participants (35.62\%) perceived that their influence was almost essential, 71 (48.63\%) reported their influence as highly influential, $22(15.07 \%)$ stated that their influence was moderately influential, and one ( $0.68 \%)$ indicated that their influence was mildly influential (see Table 3).

Working Skills. When selecting their perceived level of influence on a youth's life skill development in "Marketable Skills," 22 of the participants (15.07\%) stated that their influence was almost essential, 62 (42.47\%) reported their influence as highly influential, 48 (32.88\%) replied that their influence was moderately influential, 12 (8.22\%) reported their influence as mildly influential, and two (1.37\%) perceived that their influence was not at all influential (see Table 3). When questioned about their perceived level of influence on a youth's life skill development in "Teamwork," 41 of the participants (28.47\%) indicated that their influence was almost essential, $84(58.33 \%)$ 
reported their influence as highly influential, 18 (12.50) stated that their influence was moderately influential, and one (0.69\%) reported their influence as mildly influential (see Table 3). In regards to rating their perceived level of influence on a youth's life skill development in "Self-motivation," 30 of the participants (20.83\%) selected that their influence was almost essential, $72(50.00 \%)$ reported their influence as highly influential, $33(22.92 \%)$ stated that their influence was moderately influential, eight (5.56\%) reported their influence as mildly influential, and one $(0.69 \%)$ perceived that their influence was not at all influential (see Table 3).

\section{Health.}

Being Skills. When asked to rate their perceived level of influence on a youth's life skill development in "Self-esteem," 43 of the participants (29.86\%) reported their influence as almost essential, 82 (56.94\%) indicated that their influence was highly influential, $16(11.11 \%)$ reported their influence as moderately influential, and three $(2.08 \%)$ stated that their influence was mildly influential (see Table 3 ). When rating their perceived level of influence on a youth's life skill development in "Self-responsibility," 43 of the participants (29.86\%) rated their influence as almost essential, 71 (49.31\%) reported their influence as highly influential, 28 (19.44\%) perceived that their influence was moderately influential, and two (1.39\%) replied that their influence was mildly influential (see Table 3).

Rating their perceived level of influence on a youth's life skill development in "Character" resulted in 48 of the participants (33.57\%) stating that their influence was almost essential, $70(48.95 \%)$ reporting their influence as highly influential, $22(15.38 \%)$ reporting their influence as moderately influential, and three (2.10\%) indicating that their 
influence was mildly influential (see Table 3). When asked to rate their perceived level of influence on a youth's life skill development in "Managing Feelings," 26 of the participants (18.31\%) perceived that their influence was almost essential, 63 (44.37\%) responded that their influence was highly influential, 45 (31.69\%) reported their influence as moderately influential, and eight (5.63\%) selected that their influence was mildly influential (see Table 3). In regards to their perceived level of influence on a youth's life skill development in "Self-discipline," 30 of the participants (21.13\%) stated that their influence was almost essential, $53(37.32 \%)$ reported their influence as highly influential, $43(30.38 \%)$ rated their influence as moderately influential, $14(9.86 \%)$ reported their influence as mildly influential, and two (1.41\%) perceived that their influence was not at all influential (see Table 3).

Living Skills. When questioned about their perceived level of influence on a youth's life skill development in "Healthy Lifestyle Choices," 23 of the participants (16.20\%) stated that their influence was almost essential, 65 (45.77\%) reported their influence as highly influential, 37 (26.06\%) perceived that their influence was moderately influential, $16(11.27 \%)$ indicated that their influence was mildly influential, and one $(0.70 \%)$ reported their influence as not at all influential (see Table 3$)$. When asked to select their perceived level of influence on a youth's life skill development in "Stress Management," 24 of the participants (16.90\%) selected that their influence was almost essential, 53 (37.32\%) reported their influence as highly influential, 39 (27.46\%) perceived that their influence was moderately influential, 22 (15.49\%) reported their influence as mildly influential, and four (2.82\%) responded that their influence was not at all influential (see Table 3). 
When asked to rate their perceived level of influence on a youth's life skill development in "Disease Prevention," 20 of the participants (14.08\%) reported their influence as almost essential, 40 (28.17\%) rated their influence as highly influential, 44 (30.99\%) selected that their influence was moderately influential, $26(18.31 \%)$ reported their influence as mildly influential, and $12(8.45 \%)$ stated that their influence was not at all influential (see Table 3). In regards to selecting their perceived level of influence on a youth's life skill development in "Personal Safety," 23 of the participants (16.31\%) replied that their influence was almost essential, $60(42.55 \%)$ reported their influence as highly influential, 38 (26.95\%) stated that their influence was moderately influential, 17 (12.06\%) perceived that their influence was mildly influential, and three $(2.13 \%)$ reported their influence as not at all influential (see Table 3).

\section{Years Worked as Extension Camping Instructor}

All participants in the study were asked to indicate how many years they had worked as an Extension Camping Instructor. The options for choosing were 1 - 3, 4-6, $7-9$, and More than 9. Of the participants, 107 (78.68\%) stated to have worked between $1-3$ years. Twenty-four participants (17.65\%) reported to have worked between $4-6$ years. Five participants indicated to have worked between $7-9$ years. No participants had worked more than 9 years (see Table 4 ). 
Table 4

Years Worked as an Extension Camping Instructor

\begin{tabular}{lcc}
\hline & $\mathrm{f}$ & $\%$ \\
\hline $1-3$ & 107 & 78.68 \\
$4-6$ & 24 & 17.65 \\
$7-9$ & 5 & 3.68 \\
More than 9 & 0 & 0.00 \\
\hline
\end{tabular}

\section{Types of Venues That the Participants Worked}

As an Extension Camping Instructor, instructors could be sent to a variety of venues throughout the state. Survey respondents were asked to identify approximately how many of the various venues they worked throughout their tenure as an Extension Camping Instructor. There were three options to choose from: County camps, State camps, and other (State Fair, State 4-H Days, non 4-H events)

Sixty participants $(44.12 \%)$ stated to have worked $1-5$ county camps throughout their tenure as an Extension Camping Instructor. Forty (29.41\%) reported that they had worked $5-10$ county camps, $25(18.38 \%)$ reported they had worked $10-15$ county camps. While six (4.41\%) indicated that they had worked $15-20$ county camps and five participants (3.68\%) had selected that they had worked at more than 20 county camps (see Table 5).

When considering state camp assignments, 67 (95.71\%) of the respondents had worked $1-5$ state camps and $3(4.29 \%)$ of the participants reported working $5-10$ state 
camps. With regard to assignments at other events, $77(88.51 \%)$ of the participants stated that they had worked $1-5$ other events, nine (10.34\%) had worked $5-10$ other events and one participant (1.15\%) indicated to have worked 10 - 15 other events (see Table 5).

Table 5

Types of Venues Worked Throughout Extension Camping Instructor Career

\begin{tabular}{lcccccc}
\hline & County Camps & State Camps & \multicolumn{2}{c}{$\begin{array}{c}\text { Other (State fair, State } \\
\text { 4-H } \begin{array}{c}\text { Days, Non 4-H } \\
\text { events) }\end{array}\end{array}$} \\
& $\mathrm{f}$ & $\%$ & $\mathrm{f}$ & $\%$ & $\mathrm{f}$ & $\%$ \\
\hline $1-5$ & 60 & 44.12 & 67 & 95.71 & 77 & 88.51 \\
$5-10$ & 40 & 29.41 & 3 & 4.29 & 9 & 10.34 \\
$10-15$ & 25 & 18.38 & 0 & 0.00 & 1 & 1.15 \\
$15-20$ & 6 & 4.41 & 0 & 0.00 & 0 & 0.00 \\
$\begin{array}{l}\text { More } \\
\text { than } 20\end{array}$ & 5 & 3.68 & 0 & 0.00 & 0 & 0.00 \\
\hline
\end{tabular}

\section{Adjective Pairs}

The participants were given the chance to rate their Extension Camping Instructor experience on a sliding scale. For each scale, a pair of opposite adjectives were listed. With each sliding scale, the participant was asked to rank on a 5 point scale their opinion of their experience, with 1 representing the more negative adjective, and 5 representing the more positive adjective. The adjective pairs included "Stressful" versus "Relaxed," “Terrifying" versus "Wonderful," "Tiring" versus "Exhilarating," and "Waste of Time" versus "Learning Experience." 
When asked to rate the ECI experience on a scale from "Stressful" to "Relaxed," 10 participants $(7.41 \%)$ rated their experience as a 1,29 participants $(21.48 \%)$ rated their experience as a 2, 48 participants (35.56) rated their experience as a 3,45 participants (33.33\%) rated their experience as a 4, three participants (2.22\%) rated their experience has a 5 (see Figure 3).

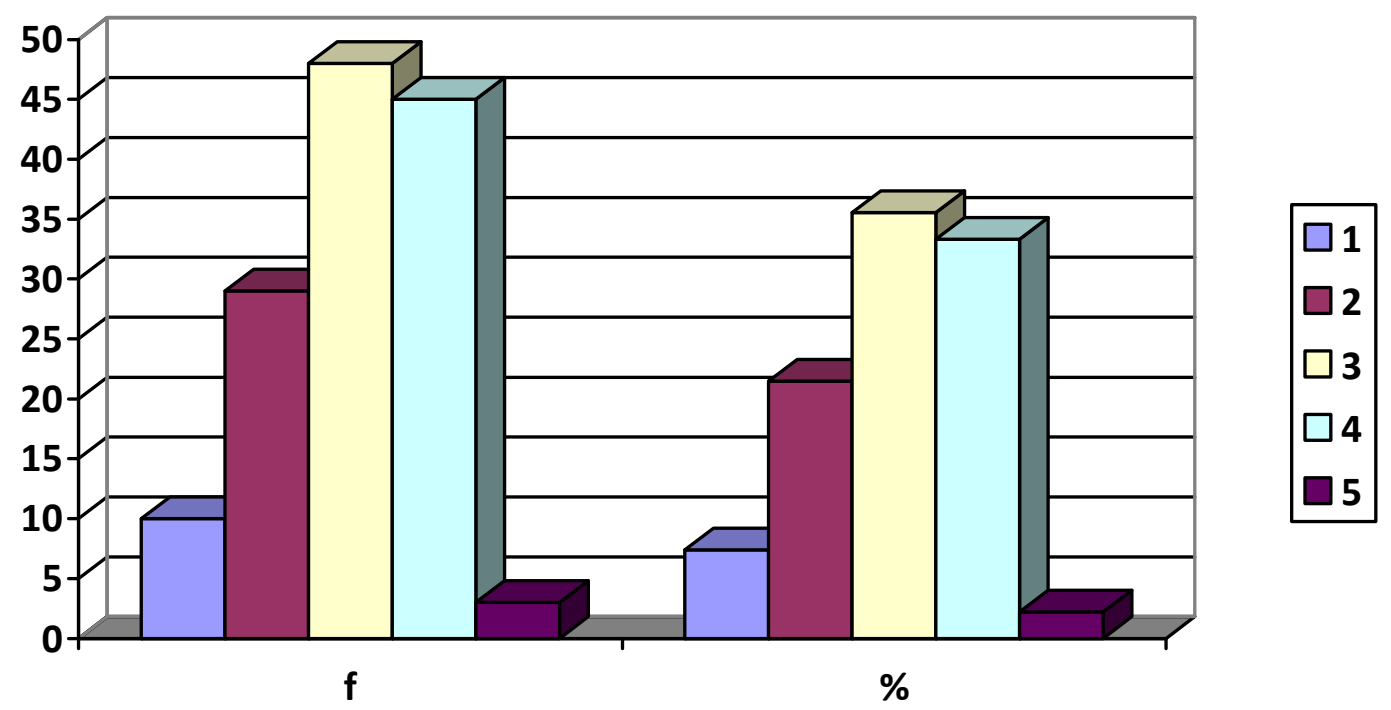

Figure 3: Stressful vs. Relaxed

In response to the adjective pair "Terrifying" versus "Wonderful," three participants (2.21\%) stated that their experience as a 2 and 13 participants (9.56) rated their experience as a 3 . While, 58 participants (42.65\%) rated their experience as a 4 and 62 participants $(45.59 \%)$ rated their experience as a 5 (see Figure 4 ). 


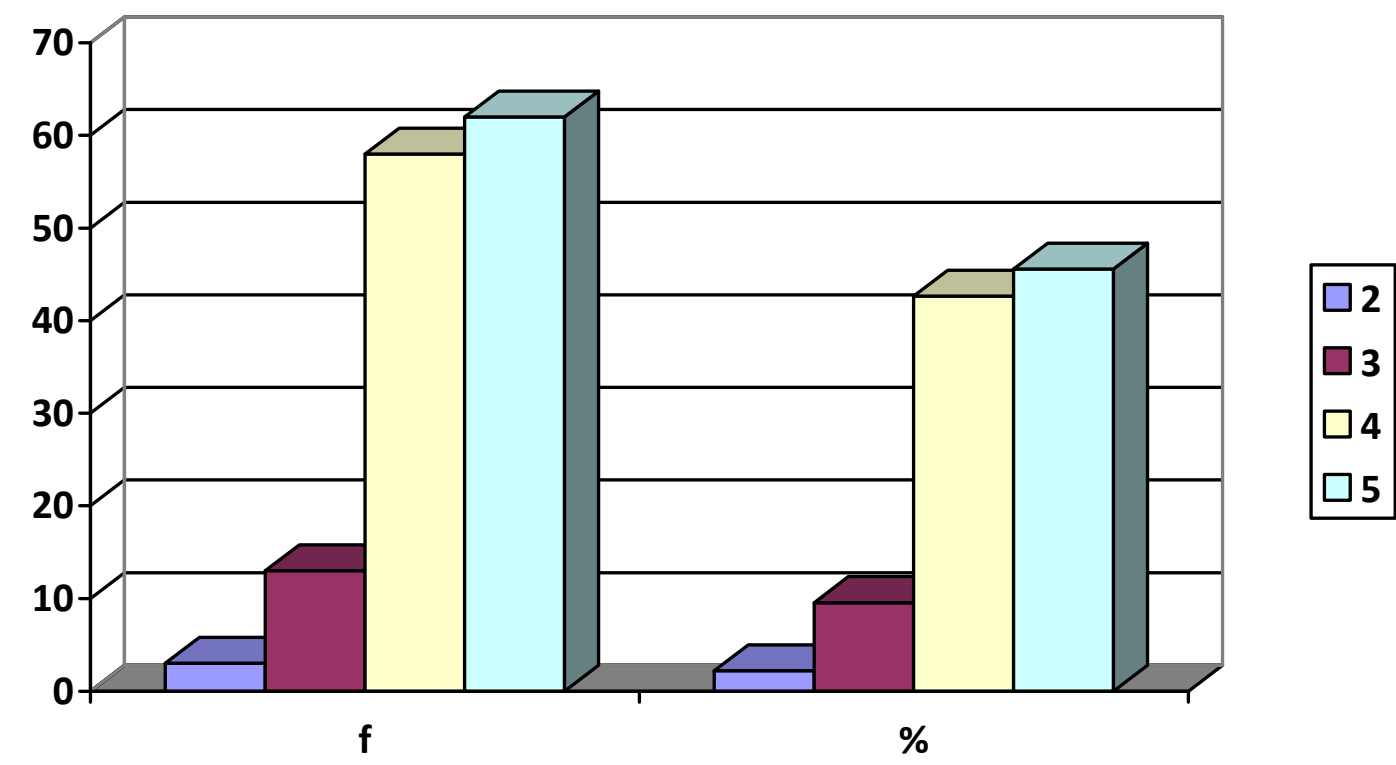

Figure 4: Terrifying vs. Wonderful

When addressing the adjective pairing "Tiring" versus "Exhilarating," four participants $(2.94 \%)$ rated their experience as a 0 , one participant $(0.74 \%)$ rated their experience as a 1 and 17 participants $(12.50 \%)$ rated their experience as a 2. While, 51 participants $(37.50 \%)$ rated their experience as a 3,43 participants $(31.62 \%)$ rated their experience as a 4 and 20 participants $(14.71 \%)$ rated their experience as a 5 (see Figure $5)$. 


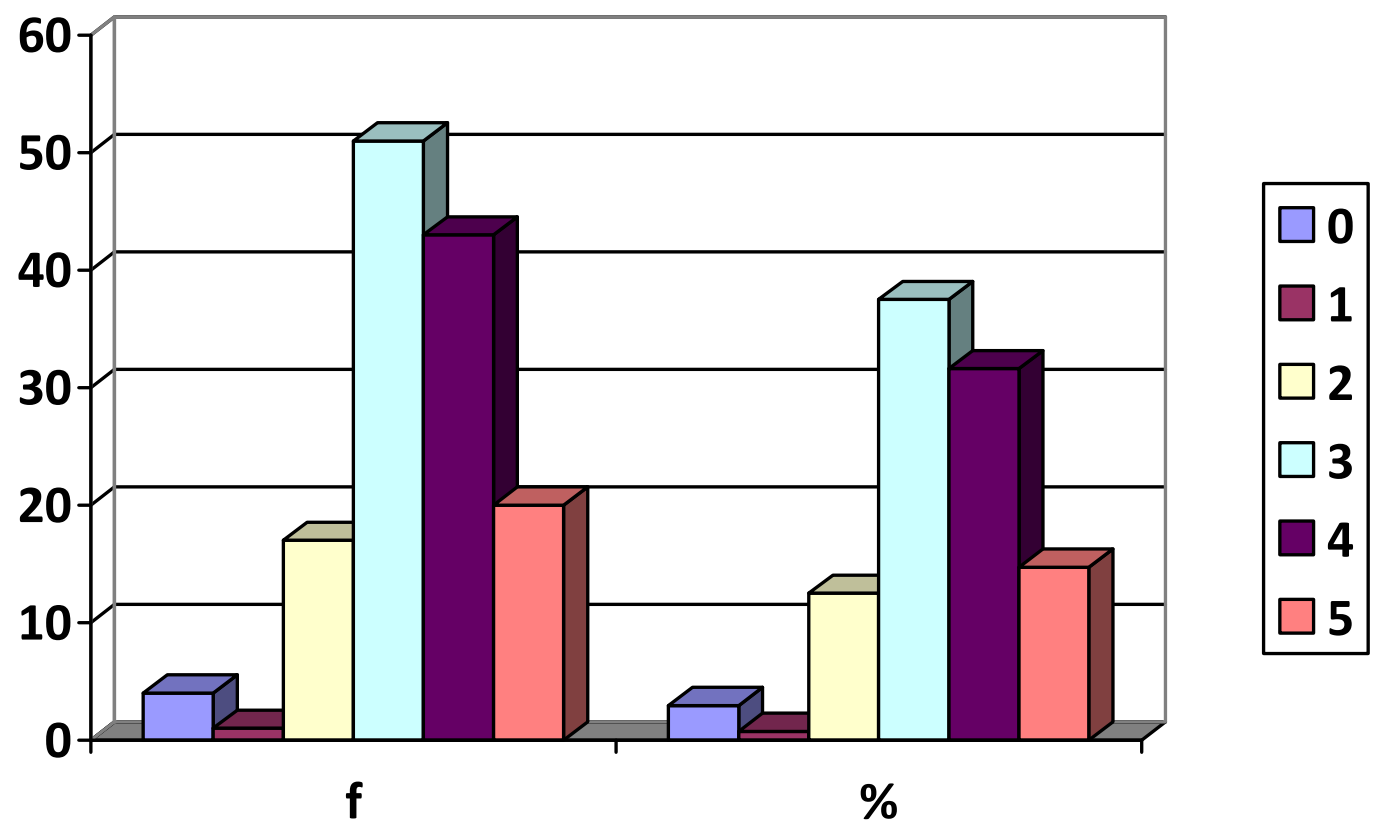

Figure 5: Tiring vs. Exhilarating

When rating their experiences with the adjective pair "Waste of Time" versus "Learning Experience," two participants $(1.50 \%)$ rated their experience as a 0 . One participant $(0.75 \%)$ rated their experience as a 1 , one other participant $(0.75 \%)$ rated their experience as a 2 , while one other participant $(0.75 \%)$ rated their experience as a 3 . However, 18 participants (13.53\%) rated their experience as a 4, 110 participants $(82.71 \%)$ rated their experience as a 5 (see Figure 6). 


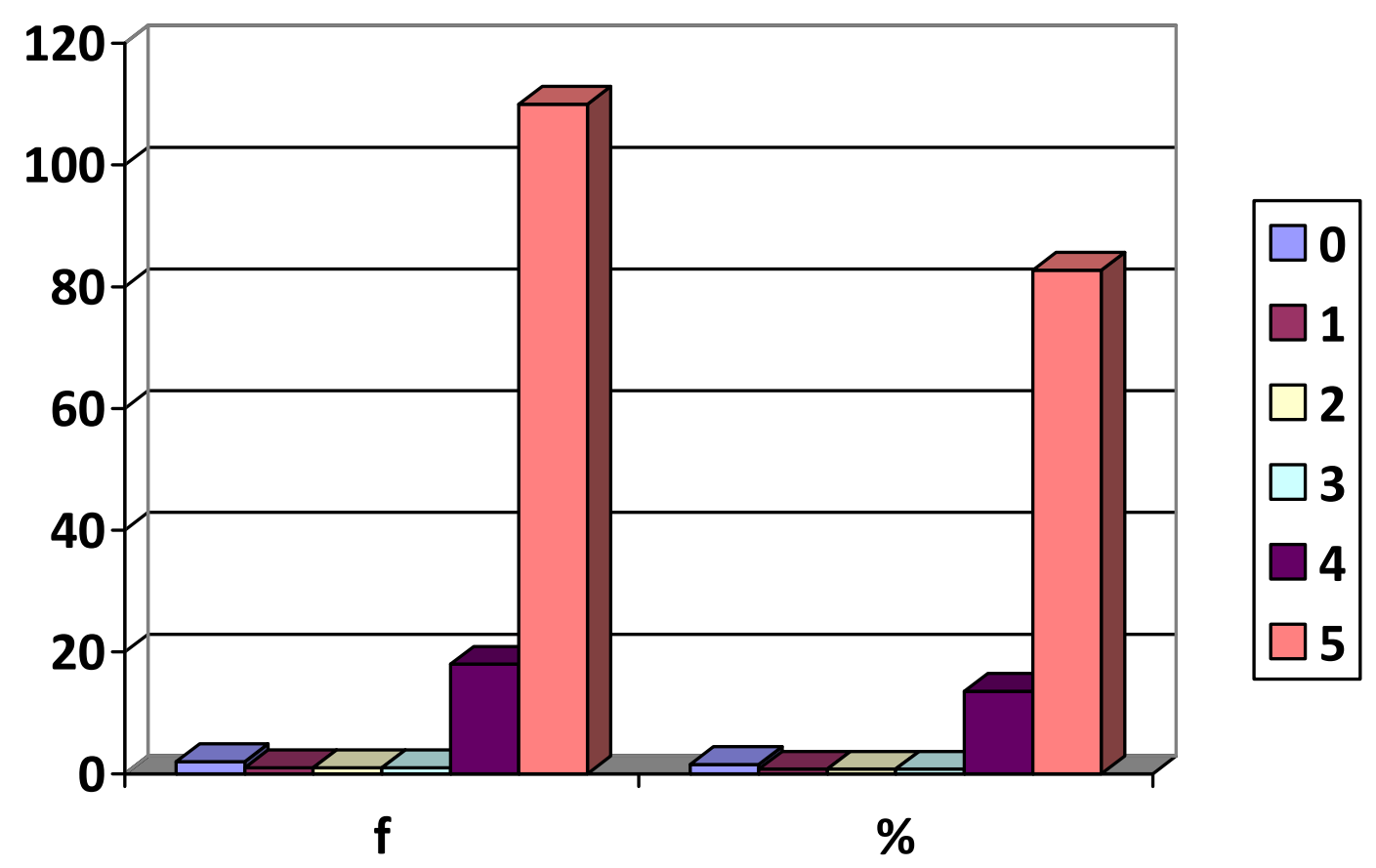

Figure 6: Waste of Time vs. Learning Experience

\section{Training}

The survey participants were given the opportunity to indicate whether or not they felt that they had been trained properly. Of the respondents 131 (96.32\%) responded that they felt they had been trained properly, while five participants (3.68\%) indicated that they had not been trained properly (see Table 6). 
Table 6

Trained Properly

\begin{tabular}{lcc}
\hline & $\mathrm{f}$ & $\%$ \\
\hline Yes & 131 & 96.32 \\
No & 5 & 3.68 \\
\hline
\end{tabular}

\section{Would you recommend the Extension Camping Instructor Position to Others?}

Respondents were asked whether or not they would recommend others apply for an Extension Camping Instructor (ECI) position. Of the respondents 135 (99.26\%) indicated that yes they would recommend others to apply for the ECI, while one participant $(0.73 \%)$ reported they would not recommend the ECI position to others (see Table 7).

Table 7

Would You Recommend being an ECI?

\begin{tabular}{lcc}
\hline & $\mathrm{f}$ & $\%$ \\
\hline Yes & 135 & 99.26 \\
No & 1 & 0.73 \\
\hline
\end{tabular}

\section{Demographic Information}

Respondents were asked how they learned of the Extension Camping Instructor position. Seven options were listed for them to choose from: parent, other family 
member, 4-H leader, other 4-H members, Extension agent, teacher, and other. If "other" was selected, the respondent had the option of writing in text answer.

Five participants (3.65\%) reported that they had learned of the position from their parent. Five participants (3.65\%) indicated that they had learned of the position from other family members, and 15 participants $(10.95 \%)$ responded that they heard of the position from a 4-H leader. Sixty-five participants (47.45\%) reported learning of the experience from other 4-H members, 20 respondents $(14.60 \%)$ had reported hearing of the position from an Extension agent, and one participant (0.73\%) had learned of the position from a teacher (see Table 8 ). For the "other" category, the majority of responses related to having participated in the 4-H Camping Program (see Appendix D).

Table 8

How ECIs Heard of the Position?

\begin{tabular}{lcc}
\hline & $\mathrm{f}$ & $\%$ \\
\hline Parent & 5 & 3.65 \\
Other family member & 5 & 3.65 \\
4-H Leader & 15 & 10.95 \\
Other 4-H Members & 65 & 47.45 \\
Extension Agent & 20 & 14.60 \\
Teacher & 1 & 0.73 \\
Other & 26 & 18.98 \\
\hline
\end{tabular}


The respondents were asked to rate how influential various individuals were in their decision to apply for the ECI position. The choices were parents, other family members, 4-H leader, other 4-H member, teacher, Extension agent, and other where they could write in the person.

When considering the influence of parents, $13(9.63 \%)$ respondents rated them as almost essential and $30(22.22 \%)$ rated them as highly influential. Thirty-three respondents $(24.44 \%)$ rated parents as moderately influential, $21(15.56 \%)$ rated them as mildly influential, and 38 (28.15\%) rated parents as not at all influential (see Table 9).

For other family members, eight participants (6.02\%) rated their influence as almost essential, $18(13.53 \%)$ rated them as highly influential. Of the respondents 29 $(21.80 \%)$ rated family members as moderately influential, $20(15.04 \%)$ rated them as mildly influential, and 58 (43.61\%) rated family as not at all influential (see Table 9).

The influence of the $4-\mathrm{H}$ leader was reported by 24 participants $(17.65 \%)$ as almost essential and $40(29.41 \%)$ reported the 4-H leader as highly influential. Twentysix respondents (19.12\%) indicated 4-H leaders as moderately influential in their decision, 18 (13.24\%) reported 4-H leader as mildly influential, and 28 (20.59\%) stated that their 4-H leader was not at all influential in their decision (see Table 9).

In regards to other 4-H members being influential in their decision, 70 participants (52.24\%) reported 4-H members as almost essential, 44 (32.84\%) indicated 4-H members were highly influential. Eight respondents (5.97\%) reported 4-H members as moderately influential, seven (5.22\%) reported them as mildly influential, and five 
(3.73\%) reported 4- $\mathrm{H}$ members as not at all influential in their decision to apply (see Table 9).

As to the influence a teacher had on their decision, one participant $(0.75 \%)$ reported them as almost essential, seven (5.26\%) reported teachers as highly influential and $17(12.78 \%)$ reported teachers as moderately influential, While eight participants (6.02\%) reported that a teacher was mildly influential and 100 respondents $(75.19 \%)$ indicated that teachers were not at all influential in their decision (see Table 9).

When asked to indicate how influential the Extension Agent was on their decision to apply for the ECI position, 35 participants (26.12\%) stated them as almost essential, 38 (28.36\%) reported the Extension Agent as highly influential and $20(14.93 \%)$ responded that the Extension Agent was moderately influential. While 15 respondents (11.19\%) indicated that the Extension Agent was mildly influential, and 26 participants (19.40\%) reported the Extension was not at all influential in their decision (see Table 9). In the first "Other" category, 18 participants (56.25\%) reported almost essential, five (15.63\%) rated highly influential, and nine $(28.13 \%)$ selected not at all influential. In the second "Other" category, two (18.18\%) had reported almost essential, and nine (81.82\%) had reported not at all influential. The most common response in both choices were former and current Extension Camping Instructors (see Appendix D). 
Table 9

Influence on Applying for ECI Position

\begin{tabular}{lcccccccccc}
\hline & & & & \multicolumn{2}{c}{$\begin{array}{c}\text { Moderately } \\
\text { Not at all Influential }\end{array}$} & Mildly Influential & & Highly Influential & Almost Essential \\
\cline { 2 - 8 } & $\mathrm{f}$ & $\%$ & $\mathrm{f}$ & $\%$ & $\mathrm{f}$ & $\%$ & $\mathrm{f}$ & $\%$ & $\mathrm{f}$ & $\%$ \\
\hline Parents & 38 & 28.15 & 21 & 15.56 & 33 & 24.44 & 30 & 22.22 & 13 & 9.63 \\
Other family members & 58 & 43.61 & 20 & 15.04 & 29 & 21.80 & 18 & 13.53 & 8 & 6.02 \\
4-H Leader & 28 & 20.59 & 18 & 13.24 & 26 & 19.12 & 40 & 29.41 & 24 & 17.65 \\
Other 4-H Member & 5 & 3.73 & 7 & 5.22 & 8 & 5.97 & 44 & 32.84 & 70 & 52.24 \\
Teacher & 100 & 75.19 & 8 & 6.02 & 17 & 12.78 & 7 & 5.26 & 1 & 0.75 \\
Extension Agent & 26 & 19.40 & 15 & 11.19 & 20 & 14.93 & 38 & 28.36 & 35 & 26.12 \\
Other (specify) & 9 & 28.13 & 0 & 0.00 & 0 & 0.00 & 5 & 15.63 & 18 & 56.25 \\
Other (specify) & 9 & 81.82 & 0 & 0.00 & 0 & 0.00 & 0 & 0.00 & 2 & 18.18 \\
\hline
\end{tabular}


This study sought to determine if being an Extension Camping Instructor influenced the participants' college major or career choice. With regard to college major, seven respondents (5.11\%) indicated it was not applicable, 18 (13.14\%) reported it as almost essential, $22(16.06 \%)$ reported being an ECI as highly influential, and 25 $(18.25 \%)$ reported it as moderately influential. Sixteen respondents (11.68\%) indicated that being an ECI was mildly influenced, and 49 (35.77\%) reported it was not at all influential in their choice of college major (see Table 10). As to whether or not being an Extension Camping Instructor influenced their choice of career, nine participants (6.57\%) indicated it was not applicable, 21 respondents (15.33\%) reported it was almost essential, 26 participants (18.98\%) reported being an ECI was highly influential in their career choice. Of the respondents, $23(16.79 \%)$ stated that being an ECI had moderately influenced their career choice, while 26 (18.98\%) reported it as mildly influential, and 32 respondents (23.36\%) indicated that being an ECI was not at all influential in the career choice (see Table 10). 
Table 10

Influence of Being an Extension Camping Instructor on College Major and Career

\begin{tabular}{lcccc}
\hline & \multicolumn{2}{c}{ College Major } & \multicolumn{2}{c}{ Choice of Career } \\
\cline { 2 - 5 } & $\mathrm{f}$ & $\%$ & $\mathrm{f}$ & $\%$ \\
\hline Not at all Influential & 49 & 35.77 & 32 & 23.36 \\
Mildly Influential & 16 & 11.68 & 26 & 18.98 \\
Moderately & 25 & 18.25 & 23 & 16.79 \\
Influential & 22 & 16.06 & 26 & 18.98 \\
Highly Influential & 18 & 13.14 & 21 & 15.33 \\
Almost Essential & 7 & 5.11 & 9 & 6.57 \\
Not Applicable & & & & \\
\hline
\end{tabular}

Respondents were asked to indicate why they discontinued their employment as an Extension Camping Instructor. Seven options were given for the participants to choose from: was not paid enough, did not have time, graduated from college, too stressful, was not asked back, did not enjoy, and other. Three respondents $(2.40 \%)$ indicated that they were not paid enough, 21 participants $(16.80 \%)$ reported that they did not have the time, 55 participants $(44.00 \%)$ reported that they had graduated from college. No one reported that the position was too stressful or that they did not enjoy the experience. Two participants (1.60\%) stated that they were not asked back and 44 participants (35.20\%) answered “other" (see Table 11). “other” responses included that the participants had other jobs that interfered with the summer schedule, had to get internships, or felt burnt out on the experience (see Appendix D). 
Table 11

Reasons for not Continuing Employment

\begin{tabular}{lcc}
\hline & $\mathrm{f}$ & $\%$ \\
\hline Wasn't paid enough & 3 & 2.40 \\
Didn't have time & 21 & 16.80 \\
Graduated from college & 55 & 44.00 \\
Too stressful & 0 & 0.00 \\
Wasn't asked back & 2 & 1.60 \\
Did not enjoy & 0 & 0.00 \\
Other (specify) & 44 & 35.20 \\
\hline
\end{tabular}

\section{Comments from participants}

The study participants were given the opportunity to provide comments regarding their Extension Camping Instructor experience. There were a number of comments made about their Extension Camping Experience, a few of the comments are included below.

I enjoyed my time as an ECI. I only worked a few weeks, but the other ECI's I worked with were great to work with and I'd work with them again. I experienced both the new agents and the very experienced and loved my time.

Being an ECI was one of the most challenging but rewarding experience [sic] that I have ever been a part of $15+$ years in $4-\mathrm{H}$, and nothing else compares. 
If I had never became [sic] an ECI, I would have never gotten to work the Junior Firefighter camp, and I wouldn't have ever joined the fire service. Thanks to being an ECI, I am now a proud firefighter at [ ] VFD and every day I try to inspire kids to follow their biggest dreams.

It's a wonderful experience. My first 2 years were the best experience ever. I started to wear down and become exhausted the older I was in the job. Also, I began to have less patience with crummy volunteers and other negative individual [sic] at certain counties. Overall, I wouldn't trade my experience for the world. It was very influential in my life and has made me a better and stronger individual.

I feel that being an ECI is the pinnacle of my development in 4-H. While all the charting experiences and life skills in 4-H were mostly conceptual, I feel being an ECI allowed me to apply my skills and be the difference I saw being acted on me. Passing it on was one of the most satisfying experiences in my life, and I honestly do not think I would have the selfawareness that helps me so much if not for the ECI program.

Being an ECI was an amazing learning experience and I think every young person should experience it.

Being an ECI has opened many doors for me personally. It is probably one of the most influential learning experiences I have ever had. I credit a huge part of my personal development throughout college to being an ECI. 
Great experience! I do think they need to work on outreach to get more males interested in the position.

I've always said that I learned more about myself, and skill sets being an ECI than I was ever able to teach or give back. It was an unforgettable and priceless experience.

4-H and being an ECI definitely shaped who I am today. I recommend it to college students every chance I get.

I love being an ECI!

I am currently employed as a full-time children's and therapeutic riding instructer [sic] and I find that I often draw on my ECI experiences when interacting with rides [sic] and planning events and camps. I will also be starting a new 4-H horse club in the near future, and I expect I will use my ECI experience even more in that capacity.

I think the ECI experience is so great for everyone. It was a very essential part of becoming a responsible adult for me. Highly recommended.

Appendix E has a complete listing of the comments from respondents. 


\section{CHAPTER V}

\section{Summary, Conclusions, and Findings}

\section{Purpose}

The purpose of this study was to determine if West Virginia University Extension Camping Instructors (ECIs) were influencing the life skill development of 4-H youth while also developing life skills of their own. This study utilized the perceptions of ECIs who were employed from the summer of 2007 to October of 2015 by examining their current level of life skills, how they felt being employed as an ECI influenced the development of each skill, and how they felt their role impacted the life skill development of 4-H youth with whom they had worked.

The following research questions were used to guide this study of the impact of an ECI on life skill development.

1. How will the ECIs perceive their current level of life skill development as defined by the Targeting Life Skills model by Hendricks (1996)?

2. How do ECIs perceive the impact of their employment on their current level of life skills?

3. How do ECIs perceive their role as an impacted the life skill development of the 4-H youth with whom they had worked?

\section{Summary}

Nearly half of the participants $(47.45 \%)$ reported that they had heard of the Extension Camping Instructor position from other 4-H members. While over half of the respondents $(52.24 \%)$ indicated that other $4-\mathrm{H}$ members were an almost essential influence on them applying for the position, while an Extension agent was reported to 
have had a strong influence on a quarter $(26.12 \%)$ of the participants decisions to apply for an Extension Camping Instructor position.

The majority of the participants $(78.68 \%)$ reported to either have worked or are still currently working as Extension Camping Instructors for " $1-3$ " years. The second highest number of years worked was " $4-6$ " years by an additional 18 percent of the respondents, a very small number (3.86\%) reported having worked as an Extension Camping Instructor 7 to 9 years.

A majority of the participants have worked between 1 and 5 county camps, state camps, and other 4-H events. It was obvious that county camps were the primary venue for Extension Camping Instructors. Almost every participant (99.25\%) indicated that they had been trained properly for their assignments as an Extension Camping Instructor.

A majority $(82.71 \%)$ of the respondents rated their Extension Camping Instructor experience as a learning experience. Respondents had mixed feelings about whether the job was stressful or relaxed; terrifying or wonderful and tiring or exhilarating. Most would agree that it was wonderful, tiring and often times stressful. As several noted in the comments, it depended on the day and the situation.

Almost all of the participants $(99.26 \%)$ indicated they would recommend someone apply to be an Extension Camping Instructor. Four skills which respondents perceived to be the most useful skill that they gained from being an Extension Camping Instructor included the ability to adapt to any given situation and think on their feet, leadership, communicate effectively, and creating a cultural awareness in working effectively with different groups of people. 


\section{Extension Camping Instructors Current Life Skills Ability}

When rating their current levels of ability for the 35 life skills, most participants considered their skill level to be between average and excellent. The life skill rated highest was concern for others which was rated excellent by $67.88 \%$ of the participants. Other life skills that were rated excellent were teamwork (65.28\%), accepting differences (67.15\%), and empathy (64.23\%). The only life skills listed that was rated below average were "keeping records" and "stress management, where several participants rated their current ability as poor or very poor.

\section{Influence of Being An ECI on Own Life Skill Development}

Extension Camping Instructor indicated that their involvement as an Extension Camping Instructor had positively influenced the development of their own life skills, with several being highly influential. Leadership had the highest perceived level of influence with nearly half of the participants (49.66\%) rating it as almost essential. Influence of being an Extension camping Instructor was perceived to be highly influential in the skill development of community service/volunteer (56.55\%), teamwork (53.47\%), problem solving (52.48\%), and communication (52.55\%).

Skills perceived to be less influenced by being an Extension Camping Instructor included areas where it was mildly influential were disease prevention (19.86\%), keeping records participants $(15.11 \%)$, stress management (14.89\%), and managing feelings (14.79\%). Two life skills reported as not at all influenced by being an Extension Camping Instructor were disease prevention (15.60\%) and keeping records (6.47\%) (See Figure 9). 


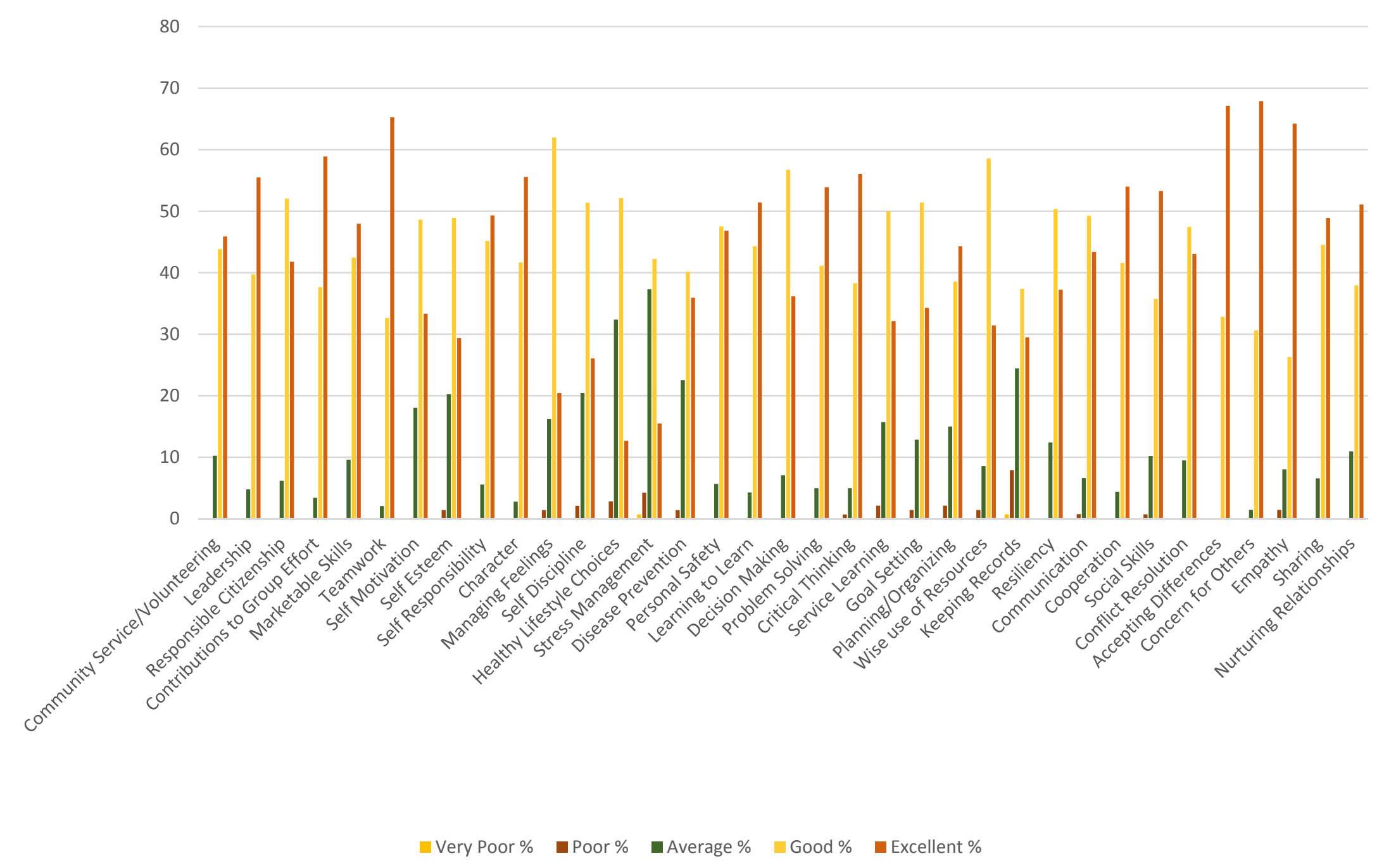

Figure 7: Current Level of Life Skills Abilities 


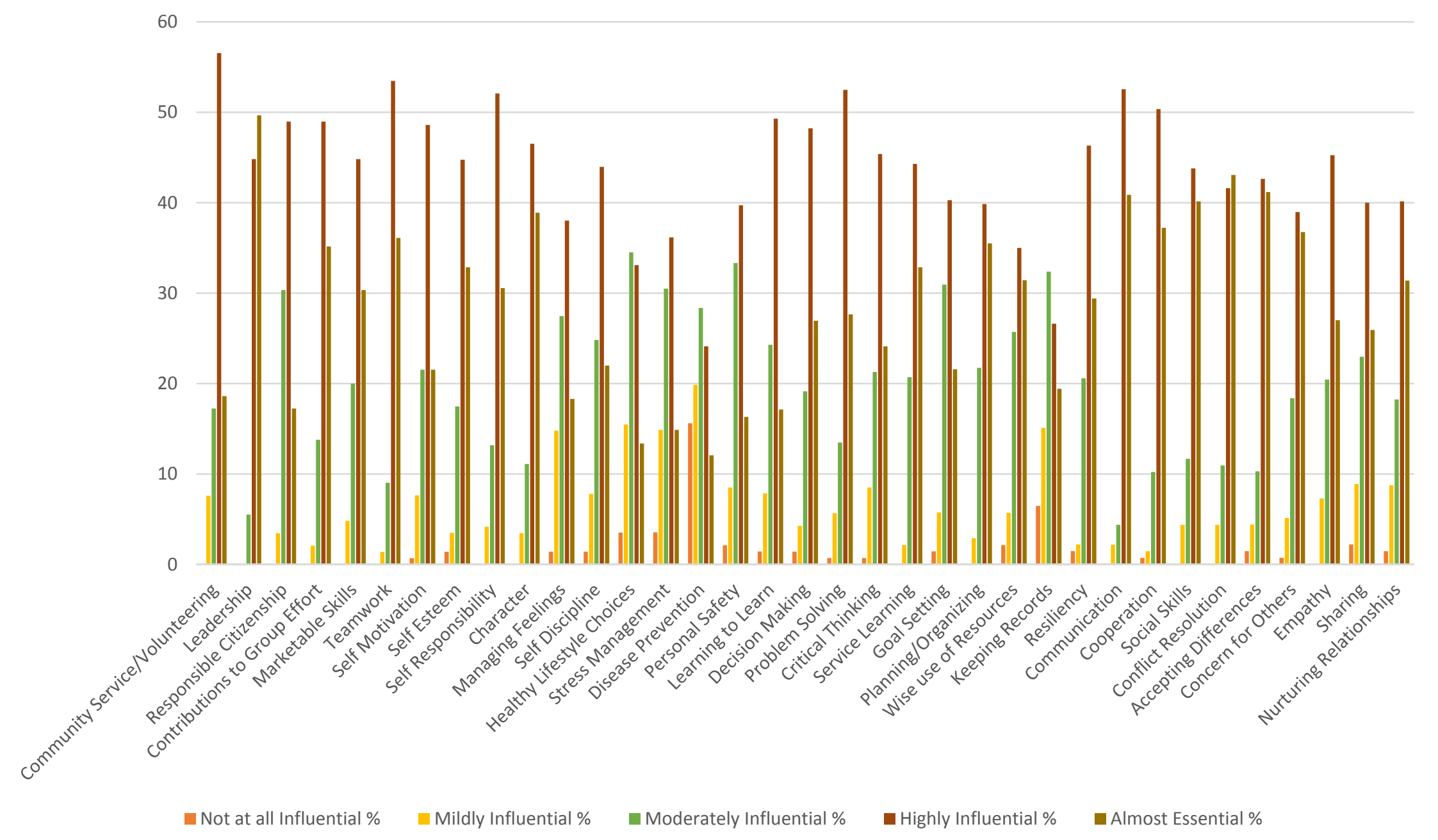

Figure 8: Influence on Own Life Skills Development 


\section{Influence of Extension Camping Instructor on Youth's Development of Life Skills}

A majority of the Extension Camping Instructors who responded to the survey indicated that they perceived their role as an ECI was highly influential in youth camper's development of life skills in leadership (63.01\%), teamwork (58.33\%), self-esteem (56.94\%), and community service/volunteering (53.10\%). Extension Camping Instructors perceived they had a lower level of influence on a youth's life skill development in keeping records $(20.71 \%)$, disease prevention $(18.31 \%)$, stress management (15.49\%), and personal safety $(12.06 \%)$. With being not at all influential in the skill categories of keeping records and disease prevention (see Figure 9).

The life skill areas where Extension Camping Instructors feel their being an ECI was highly influential on their own development and their influence on youth camper's development mirror each other. As do areas that they feel are not influential at all in both situations. 
70

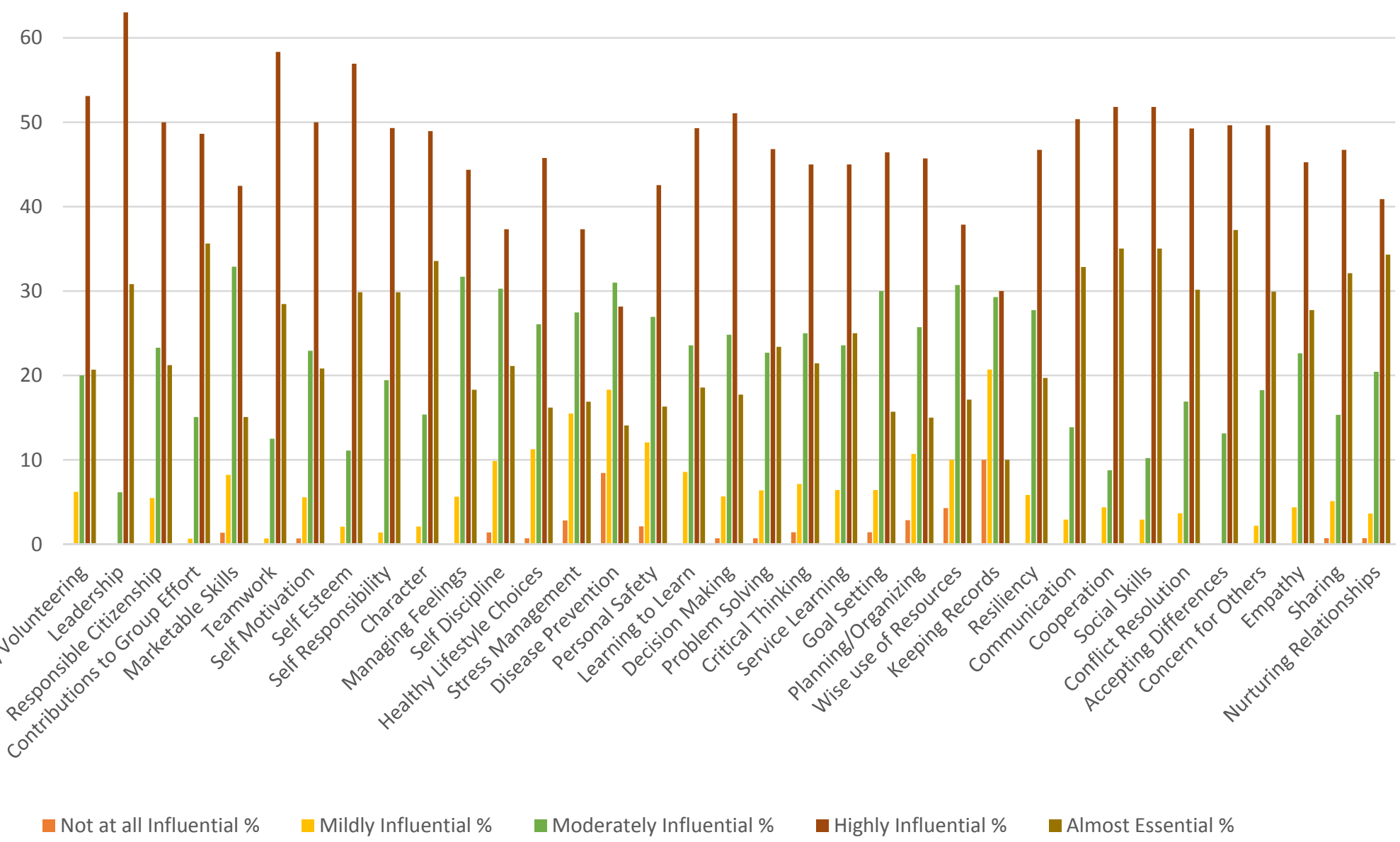

Figure 9: Influence on Youth's Life Skills Development 


\section{Conclusions}

Based on the findings of this study, the following conclusions can be made:

1. Fellow 4-H members and Extension Agents are often influential in one's decision to apply for the Extension Camping Instructor position, while teachers are often not at all influential.

2. Extension Camping Instructors often view their role as highly influential on the development of their own life skills, particularly in areas of leadership, community service/volunteering, teamwork, and self-responsibility.

3. Extension Camping Instructors often view their role as highly influential on the development of 4-H youth's development of leadership, teamwork, self-esteem, and community service which reflects the previous research of Boyd, Herring, \& Briers (1992).

4. Skills listed under the categories of head and health, particularly stress management, disease prevention, and keeping records are consistently considered to not be influenced by the Extension Camping Instructor role for the individual or the youth with whom they interact.

5. The majority of the Extension Camping Instructors enjoy the experience and would recommend the experience to others.

6. Life skills such as adaptability, leadership, communication, and working with others are highly valued skills perceived to be developed through being an Extension Camping Instructor. 


\section{Recommendations}

Based on the findings of this study, these recommendations are made:

1. 4-H members should encourage one another to seek new and exciting experiences.

2. Extension agents need to understand the influence they have on older youth becoming Extension Camping Instructors.

3. Focus more on the Health related life skills such as stress management, disease prevention, and personal safety when creating educational content for training Extension Camping Instructors and camping programs.

4. Future research should be conducted to determine perceived levels of Positive Youth Development by the Extension Camping Instructors in order to understand the full influence of their role. 


\section{REFERENCES}

Anderson, E.H. (2014). The influence of 4-H judging team participation on career life skills development (Master's Thesis). UMI:1565476

Armstrong, W.A. (2010). Life skills development of youth participations in 4-H clubs and camping (Master's Thesis). Retrieved from http://etd.fcla.edu/UF/UFE0042595/armstrong_w.pdf

Arnold, M.E., Bourdeau, V.D., \& Nagele, J. (2005). Fun and friendship in the national world: The impact of Oregon residential 4-H camping programs on girl and boy campers. Journal of Extension, 43(6).

Ary, D., Jacobs, L. C., \& Sorensen, C. (2010). Introduction to reserach in education. Belmont, CA, United States: Wadesworth.

Boyd, B.L., Herring, D.R., \& Briers, G.E. (1992). Developing life skill in youth. Journal of Extension, 30(4).

Boyd, B.L. (2004). Extension agents as administrators of volunteers: Competencies needed for the future. Journal of Extension, 42(2).

Dillman, D., Smyth, J., \& Christian, L. (2009). Internet, mail and mixed-mode surveys: The tailored design method (3rd ed.). New York: Wiley.

Duncan, R.D. (2000). Youth leadership life skills development of participants in the West Virginia 4-H camping program (Unpublished Master's Thesis). West Virginia University, Morgantown, WV. 
Garst, B.A., \& Bruce, F.A. (2003). Identifying 4-H camping outcomes using a standardized evaluation process across multiple 4-H educational centers. Journal of Extension, 41(3).

Garst, B.A., \& Johnson, J. (2005). Adolescent leadership skill development through residential 4-H camp counseling. Journal of Extension, 43(5).

Garton, M.S., Miltenberger, M., \& Pruett, B. (2007). Does 4-H camp influence life skill and leadership development? Journal of Extension, 45(4). Retrieved from http://www.joe.org/joe/2007august/a4.php

Graham, D.L. (1994). Cooperative Extension System. Encyclopedia of Agricultural Sciences, $1(415-430)$

Hamburg, B.A. (1989). Life skills training: Preventive interventions for early adolescents. Report for the Life Skills Training Working Group, New York, NY. Carnegie Council on Adolescent Development.

Hendricks, P. (1996). 4-H life skills. Oklahoma State University. Retrieved from http://oklahoma4h.okstate.edu/litol/Docs/other/4H.VOL.135\%20Life\%20Skills\% 20Definition_202.pdf

Hendricks, P. A. (1998). Developing youth curriculum using the targeting life skills model. Iowa State University.

Lerner, R.M. (2005). Promoting positive youth development. Tufts University. Retrieved from http://ase.tufts.edu/iaryd/documents/pubpromotingpositive.pdf 
Lerner, R.M., \& Lerner, J.V. (2013). The positive development of youth: Comprehensive findings from the 4-H study of positive youth development. Retrieved from http://www.4-h.org/About-4-H/Research/PYD-Wave-9-2013.pdf

Martz, J., Mincemoyer, C., McNeely, N. N., Bledsoe, L. P., Dart, P. C., Johannes, E., Arnould, A., Gressley, K., Jones, K., Lerner, J. V., McDonald, D., Worthington, K. (1999) Essential elements of 4-H youth development programs. Retrieved from http://www.4-h.org/resource-library/professional-development-learning/4-Hyouth-development/youth-development/essential-elements/

Maslow, A. H. (1943). A theory of human motivation. Psychological Review, 30 (pp. 370-396).

National 4-H Council. (2015). Retrieved from http://4-H.org/about

Robinson, J.P., Shaver, P.R., \& Wrightsman, L.S. (1991). Criteria for scale selection and evaluation. In J.P. Robinson, P.R. Shaver, \& L.S. Wrightsman (Eds.). Measures of personality and social psychological attitudes (pp. 1-16). New York: Academic Press.

Miller, L.E., \& Smith, K.L. (1983). Handling Nonresponse Issue. Retrieved from http://www.joe.org/joe/1983september/83-5-a7.pdf

Van Horn, B. E., Flanagan, C. A., \& Thompson, J. S. (1998). The first fifty years of the 4-H program. Journal of Extension, 36(6). Retrieved from

WVU Extension Service (2014). 4-H program philosophy. Retrieved from http://4hyd.ext.wvu.edu/about $4 \mathrm{~h} /$ whatis $4 \mathrm{~h} / 4 \_$h_program_philosophy 
Zarrett. N., \& Lerner, R. M, (2008). Ways to promote the positive youth development of children and youth. Retrieved from http://www.childtrends.org/upcontent/uploads/2013/01/Youth-Positive-Development.pdf 
APPENDICES 
APPENDIX A

Survey Instrument 


\section{Default Question Block}

\section{Dear Current and Former West Virginia Extension Camping Instructors:}

The primary purpose of this research study is to determine whether being employed as a West Virginia University Extension Camping Instructor has influenced both your personal life skill development and the life skill development of the youth that you have worked with.

As a WVU Extension Camping Instructor you are a valuable resource because you have experienced 4-H's impact on both members and yourself from a unique perspective. The research study will use your perceptions about your own experiences and those of the youth that you have worked with to determine the impact that the Extension Camping Instructor position is having on life skill development. We realize that everyone is busy, but we hope you will take time to provide a feedback regarding your Extension Camping Instructor experience. Your response is very important to the success of this study. Participation in this research study is completely voluntary and all information you provide will be held as confidential as possible. We would like to thank you in advance for taking the time to participate in this survey. Please submit the completed survey by November 21,2015 . If you have any questions please contact JR Davis at jadavis@mix.wvu.edu or Dr. Deborah Boone at 304-293-5450 or debby.boone@mail.wvu.edu.

Sincerely, Jeffery (JR) Davis

Graduate Student
Deborah A. Boone, Ph.D. Professor

\section{Click on arrow in lower right corner to continue:}

For the following five life skills, please indicate what you perceive to be:

- your current level of ability of each life skill,

- how influential being employed as an Extension Camping Instructor was on your development of that skill, and

- how influential your role as an ECI was on the youth's development of each life skill.

You will use the following definitions for the five life skills.

- Community Service/Volunteering - to donate time and/or effort for the benefit of a group without guarantee

- Leadership - to assist a group in meeting its goals by showing or directing; using personal influence to guide a group in reaching its goals

- Responsible Citizenship - an individual demonstrating love and devotion in response to duties, rights, and privileges as a member of a community or country

- Contributions to Group Effort - to give or supply along with others with a common purpose

- Marketable Skills - to have the abilities wanted by employers and needed to hold a job 
What is your current level of ability for each skill?

\begin{tabular}{l|cccc} 
& Very Poor & Poor & Average & Good \\
\hline Community ServiceNolunteering & 0 & 0 & 0 & 0 \\
Leadership & 0 & 0 & 0 & 0 \\
Responsible Citizenship & 0 & 0 & 0 & 0 \\
Contributions to Group Effort & 0 & 0 & 0 & 0 \\
Marketable Skills & 0 & 0 & 0 & 0
\end{tabular}

How influential was working as an Extension Camping Instructor on your development of each skill?

\begin{tabular}{l|cccc} 
& $\begin{array}{c}\text { Notatall } \\
\text { Influential }\end{array}$ & Mildly Influential & $\begin{array}{c}\text { Moderately } \\
\text { Influential }\end{array}$ & Highly Influential Almost Essential \\
\hline Community ServiceNolunteering & 0 & 0 & 0 & 0 \\
Leadership & 0 & 0 & 0 & 0 \\
Responsible Citizenship & 0 & 0 & 0 & 0 \\
Contributions to Group Effort & 0 & 0 & 0
\end{tabular}

In your opinion how influential was your role as an ECI on a youth's development of each of the life skills?

\begin{tabular}{l|cccc} 
& $\begin{array}{c}\text { Notat all } \\
\text { Influential }\end{array}$ & Mildly Influential & $\begin{array}{c}\text { Moderately } \\
\text { Influential }\end{array}$ & Highly Influential Almost Essential \\
\hline Community ServiceNolunteering & 0 & 0 & 0 \\
Leadership & 0 & 0 & 0 \\
Responsible Citizenship & 0 & 0 & 0 \\
Contributions to Group Effort & 0 & 0 & 0
\end{tabular}

For the following five life skills, please indicate what you perceive to be:

- your current level of ability of each life skill,

- how influential being employed as an Extension Camping Instructor was on your development of that skill, and

- how influential your role as an ECI was on the youth's development of each life skill.

-

You will use the following definitions for the five life skills:

- Teamwork - work done by two or more people, each doing parts of the whole task

- Self Motivation - able to make the needed effort to carry out a task or a plan; personal will to take action

- Self Esteem - pride in oneself; proper regard for oneself as a human being; valuing oneself; a feeling of ability to cope; learning to accept and like oneself

- Self Responsibility - taking care of oneself; being accountable for ones behavior and obligations; choosing for oneself between right and wrong

- Character - a person's moral strength, integrity, fortitude, reputation; a person's usual qualities or traits; adherence to a code of values or ethical principles 
What is your current level of ability for each skill?

\begin{tabular}{l|ccccc} 
& Very Poor & Poor & Average & Good & Excellent \\
\hline Teamwork & 0 & 0 & 0 & 0 \\
Self Motivation & 0 & 0 & 0 & 0 \\
Self Esteem & 0 & 0 & 0 & 0 \\
Self Responsibility & 0 & 0 & 0 & 0 \\
Character & 0 & 0 & 0 & 0
\end{tabular}

How influential was working as an Extension Camping Instructor on your development of each skill?

\begin{tabular}{l|cccc} 
& $\begin{array}{c}\text { Notat all } \\
\text { Influential }\end{array}$ & Mildly Influential & $\begin{array}{c}\text { Moderately } \\
\text { Influential }\end{array}$ & Highly Influential Almost Essential \\
\hline Teamwork & 0 & 0 & 0 & 0 \\
Self Motivation & 0 & 0 & 0 & 0 \\
Self Esteem & 0 & 0 & 0 & 0 \\
Self Responsibility & 0 & 0 & 0 & 0 \\
Character & 0 & 0 & 0 & 0
\end{tabular}

In your own opinion, how influential was your role as an ECI on a youth's development of each skill?

\begin{tabular}{l|ccccc} 
& $\begin{array}{c}\text { Notatall } \\
\text { Influential }\end{array}$ & Mildly Influential & $\begin{array}{c}\text { Moderately } \\
\text { Influential }\end{array}$ & Highly Influential Almost Essential \\
\hline Teamwork & 0 & 0 & 0 & 0 & 0 \\
Self Motivation & 0 & 0 & 0 & 0 & 0 \\
Self Esteem & 0 & 0 & 0 & 0 & 0 \\
Self Responsibility & 0 & 0 & 0 & 0 & 0 \\
Character & 0 & 0 & 0 & 0 & 0
\end{tabular}

For the following five life skills, please indicate what you perceive to be:

- your current level of ability of each life skill,

- how influential being employed as an Extension Camping Instructor was on your development of that skill, and

- how influential your role as an ECI was on the youth's development of each life skill.

You will use the following definitions for the five life skills:

- Managing Feelings- expressing one's feeling appropriately and in proportion to circumstance

- Self Discipline - control of self and one's conduct in line with moral character, personal values and societal expectations; control before acting in a hurtful way or harmful way

- Healthy Lifestyle Choices - increased knowledge, attitudes, and behaviors that both ensure current good health and future well-being (exercise, nutrition, disease prevention, personal safety, and stress management)

- Stress Management - to direct or have physical control or mental strain and pressure, or one's reaction to it; coping with change

- Disease Prevention - to anticipate and ward off conditions that keep the body from functioning normally, such as an infection or stress.

\section{What is your current level of ability for each skill?}




\begin{tabular}{|c|c|c|c|c|c|}
\hline \multirow[t]{2}{*}{$4 / 26 / 2016$} & \multicolumn{3}{|c|}{ Qualtrics Survey Software } & \multirow[b]{2}{*}{ Good } & \multirow[b]{2}{*}{ Excellent } \\
\hline & Very Poor & Poor & Average & & \\
\hline Managing Feelings & 0 & 0 & 0 & 0 & 0 \\
\hline Self Discipline & 0 & 0 & 0 & 0 & 0 \\
\hline Healthy Lifestyle Choices & 0 & 0 & 0 & 0 & 0 \\
\hline Stress Management & 0 & 0 & 0 & 0 & 0 \\
\hline Disease Prevention & 0 & 0 & 0 & 0 & 0 \\
\hline
\end{tabular}

How influential was working as an Extension Camping Instructor on your development of each skill?

\begin{tabular}{l|ccccc} 
& $\begin{array}{c}\text { Notatall } \\
\text { Influential }\end{array}$ & Mildly Influential & $\begin{array}{c}\text { Moderately } \\
\text { Influential }\end{array}$ & Highly Influential Almost Essential \\
\hline Managing Feelings & 0 & 0 & 0 & 0 & 0 \\
Self Discipline & 0 & 0 & 0 & 0 & 0 \\
Healthy Lifestyle Choices & 0 & 0 & 0 & 0 & 0 \\
Stress Management & 0 & 0 & 0 & 0 & 0 \\
Disease Prevention & 0 & 0 & 0 & 0 & 0
\end{tabular}

In your opinion, how influential was your role as an ECI on a youth's development for each skill?

\begin{tabular}{l|ccccc} 
& $\begin{array}{c}\text { Notat all } \\
\text { Influential }\end{array}$ & Mildly Influential & $\begin{array}{c}\text { Moderately } \\
\text { Influential }\end{array}$ & Highly Influential Almost Essential \\
\hline Managing Feelings & 0 & 0 & 0 & 0 & 0 \\
Self Discipline & 0 & 0 & 0 & 0 & 0 \\
Healthy Lifestyle Choices & 0 & 0 & 0 & 0 & 0 \\
Stress Management & 0 & 0 & 0 & 0 & 0 \\
Disease Prevention & 0 & 0 & 0 & 0 & 0
\end{tabular}

For the following five life skills, please indicate what you perceive to be:

- your current level of ability of each life skill,

- how influential being employed as an Extension Camping Instructor was on your development of that skill, and

- how influential your role as an ECI was on the youth's development of each life skill.

$$
\text { - }
$$

You will use the following definitions for the five life skills:

- Personal Safety-taking care to avoid danger, risk or harm; self-protection; being cautious, careful; physically and emotionally safe

- Learning to Learn- acquiring, evaluation and using information; understanding the methods and the skills of learning Decision Making- choosing among several alternatives

- Problem Solving - clearly identifying a problem and a plan of action for a resolution of the problem

- Critical Thinking - strategies for analyzing, comparing, reasoning, and reflecting focus on what to believe or do; discovering meaning; building connections with past learning.

-

What is your current level of ability for each skill?

\begin{tabular}{l|cccccc} 
& Very Poor & Poor & Average & Good & Excellent \\
\hline Personal Safety & 0 & 0 & 0 & 0 & 0
\end{tabular}


Problem Solving

Critical Thinking

$\begin{array}{lll}0 & 0 & 0 \\ 0 & 0 & 0 \\ 0 & 0 & 0 \\ 0 & 0 & 0\end{array}$

How influential was working as an Extension Camping Instructor on your development of each skill?

\begin{tabular}{l|cccc} 
& $\begin{array}{c}\text { Not at all } \\
\text { Influential }\end{array}$ & Mildly Influential & $\begin{array}{c}\text { Moderately } \\
\text { Influential }\end{array}$ & Highly Influential Almost Essential \\
\hline Personal Safety & 0 & 0 & 0 & 0 \\
Learning to Learn & 0 & 0 & 0 & 0 \\
Decision Making & 0 & 0 & 0 & 0 \\
Problem Solving & 0 & 0 & 0 & 0
\end{tabular}

In your opinion, how influential was your role as an ECI on a youth's development of each skill?

\begin{tabular}{l|ccccc} 
& $\begin{array}{c}\text { Not at all } \\
\text { Influential }\end{array}$ & Mildly Influential & $\begin{array}{c}\text { Moderately } \\
\text { Influential }\end{array}$ & Highly Influential Almost Essential \\
\hline Personal Safety & 0 & 0 & 0 & 0 & 0 \\
Learning to Learn & 0 & 0 & 0 & 0 & 0 \\
Decision Making & 0 & 0 & 0 & 0 & 0 \\
Problem Solving & 0 & 0 & 0 & 0 & 0 \\
Critical Thinking & 0 & 0 & 0 & 0 & 0
\end{tabular}

For the following five life skills, please indicate what you perceive to be:

- your current level of ability of each life skill,

- how influential being employed as an Extension Camping Instructor was on your development of each skill, and

- how influential your role as an ECI was on the youth's development of each life skill.

You will use the following definitions for the five life skills:

- Service Learning- gaining skill and experience through active participation in organized service experiences that meet actual community needs and are coordinated with the school and community; learning linked with real life

- Goal Setting - deciding on the purpose or desired result; something to work toward

- Planning/Organizing-a method for doing something that has been thought out ahead of time; how the parts can be put together

- Wise use of Resources - using sound judgement; not wasteful; being responsible; setting priorities

- Keeping Records - recording selected useful information, usually focused for a specific purpose

What is your current level of ability for each skill?

\begin{tabular}{l|ccccc} 
& Very Poor & Poor & Average & Good & Excellent \\
\hline Service Learning & 0 & 0 & 0 & 0 & 0 \\
Goal Setting & 0 & 0 & 0 & 0 & 0 \\
Planning/Organizing & 0 & 0 & 0 & 0 & 0 \\
Wise use of Resources & 0 & 0 & 0 & 0 & 0
\end{tabular}


How influential was working as an Extension Camping Instructor on your development of each skill?

\begin{tabular}{l|cccc} 
& $\begin{array}{c}\text { Notatall } \\
\text { Influential }\end{array}$ & Mildly Influential & $\begin{array}{c}\text { Moderately } \\
\text { Influential }\end{array}$ & Highly Influential Almost Essential \\
\hline Service Learning & 0 & 0 & 0 & 0 \\
Goal Setting & 0 & 0 & 0 & 0 \\
Planning/Organizing & 0 & 0 & 0 & 0 \\
Wise use of Resources & 0 & 0 & 0 & 0
\end{tabular}

In your opinion, how influential was your role as an ECI on a youth's development of each skill?

\begin{tabular}{l|cccc} 
& $\begin{array}{c}\text { Notatall } \\
\text { Influential }\end{array}$ & Mildly Influential & $\begin{array}{c}\text { Moderately } \\
\text { Influential }\end{array}$ & Highly Influential Almost Essential \\
\hline Service Learning & 0 & 0 & 0 & 0 \\
Goal Setting & 0 & 0 & 0 & 0 \\
Planning/Organizing & 0 & 0 & 0 & 0 \\
Wise use of Resources & 0 & 0 & 0 & 0
\end{tabular}

For the following five life skills, please indicate what you perceive to be:

- your current level of ability of each life skill,

- how influential being employed as an Extension Camping Instructor was on your development of that skill, and

- how influential your role as an ECI was on the youth's development of each life skill.

You will use the following definitions for the five life skills:

- Resiliency-adaptability; the ability to recover after experiencing misfortune or disease; coping with change; overcoming problems and difficulties

- Communication- exchange of thoughts, information, or messages between individuals; sending and receiving information using speech, writing, gestures, and artistic expression

- Cooperation- to work or act together for a common purpose or mutual benefit

- Social Skills- skills people use when interacting with others and to behave in the accepted manner or customs of the society in which they live; adapting well to one's social environment

- Conflict Resolution- finding and applying creative and non-destructive ways to resolve differences between people; getting along with others

What is your current level of ability for each skill?

\begin{tabular}{l|ccccc} 
& Very Poor & Poor & Average & Good & Excellent \\
\hline Resiliency & 0 & 0 & 0 & 0 \\
Communication & 0 & 0 & 0 & 0 \\
Cooperation & 0 & 0 & 0 & 0 \\
Social Skills & 0 & 0 & 0 & 0 \\
Conflict Resolution & 0 & 0 & 0
\end{tabular}

https $J / w$ vu. qualtrics.com/ContraPanel/Ajax.php?action=GetSurveyPrintPreview 
How influential was working as an Extension Camping Instructor on your development of each skill?

\begin{tabular}{l|ccccc} 
& $\begin{array}{c}\text { Notat all } \\
\text { Influential }\end{array}$ & Mildly Influential & $\begin{array}{c}\text { Moderately } \\
\text { Influential }\end{array}$ & Highly Influential Almost Essential \\
\hline Resiliency & 0 & 0 & 0 & 0 & 0 \\
Communication & 0 & 0 & 0 & 0 & 0 \\
Cooperation & 0 & 0 & 0 & 0 & 0 \\
Social Skills & 0 & 0 & 0 & 0 & 0 \\
Conflict Resolution & 0 & 0 & 0 & 0 & 0
\end{tabular}

In your own opinion, how influential was your role as an ECI on a youth's development of each skill?

\begin{tabular}{l|ccccc} 
& $\begin{array}{c}\text { Notat all } \\
\text { Influential }\end{array}$ & Mildly Influential & $\begin{array}{c}\text { Moderately } \\
\text { Influential }\end{array}$ & Highly Influential Almost Essential \\
\hline Resiliency & 0 & 0 & 0 & 0 & 0 \\
Communication & 0 & 0 & 0 & 0 & 0 \\
Cooperation & 0 & 0 & 0 & 0 & 0 \\
Social Skills & 0 & 0 & 0 & 0 & 0 \\
Conflict Resolution & 0 & 0 & 0 & 0 & 0
\end{tabular}

For the following five life skills, please indicate what you perceive to be:

- your current level of ability of each life skill,

- how influential being employed as an Extension Camping Instructor was on your development of that skill, and

- how influential your role as an ECI was on the youth's development of each life skill.

You will use the following definitions for the five life skills:

- Accepting Differences- to recognize and welcome factors that separate one person from another

- Concern for Others- to worry about or give attention to the well-being of others

- Empathy- being sensitive to or identifying with another person's situation, feelings, or motives

- Sharing- to have, use, or do together with another or others

- Nurturing Relationships- two or more people forming a connection that contributes to their mutual well-being, each providing care and attention to the other person

What is your current level of ability for each skill?

\begin{tabular}{l|ccccc} 
& Very Poor & Poor & Average & Good & Excellent \\
\hline Accepting Differences & 0 & 0 & 0 & 0 & 0 \\
Concern for Others & 0 & 0 & 0 & 0 & 0 \\
Empathy & 0 & 0 & 0 & 0 \\
Sharing & 0 & 0 & 0 & 0
\end{tabular}

How influential was working as an Extension Camping Instructor on your development of each skill?

Notatall
Influential Mildly Influential $\begin{gathered}\text { Moderately } \\ \text { Influential Highly Influential Almost Essential }\end{gathered}$

https:/Nwvu.qualtrics.com/Contra Panel/Ajax. php?action=GetSurveyPrintPreview 
4/26/2016

Accepting Differences

Concern for Others

Empathy

Sharing

Nurturing Relationships
Qualtrics Survey Software

$\begin{array}{lllll}0 & 0 & 0 & 0 & 0 \\ 0 & 0 & 0 & 0 & 0 \\ 0 & 0 & 0 & 0 & 0 \\ 0 & 0 & 0 & 0 & 0 \\ 0 & 0 & 0 & 0 & 0\end{array}$

In your opinion, how influential was your role as an ECI on a youth's development of each skill?

\begin{tabular}{l|ccccc} 
& $\begin{array}{c}\text { Notatall } \\
\text { Influential }\end{array}$ & Mildly Influential & $\begin{array}{c}\text { Moderately } \\
\text { Influential }\end{array}$ & Highly Influential Almost Essential \\
\hline Accepting Differences & 0 & 0 & 0 & 0 & 0 \\
Concern for Others & 0 & 0 & 0 & 0 & 0 \\
Empathy & 0 & 0 & 0 & 0 & 0 \\
Sharing & 0 & 0 & 0 & 0 & 0 \\
Nurturing Relationships & 0 & 0 & 0 & 0 & 0
\end{tabular}

What do you feel was the most useful skill that you gained from being employed as an Extension Camping Instructor? Why?

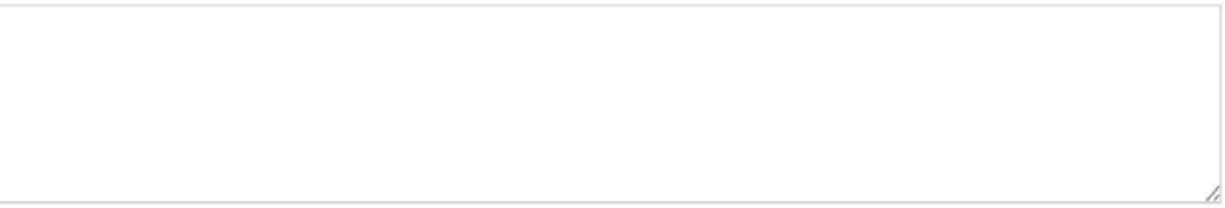

Please indicate how you initially learned of the Extension Camping Instructor position. (Check all that apply)
Parent
Other family member
4-H Leader
Other 4-H Members
Extension Agent
Teacher
Other (Please specify in box below)

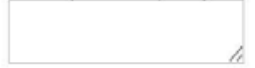

Please indicate to which level each of the following influenced your decision to apply for the position of Extension Camping Instructor? (Where $1=$ not at all influential to $5=$ Almost Essential)

\begin{tabular}{l|ccccc} 
& $\begin{array}{c}\text { Notatall } \\
\text { Influential }\end{array}$ & Mildly Influential & $\begin{array}{c}\text { Moderately } \\
\text { Influential }\end{array}$ & Highly Influential & Almost Essential \\
\hline Parents & 0 & 0 & 0 & 0 & 0 \\
Other family members & 0 & 0 & 0 & 0 & 0
\end{tabular}

https: $/$ wvu. qualtrics.com/Control Panel/Ajax php?action=GetSurveyPrintPreview 
Teacher

Extension Agent

Other (specifv)

Other (specify)

$\begin{array}{cccc}0 & 0 & 0 & 0 \\ 0 & 0 & 0 & 0 \\ 0 & 0 & 0 & 0 \\ 0 & 0 & 0 & 0 \\ 0 & 0 & 0 & 0 \\ 0 & 0 & 0 & 0\end{array}$

Please indicate how many years you worked as an Extension Camping Instructor
$1-3$
4-6
$7-9$
More than 9

Over your tenure as an Extension Camping Instructor, approximately how many weeks did you work at the following types of assignments?

\begin{tabular}{l|ccccc} 
& $1-5$ & $5-10$ & $10-15$ & $15-20$ & More than 20 \\
\hline County Camps & 0 & 0 & 0 & 0 & 0 \\
State Camps & 0 & 0 & 0 & 0 & 0 \\
Other (State fair, State 4-H & 0 & 0 & 0 & 0 & 0 \\
Days, Non 4-H events) & & 0 &
\end{tabular}

Do you feel that you were properly trained with the necessary skills to succeed in your ECI assignments?
Yes
No

Please explain which elements of your training needed improvement:

Using the following adjective pairs please describe your experiences as an Extension Camping Instruct. For example, if your experiences were very stressful, you may want to take the slider to " 1 ." If you felt totally relaxed and absolutely no pressure, you would move the slider to "5." If your experiences were somewhere in between, move the slider to the appropriate number. Continue this process for all pairs of adjectives. 


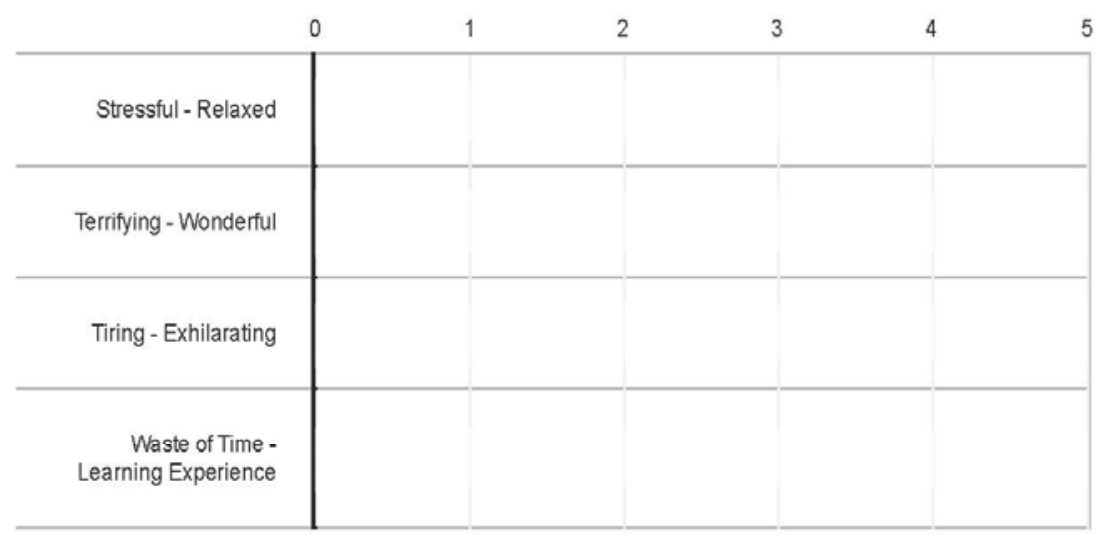

Please indicate how much influence being employed as an Extension Camping Instructor had on the following:

\begin{tabular}{l|cccccc} 
& $\begin{array}{c}\text { Notatall } \\
\text { Influential }\end{array}$ & $\begin{array}{c}\text { Mildly } \\
\text { Influential }\end{array}$ & $\begin{array}{c}\text { Moderately } \\
\text { Influential }\end{array}$ & $\begin{array}{c}\text { Highly } \\
\text { Influential }\end{array}$ & $\begin{array}{c}\text { Almost } \\
\text { Essential }\end{array}$ & NotApplicable \\
\hline College Major & 0 & 0 & 0 & 0 & 0 & 0 \\
Choice of Career & 0 & 0 & 0 & 0 & 0 & 0
\end{tabular}

Please indicate your reasoning for not continuing your employment as an Extension Camping Instructor. (Select all that apply)
Wasn't paid enough
Didn't have time
- Graduated from college
Too stressful
Wasn't asked back
Did not enjoy
Other (specify)

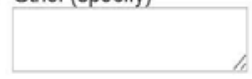

Would you encourage others to apply and have the Extension Camping Instructor experience?

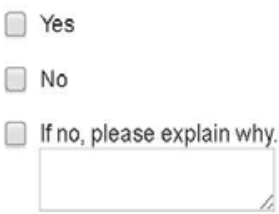

Please list any comments or suggestions that you may have:

https:/Wvu.qualtrics.com/ControlPanel/Ajax.php?action=GetSurveyPrintPreview 
APPENDIX B

Initial Cover Letter 
November 9, 2015

Dear Current and Former Extension Camping Instructors,

As an ECI you have experienced 4-H's impact on both members and yourself from a unique perspective. Extension Camping Instructors have the opportunity to travel around the state and participate in various $4-\mathrm{H}$ settings. The various experiences can influence not only the youth in our state, but you as well. In an effort to determine the impacts on individuals who have been employed as Extension Camping Instructors, it is important that we look to current and former Extension Camping Instructors to gather your perspectives on your own experiences and abilities.

My name is Jeffery Davis or JR as I'm most known, a graduate student at West Virginia University. I am working with my advisor, Dr. Deborah Boone, to conduct a study to determine the impact that being an Extension Camping Instructor has had on your own development of life skills and the youth that you have worked with. The results of this study will be used to prepare a thesis to partially fulfill the requirements for a Master's of Science degree in Agricultural and Extension Education.

We are surveying both former and current Extension Camping Instructors that were employed at some time between the summers of 2007 to 2015 . The results will provide insight to many groups of people including county Extension Agents on reasons to encourage local youth to become Extension Camping Instructors, as well as other professionals in the Extension field, such as the office of 4-H Youth Development on how to recruit and what benefits can be gained from being an Extension Camping Instructor. Please take a few moments and share your opinions and experiences with us.

Participation in this research study is completely voluntary and all information you provide will be held as confidential as possible. The survey should only take about twenty minutes to complete, and your response to the survey is crucial to the success of our study. You may skip any question you are not comfortable answering and you can stop at any time. You will receive an email that includes a link to our survey which will direct you to a website called Qualtrics. Survey results will be reported in a summary format and individual responses will not be identifiable as the website uses completely anonymous results.

The Institutional Review Board (IRB) at West Virginia University has approved this study and acknowledgement of this research is on file. If you have any questions or concerns about completing the questionnaire or about being in this study, you may contact me at jadavis@mix.wvu.edu or my advisor Dr. Deborah Boone at debby.boone@mail.wvu.edu or 304-293-5450. Please submit your completed questionnaire before November 20, 2015. Thank you in advance for your participation in this study. We sincerely appreciate your participation.

Sincerely, 
APPENDIX C

Second Cover Letter 
December 1, 2015

Dear Current and Former Extension Camping Instructors

Recently you were sent a survey about your experience as an Extension Camping Instructor. The results from this survey will help to better understand the influence that being an Extension Camping Instructor had on the life skill development of individuals who were employed between the summers of 2007 to 2015. As of today, we have not received your completed survey. This is an opportunity to express your opinions and share your experiences.

My name is Jeffery Davis or JR as I'm most known, a graduate student at West Virginia University. I am working with my advisor, Dr. Deborah Boone, to conduct a study to determine the impact that being an Extension Camping Instructor has had on your own development of life skills and the youth that you have worked with. The results of this study will be used to prepare a thesis to partially fulfill the requirements for a Master's of Science degree in Agricultural and Extension Education.

We are surveying both former and current Extension Camping Instructors that were employed at some time between the summers of 2007 to 2015. The results will provide insight to many groups of people including county Extension Agents on reasons to encourage local youth to become Extension Camping Instructors, as well as other professionals in the Extension field, such as the office of 4-H Youth Development on how to recruit and what benefits can be gained from being an Extension Camping Instructor. Please take a few moments and share your opinions and experiences with us.

Participation in this research study is completely voluntary and all information you provide will be held as confidential as possible. The survey should only take about twenty minutes to complete, and your response to the survey is crucial to the success of our study. You may skip any question you are not comfortable answering and you can stop at any time. You will receive an email that includes a link to our survey which will direct you to a website called Qualtrics. Survey results will be reported in a summary format and individual responses will not be identifiable as the website uses completely anonymous results.

The Institutional Review Board (IRB) at West Virginia University has approved this study and acknowledgement of this research is on file. If you have any questions or concerns about completing the questionnaire or about being in this study, you may contact me at jadavis@mix.wvu.edu or my advisor Dr. Deborah Boone at debby.boone@mail.wvu.edu or 304-293-5450. Please submit your completed questionnaire before $<$ Date $>$. Thank you in advance for your participation in this study. We sincerely appreciate your participation.

Sincerely, 


\section{APPENDIX D}

\section{Responses to open-ended questions}




\section{Comments}

Note: The use of brackets [ ] indicates where a proper name was removed. IE: Individual's name, State, or University.

\section{Other individuals from whom you learned of the Extension Camping Instructor position:}

4-H camp and other ECIs

4-H camp (5)

Brother

Other 4-H members/ Parent/ Extension Agent

going to camp and meeting them throughout my life

My cousin, was a VCA. He and other ECIs inspired me to do the same.

by being a camper and asking the current ECI(s) about their job.

\section{Earlier VCAs}

[ ] University Jobs site

\section{Current ECI's}

I grew up a 4-H'er and it was something I wanted to do since childhood

My years of 4-H camping experience

Brother and my time spent at 4-H camps each summer seeing the ECI in action

I have been in $4 \mathrm{~h}$ my entire life so I knew by experience.

By Being a Camper for Several Years/Other ECIs

Being involved with 4-H from the time I was 8 and having many influential ECIs at my own camps.

Being a participant in 4-H.

It would not allow me to select more than one response, but 4-H leader, other 4-H members, and extension agent

email advertisement

All of the above, plus, growing up in the 4-H program from the age of 6, being an ECI was a dream come true.

It wouldn't let me click all that apply. / -4-H leader/ -other 4H members/ -extension agent 
Other individuals who influenced the decision to apply for the Extension Camping

Instructor position:

4-H Friends

ECI of county camp

Current and Past ECI's/VCA (6)

Self motivation

4-H Program Assistant

Camp director

Friends

Camp Volunteers

Experiences with VCA/ ECI's in past

Non 4-H friends

Grow Group Leader

self

Self desire

[]!

Desire to experience being an ECI

Camp Counselors

\section{Which elements of your training needed improvement?}

Just need to learn how to work with large groups. Also the recreation classes were great only if it didn't rain.

The Charting Instruction could use some improvement as well as more training in on-thespot time situations. I also feel it would be helpful to train ECI's for more worst-casescenario situations, because a lot can happen that you can't prepare for, so it would help to talk about how to react to what could happen.

song leading- I was a terrible song leader haha

My first year of training was the only one I felt lacked main elements. All of the issues I felt I needed more on were addressed in later trainings. My first year of did not train me specifically on the role of a VCA (at the time), but was more general training about camp. 


\section{What do you feel was the most useful skill that you gained from being employed as an Extension Camping Instructor? Why?}

The most important skill that I gained from being an ECI is adaptability. At a moment's notice, I had to be prepared for anything that may be thrown my way and find a way to work around / through the little road block. Being an ECI really helped me practice with that skill and to keep moving in a forward direction, come what may. /

Leadership, it's a skill that has been useful all my life since.

Leadership, forced to lead up to $200+$ people

Leadership and the ability to teach others, adapt to different situations, and perform under stress.

Confidence and awareness of you surroundings. Public speaking skills.

To be observant, because it's easy to watch a group of campers all succeed at a skill while sometimes it's tougher to pick out the camper who is struggling or is not having as great of a day as I feel the most useful skill was becoming able to see multiple points of view for a single situation. / / An example was in some conflict resolutions. The two sides often couldn't see what made the other think/feel as they did. I was able, after a time, to try an help put a perspective on it for both sides so they could realize that maybe they each had a valid argument/complaint that they could each work better on fixing. / / Through those situations as an ECI I learned how to play Devil's Advocate really well, and can now think through what others might think of an idea. the others

The skills that stick out as the most influential during my time as an ECI would be team work, cooperation, and communication. Whether it was a camp that I worked by myself or one with up to three fellow ECI's, I needed to be able to work well with many individuals who I had never met before the first day of camp or others with whom I may have only known as fellow 4-Her's. Sometimes they were good friends or role models, but overwhelmingly they turned out to be mere acquaintances with whom I needed to learn how to share leadership roles and responsibilities quickly for a successful week of camp to be had by all.

The ability to adapt to my situations and surroundings.

Planning and organizing were essential but also resiliency to respond to situations that weren't in the plan.

The most useful skill was leadership.

Learning how to work with a variety of different people from different parts of the state. I feel that being a VCA/ECI was a very important step in my life and helped me to learn about how people work and myself.

I would have to say that it gave me exposure to being at the reins, to be able to juggle multiple responsibilities effectively. From dealing with campers' concerns to handling staffing issues and problems, to just keeping all the activities and itineraries of the camps 
and functions gave me a real taste of leadership. I figure this is the most invaluable skill I have obtained.

Critical thinking/problem solving was the most useful skill I learned as an ECI. This position required one to think quickly in many different types of settings while including $150+$ people including youth and adults while promoting positive youth development.

The most useful skill that I gained from working as an ECI was organization. During camps, there can be mass chaos depending on which camp you are going to. Some have more strict schedules while others expect you to lead and manage all or most activities or free time. Being able to stay organized and plan even in the midst of chaos has allowed me to keep a very low stress level. Being organized has helped to make my career easier as I know what to expect and I know how it is to be done.

How to pick just one! I think communication, organization, and application of material to a large group of people is my most valued skill I perfected as an ECI. During my time as an ECI, constructing activities, teaching, and engaging large camps fostered these skills. I use these skills daily as I get my Ph.D. and teach large lectures at [ ] on a daily basis.

Being able to speak to large groups. Its important to be able to communicate to groups or individuals in a numerous amount of settings for example your career or for classes.

I feel as if the most useful skill I learned from being an ECI was the interpersonal and leadership skills. I learned to become a life-long learner. I learned that to be successful in camp and in life, that I still have a lot to learn not only about the camp and the campers, but also about myself. I have more of a I want to learn attitude now. In reality the job position has taught me so much aside from the few mentioned skills. I couldn't put into words how much the position has effected the way I now think and act. I never realized how things of such small importance could mean so much to a child and I am very glad I was able to be a part of it. 100 years from now it won't matter what my back account was, the type of house that I lived in or what kind of car I drive... / But, the world may be different because I was important in the life of a child.

The ability to act on a moment notice depending on what is going on and being able to keep everyone calm.

Leadership, Being an ECI was the first time that I was put in a leadership position with people I did not know.

Networking connections and friendships were the most important thing that I gained from being and ECI. I know this isn't exactly a "skill," per say, but it has made a world of difference to me to know that I have people all over the state that I can call upon for any reason.

The most useful skill I learned was leadership. I was always a follower until I became an ECI. As an ECI you have to be in a leadership position. Being an ECI helped me open up and step up out of my comfort zone. This helps me today in everyday life.

Patience and mood control. When kids don't listen you have to have patience and not let your mood get in the way of activities. 
I believe that the independence and the ability to work with individuals from varying backgrounds are the two most useful skills I obtained while working as an ECI. Making decisions, either personal or professional, and being expected to support those decisions allowed me to develop a strong sense of conviction and self confidence. I find that I am able to function well in the workplace in a management position due to the responsibilities that were given to me as an ECI. This also translates in to the ability to be able to work with people who are very different than I am. Extension services and programs reach many groups of people including various ages, economic status, religious affiliations, etc, and being exposed to differences in a supportive environment was a positive experience that directly feeds into working relationships outside of the extension program.

The most useful skill I gained from being an ECI was learning how to effectively communicate my thoughts to others in a way that will keep them listening.

Being able to keep and maintain a routine schedule despite difficulty staying on time.

I learned a lot of different ways to help strangers become comfortable around each other. These mixer activities have helped me in my line of work.

It allowed me to sharpen my leadership abilities. It also helped me to be able to use whatever resources I had effectively. While I was a ECI I found my voice, and my confidence in it. Without that, I wouldn't be able to lead a camp, or make the best out of a situation. Now, I am able to use that voice and leadership in my academics, as I am the student government vice president. I'm able to speak infornt of the president of the college without issue. After all, nothing is more intimidating that forgetting song lyrics in front of 100 campers.

Relating with youth

Being an ECI helped me come out of my shell and realize that people actually do want to hear what I have to say.

Communication, right now $\mathrm{i}$ am a school teacher and without this skill $\mathrm{i}$ would not be very good at my job.

Large group management, it assists in my career path of teaching.

Understanding that a little goes a lot in shaping the youth of [ ]. It benefited me the most to know that a small act of compassion towards campers can impact them in a myriad of ways. That's why it's vital to always show compassion to others.

awareness. I feel as if being able to be aware of my surroundings I can find that kid that needs extra help either mentally or financially, as well as being able to use things around me to help survive, or to help myself to lose that freshman 15 my being aware of the healthy choices that are easier to find than that of the gross fattening foods.

Being able to spare the love for 4-H to some that may have never heard of it before.

The most useful skill I gained from being employed as an ECI was group management techniques. This was the most useful skill I learned because I am able to use these skill everyday as a 7 th grade teacher. I was very fortunate to have been employed as an ECI 
because I was able to learn first hand techniques that allow me to gain the attention of a large group of people in a positive manner rather than simply shouting over a busy crowd. I also learned how to convey a sense of excitement and enthusiasm that can make even the most mundane task like reading from a textbook seem like a fun and interesting idea.

Self confidence --being a role model to these kids gave me the gumption (if you will) to really love who I am as a person. You cannot expect to make a difference in lives if you are down on yourself all the time. Learning confidence through being an ECI has also allowed me to share that quality with the youth I come in contact with during my job. I want these kids to feel as special as they have made me feel.

The most useful skill I gained from being employed as an Extension Camping Instructor would have to be dependability. Keeping to the camp schedule was essential to the flow of camping activities and ensured campers were able to participate in their favorite camp traditions. Due to todays social media driven world I have been held to a higher standard by my previous campers. I have been able to keep in touch with them and knowing they are keeping up with what I am doing in my life has helped me to make sure I continue to set an example for them to follow. Being an ECI is not a one week at a time commitment; but a lifetime obligation to uphold standards and values you set for the campers to follow.

Learning to adapt to different camps, staff, procedures, and traditions quickly. It helped me learn how to adapt to new situations better.

flexibility - At camp the schedule hardly ever goes as planned, and as the ECI you are looked to adapt quickly and smoothly to lead the whole camp through the change.

How to handle homesickness

Learning to think on the fly and adapting to what I was given. Not all situations are perfect but you have to learn to make the best of them.

I feel that I learned how to be a leader in groups with highly varied members.

Being open minded and open hearted was the best skill I gained/enhanced as an ECI. With an open mind, you let yourself be flexible, creative and free to the ideas and needs of those around.

The ability to think on your feet--my current job requires me to change which position I'm filling several times a day, usually unexpectedly. / Lack of shyness--I'm not bothered at all to express myself in front of a group of parents or students.

Being able to communicate with many different types of people: ages, backgrounds, ethnicity. it is a valuable tool to have when working and getting a high education.

Learning to successfully cooperate with individuals with much different backgrounds than my own.

Increasing my leadership skills and my ability to work with different types of people because I was a role model as I set the example I realized how important it was too be able to work with all types of people. 
Being able to make decisions and act quickly especially with constantly changing circumstances. Also, public speaking and responsibility

The most useful skill I've learned as an ECI has been flexibility. Prior to working this job, I would become anxious when things didn't go as planned or when unexpected things would come up. However, it is very rare that thing go as planned as an ECI; unexpected events always pop up. I've become much more flexible and less anxious because of my experiences as an ECI.

The skill gained the most from being an ECI was leaning to become more sociable.

Public speaking skills; leading large groups of youth required diligent communication and good time management, which are crucial to public speaking.

I think the ability to assess situations and make quick decisions is a key skill I learned this year.

Leadership and facilitation skills. These two skills are valuable in nearly any job, school, or life position and benefit me greatly daily.

Learning how to improvise and work with what I have was an invaluable skill that I continue to use but developed while being an ECI

Time management and flexibility because you have to stick to daily schedule and be ready for what comes your way including change of plans on short notice

Communication- as an ECI you must be able to communicate everything with a vast array of individuals, everyone from the cloverbuds around 6 years old that come to spend a day at camp all the way up to the county agents and state directors. An ECI has had have the ability and the vocabulary to communicate effectively with both of those parties and anyone in the middle.

I feel that my problem solving skills were the most useful skill I gained from being employed as an ECI because that's what the job entailed. Things went as planned sometimes, but a lot of the times, we just had to "wing it" and solve the current problem in front of us. I got better at this as the weeks went on and by the end felt confident that I could handle anything that was thrown at me.

the ability to be a leader and communicate effectively with different walks of life around our state.

Confidently taking a leadership position in a large group. It's necessary I. Running a camp.

Learning to make wise decisions on the fly while keeping a cool head

Patience

Ability to think and make good decisions under stress/pressure/time constraint.

Being able to work with a crowd of individuals with diverse learning styles and abilities. This allowed me to work in different counties around the state. Being able to bring a group together allowed the camps to run in an efficient manner. The cohesiveness of the 
staff and their interaction with the campers was an attitude that was set by the ECI there. If the ECI is not prepared and able to include everyone, then someone is left to themselves.

Public speaking and leadership roles. It taught me how to lead youth and get in front of crowds and communicate when uncomfortable. Placed eci's in many situations and confront many issues head on and be up front in center as a leader and you had to be ready to go because you are in charge.

Flexibility. The best laid plans for a camp change in an instant when something unexpected occurs and you have to keep the attention of upwards of 100 youth.

While teaching charting i learned more about myself not only from a learning perspective but a teaching side. It was interesting to see myself from the other side of the table $\mathrm{i}$ learned that $\mathrm{i}$ could teach others if they wanted to lean to from me.

The most useful skill I gained from my years as an ECI is my ability to adapt to changing situations; this skill has come into great use in my career as a nurse.

Responsibility. Each time I stepped foot into a new county to be the ECI for the week, I was RESPONSIBLE for the well-being and the type of experience hundreds of kids had while at 4-H camp. Did I impact every kids life that week at camp? No. However just knowing I was responsible for them made me want to do the best I could. So I took my job as an ECI very seriously because I wanted to be able to provide a great experience for as many kids as I could in the state of [ ] / / Growing attending a 4-H camp as a camper every summer until I turned 21, I knew the impact an ECI could have on the kids while at camp. I remember the great ECI's I had and I remember the not so great ECI's I had. Each one made my camping experience unique and I want to try my best to provide the best experience for the kids I was an ECI for and being responsible was a key component for doing that!

Exposure to many different kinds of people and having the skills to adapt to any situation or task at hand. Being able to morph into whatever is needed was a priceless skill to have gained. I use these skills daily.

Communication, because I am able to effectively communicate with a wide variety of people, young and old, in personal and professional environments.

The most influential skill I gained from being an ECI was adaptability. I never knew what kind of situation or camp I was walking into and had to learn to change my game plan or completely throw it out the window if necessary.

I feel that the most useful skill I learned was group management because I use that a lot in my teaching field.

Social interactions and communication because without those skills working a camp with a bunches of people who don't know you will only be successful if you commutation well and have solid interactions

Communication and the ability to work with others were the most important skills that I learned as an ECI. I feel as if these two qualities go hand in hand. As an ECI, every week 
of summer is a different camp that requires you to adapt to an entirely new environment, campers, staff and program. The ability to adequately communicate is crucial to a camp and ECI's success. Being an ECI helped me prepare for my college internship at a camp for kids with chronic and terminal illnesses which later prepared me for medical school and residency. The ability to communicate and work with others was an invaluable gift that $4-\mathrm{H}$ and the ECI program gave me.

Being able to handle pressure. I was under a lot of pressure to make sure that the campers had a good camping experience. Eventually I learned to use that pressure as motivation, and not let it be a hindrance.

Learning to laugh at oneself and that making mistakes is okay was essential for me. I learned that its okay to laugh at myself, and I feel like that is a very important skill to have in life.

The skill I gained the most out of my experience was strengthening my leadership skills and my self esteem in front of crowds.

Quick thinking, it has allowed me to become a better decision maker.

I believe the most useful skill I gained from being an ECI was self confidence. I believe I did have some self confidence before becoming an ECI from participating in the 4-H program, but being an ECI helped me learn more about myself and my ability to do anything I set my mind to do.

The most useful skill I gained was ability to adapt and think quickly through situations

I gained many skills during my time as an ECI so narrowing it down to the most useful is difficult. I learned to think on my feet, manage large crowds, and work with people of all ages, but I think the most useful thing I gained was a network of people that I could go to for support. /

Time management bc the demands of camps and keeping 100 plus kids 8-18 happy and safe and engaged

I think the most useful skill I gained from being an ECI is confidence in myself. While this may not be seen as a skill, per say, I have gained confidence seven-fold while working as and ECI. I have learned so much about what I can do and who I am that it has insanely increased my confidence in myself.

Adapting to any situation has been very important to me. Adjusting plans based on new information such as weather or absence of important materials or personnel happens quite often.

Being able to plan and work together with other people that have different opinions and beliefs. Being able to find common ground.

The involvement of our youth into our community and/or getting then to participate in any activity.

Ability to adapt and be resilient. Each week of camp was very different, and ECIs face such a wide variety of situations, even within the same week. If I were not able to adapt 
to new situations and be resilient when something went wrong, I would have failed miserably. I learned these skills quickly and continued to build them throughout my time as an ECI.

Being able to adapt and modify plans in an instant.

Adaptation and working with others. It was the first job where I was working with an equal constantly and always having to find that groove and balance.

Resiliency because every camp I counseled was very different and had it's own unique aspects that required adaptation. Also, events within each camp often required adaptability, for example when there were extreme weather conditions or contagious health conditions.

Being a good role model to the younger campers

THE LEADERSHIP THAT YOU GAIN FROM ORGANIZING AND FACILITATING DIFFERENT ACTIVITIES. I THINK THAT IT MAKES YOU HAVE THE CONFIDENCE THAT IS NECESSARY TO FACE DIFFERENT CHALLENGES LATER IN LIFE.

Recognition of my ability to be able to assist others in developing social/ emotional skills. Through the process of leading Charting classes, I was able to see social/ emotional develop in participants. Activities used allowed participants to explore social/ emotional issues that they may have not developed or to learn how to appropriately apply through a group atmosphere.

Being able to stand in front of a crowd of kids and make a fool of yourself singing the milk song. Taking initiative and executing decisive action.

I believe the most useful skill that I gained from being an ECI was my ability to bring groups of people together no matter what they looked like, their skin color, where they came from, how much money they had, whether or not they were considered "popular" and so on. This was useful to me because everyone should feel that they are a part of something bigger. Youth and adults should be comfortable being around people who are not like them in every way and they should learn to be accepting of each others differences. I do not want a child to feel excluded from a group of people, so my goal was to bring everyone together for a common good to enjoy the activities at the camps I worked and to help create lasting friendships among the campers and adults.

The ability to be a leader in any given situation. I am comfortable and able to lead a large group of people in a project, community group, or just a game.

The most useful skill I gained as an Extension Camping Instructor was cooperating and working with others who have differing beliefs, perspectives, and backgrounds. As an ECI, I not only worked with ECIs who were different than me, I worked with agents, camp volunteers, extension staff and the campers themselves who all differed from me. Working out differences is very important and this summer, I saw that cooperation is so valuable. 
Leadership, when you are leading a camp as an ECI it is kind of sink or swim. When there are 100 little faces looking at you for what to do next you learn very quickly how to lead a group.

I feel as if the most important skill I learned as an extension camping instructor was strategic planning equally with resourcefulness. Both skills are essential in making a camp, or even groups outside of camping successful. With both planning and being resourceful the instructor manages to use many of the skills also mentioned. Both are involved in daily decision making whether it be at work, parenthood, or around the house.

Becoming a team player and adapting to different situations. As an ECI, you have to follow a schedule, but that schedule can easily be changed due to weather, illness, or a number of situations. Therefore, it is so important to be a team player and learn to "go with the flow". Not everything can be controlled, and that was a huge lesson that being an ECI taught me.

The most useful skill I gained from my time as an ECI is the ability to quickly adapt. This skill has been very useful in my career as an RN.

Adaptation- understanding of the culture and complexity of 4-H camping and immersing into that.

Being employed as an ECI definitely helped me to be an effective leader. When you walk into a camp, people immediately look to you for answers, insight, and enthusiasm. I know that being challenged in that area has made me a much better leader than I would have been otherwise.

Increase in efficient and effective communication. It has made life in the career world so much easier for me than for my colleagues who struggle with supervisors and delegation as well as teamwork; all things I have learned through the communication skills gained as an ECI.

Leadership and responsibility. You are responsible for every action you make due to the fact that you are leading/influencing such a large group of kids.

Marketable Skills - After ECI training I felt so prepared for other jobs and just had an overall more professional outlook on life. My social media presence I feel did a total 180 and I feel much more confident in myself.

Communication skills...because so an ECI we worked with individual's. Ages 9 to 80 . With this range of individuals, communication at different levels is important in the success of the task. By communicating properly, I was able to form the appropriate relationship with the individual.

Leadership. I feel that many camp directors relied on ECIs to fill in with instantactivities, conflict resolution, empathy, encouragement of campers, ENTHUSIASM and overseeing that camp and camp activities were running smoothly. While the role of an ECI is not for everyone, and individual personality traits may or may not "click" with other staff, the ECI is an ESSENTIAL element to nearly all the camps that I worked. 
Growing up in 4-H, the ECI is what made camp special. In a week of familiarity, the ECI was the new face with the best games, songs, and stories.

To Stand up in front of a crowd...it is important not to be afraid to talk to a group of people or to be yourself in front of a group.

Being able to think on my feet very quickly. I was always having to think of a game, song, activity, etc. with very little time. This has allowed me to work effectively in highpressure situations in and out of camp.

The cultural awareness that I was able to obtain while working in various parts of the state with various people and backgrounds.

I feel the most useful skill that I gained from being employed as and ECI is my ability to adapt to any situation. This is very important in my profession, as well as in any life situation to ensure personal success, as well as teamwork because you never know what life or work is going to throw your way. The most important thing is how you respond to those situations.

Creating nurturing relationships was the most useful skill that I gained from being an ECI. In my personal life, I tend to be a friendly person but not have as many close friends. As an ECI, I would be the stranger who would go into a 4-H Camp and have to create those relationships in order to have a positive week. To this day, I still keep in contact with many of my former campers and colleagues.

Learning to properly use teamwork as well as learning to roll with the punches

Definitely communication.

The most useful skill I learned from being an ECI was learning to adapt to different situations and "rolling with the punches."

Being open and honest with your feelings and being able to explain that, or nurture it, with the children and young adults we were with.

\section{Other reasons for not continuing employment as an Extension Camping Instructor}

Became a firefighter and had training (thanks to the [ ] fire extension service) and joined the military

Felt as if I grew beyond it. Wanted to focus more on staying involved with local 4-H program.

I graduated from college and joined the Peace Corps. I spent my last few weeks in country working three different county camps. Upon my return I needed to readjust and find full time employment.

Burnt out of the enthusiasm it takes to run a camp well. Left it for the young guns.

Main job took precedence, too busy

Took an internship out of state. 


\section{ECI'ing in the Navy}

I became pregnant with my son.

Academic Purposes

another job

Took a summer job that lasted the whole summer.

At times did not feel wanted

I was working full time throughout the school year and needed a break in the summer. The next to last summer I worked I was supposed to work 4 camps, but ended up with mini at the end of the second camp. It was my body's way of telling me to slow down. I worked one the following summer to help with busy week.

Needed a full time job

Moved out of state

The relationship which was my primary tie to [ ] 4-H was ended.

I had to find work within my field of study. Also, I wasn't paid enough. I ended up going through a really tight spot (monetarily) after the summer was over and that wasn't cool.

Offered a position that more closely aligned with my interests.

I plan on continuing

Needed regular checks to pay bills

\section{Started career}

The travel required to some county camps was too far of a drive to be able to adequately reach the camp in a manner that allowed me to still have energy for the campers.

Had to spend summers doing a school internship

Was offered a full time job in a private camp as an assistant director

I had to give up my third year as an ECI for my college summer internship

Family issues and needed to be home

I had other jobs that conflicted with the program.

Moved

summer classes

May be back, may be employed.

Got too busy in the summer

Started a new career. 
Age, Graduate School

Other opportunities seemed more important to my fledgling career

I would like to continue being an ECI. I loved it!

Well you can't select all that apply, so I will write my answer here. I didn't return because of the leadership at the extension level. The scheduling process failed every year that I worked as an ECI. I know the process has changed but I hear the results are the same. There needs to be a higher respect for seniority and the true quality of an ECI. Politics and favorites are riddled through the program and it makes for a poor experience. I wish would [ ] hire less ECIs and really build a pool of high quality ECIs. As this survey will find, an ECI can make or break a camp. I get sick to my stomach when I hear of an ECI ruining a camp. The system has failed when this happens. These individuals should have never been hired in the first place.

Felt as if I didn't get enough weeks to counter the money spent on gas getting there.

Summer classes

Attending Summer Term

I realized I rather work inside and with adults.

Along with finishing college, I had health issues within my immediate family which then led to working full time on top of finishing my education. That then led to getting engaged and starting a family.

Schedule was not out fast enough. I was a waitress also and they needed my schedule so I had to give up the ECI position.

Took an internship in the Governor's Office.

\section{Reasons for not recommending one to apply for the Extension Camping Instructor position:}

No. For the reasons I explained in the last question. There is a lack of respect for the ECI. 
APPENDIX E

\section{Comments}




\section{Comments}

The following comments were taken verbatim from the original survey instrument. No editing was performed.

I enjoyed my time as an ECI. I only worked a few weeks, but the other ECI's I worked with were great to work with and I'd work with them again. I experienced both the new agents and the very experienced and loved my time.

Being an ECI was one of the most challenging but rewarding experiences I have ever been a part of. $15+$ years in $4-\mathrm{H}$, and nothing else compares.

If I had never became an ECI, I would have never gotten to work the Junior Firefighter camp, and I wouldn't have ever joined the fire service. Thanks to being an ECI, I am now a proud firefighter at [ ] VFD and everyday i try to inspire kids to follow their biggest dreams.

It's a wonderful experience. My first 2 years were the best experience ever. I started to wear down and become exhausted the older I was in the job. Also, I began to have less patience with crummy volunteers and other negative individual's at certain counties. Overall, I wouldn't trade my experience for the world. It was very influential in my life and has made me a better and stronger individual.

I feel that being an ECI is the pinnacle of my development in 4-H. While all the charting experiences and lifeskills in 4-H were mostly conceptual, I feel being an ECI allowed me to apply my skills and be the difference I saw being acted on me. Passing it on was one of the most satisfying experiences in my life, and I honestly do not think I would have the self-awareness that helps me so much if not for the ECI program.

Some things 4-H taught me: / 1. Be yourself no matter what. In 4-H we don't judge ANYONE. Not by race, personality, IQ, money, etc. In 4-H everyone's truly equal. We all participate in the same activities. We are all encouraged to work together, to make a difference in others lives and to be the best person we can be. 4-H is the one week you're free of everything and everyone. The goal is to forget the worries, demands and stresses of life. We are all equal, we all have the same desires, wants and needs no matter how different we may seem. / 2. How to become organize and manage my time. With project deadlines and meetings to attend my passion for the program and finally acceptance into something drove me to both of these without realizing it. / 3. How to adapt to change. Rather it be a bump in the schedule or the weather. Things won't always go as planned. I 4. MANNERS. We eat family style, treat others respectfully, use please, thank you, open doors, etc. I learned in such a positive, fun way at a young age that I didn't realize it happened. / 5. I am an effective leader. I thought I was before, but becoming an ECI took that to a whole new level. Being sleep deprived, the biggest role model and sole leader of numerous activities you learn to adapt quickly, observe those you're working with, risk managements now second nature, I can pull out songs/activities on the fly now, communicate efficiently with all ages, etc. / 6. I have become more appreciative, 
appreciate all I have the role models, materialistic items, nature, etc Nature is beautiful, being able to travel the state of [ ] has been breathtaking, rewarding and I know there's so much more of the world to see. Nature is serene, tranquil and others should set the electronics aside and enjoy it. See what nature has to offer. / 7. I learned more than just about agriculture. Most think 4-H is all about animals and food. There's a project, presentation, club or speaker that will interest everyone. If there's not 4-H is always encouraging, with the amount of helping hands and individuals I bet you could start it. / 8. Community service isn't required, but once you're involved with the program it just feels right. We do community service for fun because that's what we are all about making our world a better place. / 9. Communication. I was the shy kid in the back of the classroom and tribe. I realized quickly that nobody was judging me and to maximum my fun I'd step outside my comfort zone and participate in council circle activities. I participated in activity day to go to camp which was giving a 5-10 minute speech. I happily participated because there's no way I was missing camp. / 10. I am an outgoing, personable individual. I was exposed to the social setting all the time. Rather it be club meetings, camp, community service projects, etc. / 11. we are the most compassionate individuals you will ever meet. In 4-H everyone else who is in 4-H is your family, even the furry little critters. My 4-H friends have proven to be the greatest friends I have ever met. We may only see one another once a year sometimes, but we always pick up right where we left off. If I ever needed anything I know I can count on a 4-Her. If someone's sick, 4-Hers will go above and beyond to raise money to pay for medical bills. I had a friend who had leukemia. I told my college friends simply they said sorry and my 4-H friends they caught wind and had spaghetti dinners, sold shirts, ran a $5 \mathrm{k}$, you name it they did it. I didn't even have to ask. My friend ended up passing away, but at the funeral everyone showed up rather they knew my friend or not. We are supportive, caring, motivating and loving of one another. In 4-H we ARE family. Heck we even treat our animals like family. Sometimes I bet we treat them better then ourselves sometimes. It may be because we want to get the grand champion at the fair, but look at who we are because of it? / / I encourage EVERYONE to join 4-H. I believe that the amount of life lessons taught through our learning by doing mindset everyone no matter how young or old can benefit. I find myself at the age of 21 still learning new things everyday about myself and others. I don't know who I would be today if I weren't in 4-H for 17 years. It provided me with so many opportunities, memories, positive role models and learning experiences that the program truly did change my life in one way or another.

When evaluating this experience on this last page I disliked the comparisons of stressful/relaxed, terrifying/wonderful etc. It was all of these things; one minute stressful and terrifying as you confront the challenges you never expected to face. The next exhilarating and wonderful as you overcome them. It was relaxing in the afternoons and during rainstorms when you and a friend you just made talk about hopes and dreams or just watch the scenery in companionable silence. Every camp is different as well with no way to evaluate them together. And when it's finally over and the exhilaration of the week wears off collapsing into bed for 14 hours to catch up on all the sleep you lost. In my humble opinion the sliders are a bad way to quantify the experience. 
Being an ECI was an amazing learning experience and I think every young person should experience it.

Being an ECI has opened many doors for me personally. It is probably one of the most influential learning experiences I have ever had. I credit a huge part of my personal development throughout college to being an ECI.

Great experience! I do think they need to work on outreach to get more males interested in the position.

I've always said that I learned more about myself, and skill sets being a ECI than I was ever able to teach or give back. It was a unforgettable and priceless experience.

Sections of this survey said click all that apply, but only allowed one response. Just FYI

4-H and being an ECI definitely shaped who I am today. I recommend it to college students every chance I get.

Being an ECI was like the "next step" in my 4-H career. I wanted to be able to give back to the organization that gave me so much and I wanted to be that special person that helped make an impact of kids all over the state or others geographic areas (exchanged campers). being an ECI has helped me grow even farther into my major/career and into being the person I am today in hopes that I can continue in lie with my taught ECI skills.

I love being an ECI!

I believe that everyone can benefit from being employed as an ECI. I also believe that ECI style training should be if not mandatory at least be offered for anyone seeking a career in education.

Continuing the old way of training. During the VCA DAYS /

I wish I would have applied earlier in my college career to become an ECI. One summer was not enough, but I learned so much about myself that summer and grew a passion for children and families.

I am currently employed as a full-time children's and therapeutic riding instructor, and I find that I often draw on my ECI experiences when interacting with riders, and planning events and camps. I will also be starting a new 4-H horse club in the near future, and I expect I will use my ECI experience even more in that capacity.

Don't forget that many ECI's are still campers in other camps. If you cut their ability to work and go to camp to age out, they are going to pick aging out almost every time. You will lose older ECI's that can be influential to your first years.

Although most other ECIs, ECI instructors, and 4-H campers were very accepting of an ECI with a non-4H background, a significant portion of the 4-H adult leadership in various counties was quite adverse to the idea of an ECI without a 4-H background. This 
reaction is certainly understandable, but biased thinking may repel talented future ECI applicants if they have similar experiences.

The slider keeps changing for the last 2, I would say 4 did exhilarating and 4.5 for wonderful.

I think ECI experience is so great for everyone. It was a very essential part of becoming a responsible adult for me. Highly recommended.

There needs to be an age limit, after a certain age say 24. Many have surpassed that age as ecis and have been accounted good ecis but I can't help but feel they are past the age the position is intended for.

The [ ] 4-H program molded me into the person I am today and for that I am forever grateful. The very first county camp I ever worked was [ ] County older. Only one camper knew what the chatting program was and NONE of the campers had even heard of the State 4-H campus. One of my biggest, heartfelt moments was attending OMC the week after this camp and having 6 campers from [ ] County older 4-H camp sign up as walk-ins. Tear jerker for sure when they yelled my name from their car.

One factor that a lot of ECI's have mentioned, would be paying for travel. We understand that it was part of the job. With the rising price of fuel, it can often taken a portion of our pay to fund our traveling.

Wishing more people got involved with eci, just a chance i even came across the job and loved it! really shapped my life into something amazing and have lifelong friends from that adventure. still involved in 4-h and wish my career was more involved with it.

Loved my summers as an ECI wish I could still do it! I met life long friends i will cherish forever / / How How..... GO CHEROKEES

I wouldn't trade my ECI experience for the world! Being in 4-H and an ECI made a huge impact on who I am to this day!

I enjoyed being an ECI and would have continued the job if the pay was better and my full time job didn't overlap.

I think the sliding rulers are a little inaccurate/inefficient. With the exception of waste of time, I think all the other adjectives can be used to describe work as an ECI. Working as an ECI is tiring but also exhilarating, so your exhausted at the end of the day but the good kind of exhausted. / / I love the ECI program and hope your survey gives you great results. Sorry it took me so long to answer.

I've been very impressed with how easily ECIs are incorporated into non-4-H events and how well 4-H has incorporated non-4-H programs, such as STEM into its curriculum.

I LIKED THE POSITION, BUT THE INCONSISTENCY OF WORK BECAUSE IT IS SEASONAL AND FOR THE AMOUNT THAT IT PAYS, IT WAS MUCH MORE 


\section{BENEFICIAL FOR ME TO WORK FULL TIME THROUGH THE SUMMER AT JUST ONE JOB.}

Another important aspect of the ECI program is the work-life relationship of the other ECI(s) with whom you work. This is something that I failed to mention in the previous section. The fact of the matter is that a lot of us never had the opportunity to work with someone on such a close degree before becoming an ECI. Everyday all day coordinating and communicating effectively with that one person really forces the ECI to become an effective listener, communicator and just an overall responsible partner.

I would highly encourage anyone to apply for a job as an ECI. I believe this experience can have a positive impact on both the ECI's and the campers they will encounter. You will learn great leadership skills, time management skills, responsibility, be more comfortable stepping out of your comfort zone and gain so much experience that can be taken with you to just about any job or career path you may come across.

This survey is a poor way to collect any accurate results for life development through being an ECI. First of all it has been proven many times in surveys like that either people answer average for everything or excellent to feel better about one self. So if you develop any cause and effect statistics from this then they are an exaggerated of the truth. You would be better off doing interviews with highly experience ECIs with many years and weeks under their belt. Good luck though.

Great job! As a long time state camper, I was really interested in ECling and it's something that has really influenced my life and my future. I'm sad to not be ECIing this upcoming summer, but I think it is important to do something new and gain new learning from those experiences. I think that attitude on the job is a skill ECIing really developed. Especially when I would be on week 5 of camping, learning to keep a positive attitude is something that has carried over into other jobs and academic efforts.

Being an ECI taught me many valuable skills I use everyday that I do not know if I would have learned had I not been a part of this program. It took skills I learned as a 4-Her and completely expanded and improved them. I was only an ECI for 1 year because I realized that being outside in the heat all day and being around that many kids was just not for me. I did learn from my time as an ECI and would not be the person I am today without this experience.

I recommend the 4-H program to families all the time and credit being involved with this wonderful organization to teaching me the values or everyday life and leading me towards a straight path in life.

This was the most eye opening job of my life thus far. I was around all different types of children and adults. It is so exhilarating to see the different personalities across our beautiful state, and if asked if I would do it again-I would do it before they could finish their sentence. This is a wonderful program-no matter what your title is in the 
environment. However, being an ECI is refreshing. So many people look up to you, learn from you, remember you, and want to be you. It is truly a humbling experience.

Being an ECI was one of the pivotal stepping stones into adulthood.

I loved being and ECI and I wish I would've started 2 years sooner. I hope to do it as long as I possibly can!

My summer as an ECI was by far the most exciting and personally rewarding summer I've ever experienced. It changed me - in a good way.

Looking back on my years as an ECI, I couldn't have asked for a better job. Being paid to attend a $4-\mathrm{H}$ camp is something that all $4-\mathrm{H}$ members would love.

Working as an ECI and being in 4-H as a whole made me the person I am today 
VITA

Jeffery A. Davis, Jr.

Education:

WEST VIRGINIA UNIVERSITY, Morgantown, WV 26506

Master of Science in Agricultural and Extension

Education.

Graduated May 2016

CONCORD UNIVERSITY, Athens, WV 24712

Bachelor of Science in Recreation and Tourism Management

Graduated in May 2012

Professional

TEXAS ROADHOUSE, Morgantown, WV 26505

Experience:

Server, Food Runner, Busser

WALMART, Morgantown, WV 26505

Cashier

ELKVIEW INN AND SUITES, Elkview, WV 25071

Front Desk Worker

CONCORD UNIVERSITY GAME ROOM, Athens, WV 24712

Front Desk Worker

WVU EXTENSION SERVICE, Morgantown, WV 26506

Extension Camping Instructor 